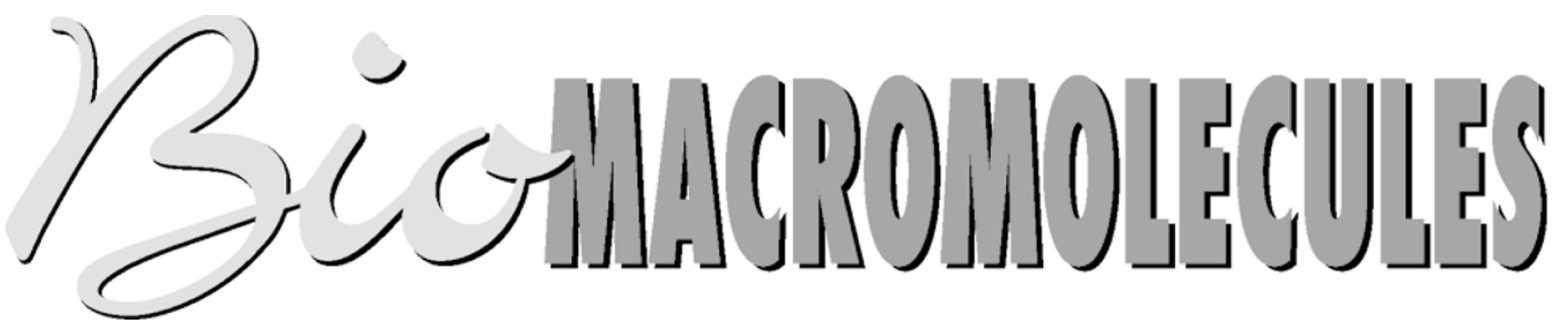

September $2009 \quad$ Published by the American Chemical Society

Volume 10, Number 9

(C) Copyright 2009 by the American Chemical Society

\title{
Reviews
}

\section{Nonthermal Plasma Technology as a Versatile Strategy for Polymeric Biomaterials Surface Modification: A Review}

\author{
Tim Desmet, ${ }^{* \dagger}$ Rino Morent, ${ }^{\ddagger}$ Nathalie De Geyter, ${ }^{\ddagger}$ Christophe Leys, ${ }^{\ddagger}$ Etienne Schacht, ${ }^{*}$, \\ and Peter Dubruel* \\ Polymer Chemistry \& Biomaterials Research Group, Ghent University, Krijgslaan 281 S4 Bis, Ghent, 9000, \\ Belgium, and Research Unit Plasma Technology (RUPT), Department of Applied Physics, Faculty of \\ Engineering, Ghent Univeristy, Jozef Plateaustraat 22, 9000 Ghent, Belgium
}

Received February 12, 2009; Revised Manuscript Received April 25, 2009

\begin{abstract}
In modern technology, there is a constant need to solve very complex problems and to fine-tune existing solutions. This is definitely the case in modern medicine with emerging fields such as regenerative medicine and tissue engineering. The problems, which are studied in these fields, set very high demands on the applied materials. In most cases, it is impossible to find a single material that meets all demands such as biocompatibility, mechanical strength, biodegradability (if required), and promotion of cell-adhesion, proliferation, and differentiation. A common strategy to circumvent this problem is the application of composite materials, which combine the properties of the different constituents. Another possible strategy is to selectively modify the surface of a material using different modification techniques. In the past decade, the use of nonthermal plasmas for selective surface modification has been a rapidly growing research field. This will be the highlight of this review. In a first part of this paper, a general introduction in the field of surface engineering will be given. Thereafter, we will focus on plasma-based strategies for surface modification. The purpose of the present review is twofold. First, we wish to provide a tutorial-type review that allows a fast introduction for researchers into the field. Second, we aim to give a comprehensive overview of recent work on surface modification of polymeric biomaterials, with a focus on plasmabased strategies. Some recent trends will be exemplified. On the basis of this literature study, we will conclude with some future trends for research.
\end{abstract}

\section{Surface Engineering: General Introduction}

Within this first part, we will briefly discuss the field of biological surface engineering. Two questions will be addressed. First of all, we will address why there is a need to change surfaces. Second, we will address how surfaces can be changed in order to achieve the desired properties. In the second part we will highlight the more common methods That are used in the field of biomedical applications.

1.1. Why Change Surfaces? 1.1.1. Introduction. Most biochemical reactions are investigated and described as occurring in the solution phase. In biology however, most reactions in organisms or other biological environments occur at surfaces.

* Corresponding author. E-mail: ti.desmet@ugent.be (T.D.); peter.dubruel@ugent.be (P.D.); etienne.schacht@ugent.be (E.S.).

Polymer Chemistry \& Biomaterials Research Group.

Research Unit Plasma Technology (RUPT).
From a philosophy-of-science-point-of-view, this could be considered as a so-called laboratory effect. In order to make reality accessible by experimental means, biochemical reactions are often studied in solution only, but this approach can be considered an oversimplification of the reality. By now, however, it is generally accepted that the surface at which an interaction or reaction occurs is of crucial importance.

The study of surfaces was initiated in the first few decades of the twentieth century. Especially, the work of Langmuir and Blodgett revolutionized the field of surface science. ${ }^{1}$ They developed molecular assembled films at an air-water interface that could be transferred in a compressed, monolayer state to a solid surface. This is the so-called Langmuir-Blodgett film. The further study and implications of these findings together with information from biology and biochemistry gave rise to the origin of "biological surface science" or "biointerface 
science". Biointerface science has been defined as the study and control of biomolecular interactions at surfaces. ${ }^{2}$

The most important biological interfaces include the cell surface/synthetic biomaterial, extracellular matrix (ECM)/biomolecule, ECM/cell, hydrated tissue/air (lung), and mineral/ protein. ${ }^{1}$ One can think of numerous applications where these surfaces are of interest. Examples include implant biomaterials, hemodialysis, surface diagnostics, cell culture surfaces, biosensors, affinity chromatography, proteomics, genomics, and so forth. ${ }^{2,3}$

The final purpose of an implant will determine which properties the surface should possess. In order to illustrate this, we will briefly discuss some examples in the next paragraph. In this work we will focus on the interaction between artificial implants with proteins and cells.

1.1.2. Surface Modification: Case Studies. In this section, some case-studies of practical cases in which surface modification is desirable will be outlined. First of all, the improvement of biocompatibility and biointegration will be discussed. Second, some cases in which the avoidance of nonspecific protein adsorption are presented, focusing on blood-contacting materials. Third, the controlled adsorption of proteins and/or cells to engineered surfaces will be discussed, with practical implications such as cell-sheet engineering. The fourth case concerns antibacterial properties, followed by surface treatment of alloys. In the last part, tissue-engineering applications will be discussed.

Biomaterials have been defined as substances other than foods or drugs contained in therapeutic or diagnostic systems. ${ }^{4,5}$ Through history, several attempts to replace tissue by biomaterials have been identified. Early examples include the use of artificial eyes, ears, teeth, and noses in ancient Egypt ${ }^{6}$ or Aztec, Chinese, and Roman culture. ${ }^{7}$ The materials used include metals such as gold in dentistry, but also wooden teeth and glass eyes were discovered. ${ }^{5}$ As medicine evolved, implants became more sophisticated, and the use of ceramics, metals and polymers for the fabrication of implants became common practice. ${ }^{8}$ A major concern is that only methods that avoid risk, rejection, or complications in the body should be applied..$^{9-12}$ In order to achieve this, biocompatible materials, which do not have the potential to elicit an immunological, or clinically detectable primary or secondary foreign-body reaction, are of great interest. It is clear that, by modifying the surface of an implant, it can become more biocompatible or this can lead to a better biointegration in the surrounding tissue. ${ }^{13,14}$

A common strategy to change the surface in order to make the implant more biocompatible includes coating with natural molecules such as proteins and/or polysaccharides. As an example, biomacromolecules such as chitosan, heparin or insulin were tethered on poly(acrylonitrile)-based membranes to improve the hemocompatibility. ${ }^{15}$ Other examples include the covalent immobilization of collagen, gelatin, or chitosan to poly$\varepsilon$-caprolactone (PCL). ${ }^{16}$

For certain biomaterials, it can be of major importance to avoid unspecific protein adsorption. As an example, this is the case for intraoculars, contact lenses, wound healing materials, catheters, and biosensors. ${ }^{17}$

The adsorption of proteins is a complicated process which is considered to be mainly dependent on the surface energy. Generally, it can be stated that the more hydrophobic a surface is, the more proteins tend to adsorb. ${ }^{3}$ A second parameter to be considered is the electrostatic interaction between proteins and surfaces. This interaction however, is highly dependent on $\mathrm{pH}$ and ionic strength. Other factors which determine protein adsorption are the protein concentration ${ }^{18,19}$ and the structural properties of proteins. ${ }^{19}$ Furthermore, the interfacial properties of an adsorbed protein layer alter with time due to two effects; the Vroman effect and time-dependent unfolding, which both change the protein conformation. ${ }^{3,20,18,19}$

The adsorption of proteins can be decreased by changing the hydrophobicity, and thus the wettability of the surface. ${ }^{3}$ The most common strategy to achieve this is the grafting of poly(ethylene oxide) (PEO) onto surfaces. ${ }^{3,21-24}$ As a result, the surface becomes more hydrophilic because of the highly polar nature of the PEO repeat units. Since proteins tend to adsorb less onto hydrophilic surfaces, obtained surfaces can be considered nonfouling.

The control of protein adsorption is a key issue in the area of blood-contacting materials. The problems related to these blood-contacting materials are mainly due to the fact that blood interacts with the surface of the artificial organ or implant. In order to achieve a better blood compatibility and to decrease thromboembolism, scientists try to engineer the surface. The goal can be to achieve the adhesion of endothelial cells to the implant. The underlying assumption is that a confluent layer of endothelial cells will maintain their nonthrombogenic phenotype, thus avoiding thrombogenicity and the related problems. An excellent review summarizing studies addressing the influence of biomaterials (and surface-engineered biomaterials) on endhothelial cell thrombogenicity is available. ${ }^{25}$

Thromboembolism is one of the major clinical complication issues of mechanical heart-valve prosthetics. ${ }^{26}$ Vascular prostheses substituting smaller arteries (internal diameter $<5 \mathrm{~mm}$ ) cause problems due to stenosis, which is a localized constriction of the blood flow. ${ }^{27}$ Eventually, this blocks the blood flow through the vessel. Normally, these devices are treated to minimize thrombi and emboli generation and to increase the lifetime. $^{28}$ The general trend is to immobilize (covalent, ionic, adsorptive) antithrombotic molecules onto the polymers that were previously plasma grafted with specific chemical groups. ${ }^{17}$ Another example includes the fluoropolymer coating or the Arplasma treatment of a dacron vascular graft. ${ }^{29}$ Other work has focused on incorporation of phosphorylcholine-derived molecules in order to reduce platelet adhesion and subsequent blood clotting. ${ }^{30-32}$

The strategies discussed in the previous paragraph focus on minimizing protein adsorption. Another possible scenario is that researchers do not necessarily wish to avoid protein adsorption but that they want to be able to control the adsorption of specific proteins or cells in a reversible manner. ${ }^{3}$ This can be achieved by the binding of so-called stimuli-responsive polymers (SRPs) on surfaces.

This technique can be of major importance in the development of lab-on-a-chip bioanalytical devices such as biosensors, as well as in the fabrication of peptide and protein arrays. A very promising application of this technology is the creation of monoor multilayer cell sheets. ${ }^{33}$ In cell-sheet engineering, cells are cultured on a thermoresponsive poly( $N$-isopropylacrylamide) (PIPAAm) surface. The surface was obtained by electron-beam irradiation and subsequent grafting onto polystyrene (PS). This PIPAAm surface has the unique property that, when the temperature is higher than $32{ }^{\circ} \mathrm{C}$, the surface is slightly hydrophobic, allowing for cell attachment and proliferation similar to that of normal tissue culture plate styrene (TCPS) dishes. After cells have reached confluency, the temperature is lowered to $20{ }^{\circ} \mathrm{C}$, which is below the lower critical solution temperature of the PIPAAm polymer, and the surface becomes hydrophilic, due to the transition of the polymer from collapsed globule to extended coil formation. When this occurs, the 
polymer swells and a hydration layer is created such that the cell sheet with deposited ECM detaches spontaneously and can float freely, without the need for proteolytic enzymes or chelating agents. ${ }^{34}$ In this way, entire cell-sheets can be lifted off, to a stamp, with their ECM intact. Repeating the process several times has enabled researchers to create multilayer sheets. These have been implanted to the cornea in order to repair disease or injury-related damage. ${ }^{33,35}$

For certain biomaterials, it is important that the material possess antibacterial properties. ${ }^{36}$ Bacteria and cells compete to adhere and grow onto implants. A known strategy for the creation of antibacterial surfaces is the introduction of quaternary amine-groups on surfaces. ${ }^{37}$ Another possibility is the plasmaimmersion ion implantation of antibacterial ions such as $\mathrm{Cu}$ ions. $^{38}$

Another concern related to implantable biomaterials is the possible release of toxic components from the biomaterial in the body. A surface that can be homogenously engineered in order to prevent leakage of these compounds into the surrounding tissue is crucial for certain biomaterials. A recent example includes the surface modification of NiTi alloys. These alloys demonstrate good shape memory properties and superelasticity, making them good candidates for gradual correction of spinal deformity. The leaching of toxic Ni ions however, is problematic. A surface modification with plasma in order to prevent leakage was therefore proposed. ${ }^{39,40}$ For metallic implants, the corrosion degradation and the prevention of this phenomenon are of major importance. There are several preventive measures to improve corrosion resistance by surface modification and to increase the bioactivity of the metallic surfaces. A review on the subject is available. ${ }^{41}$

The past decade, a shift from biostable to biodegradable implants is occurring. The field of tissue engineering focuses on the development of biological substitutes that restore, maintain, or improve tissue function. ${ }^{42-45}$ Tissue engineering integrates the advantages of tissue/organ transplantation and purely synthetic prostheses by combining cells with synthetic ECMs. ${ }^{46}$ A tissue engineering scaffold should serve three primary purposes: (1) they must define a space that will shape the regenerating tissue, (2) they must provide temporary function in a defect while tissue regenerates, and (3) they must facilitate ingrowth of tissue, thus serve as an adhesion substrate, and possibly deliver cells, proteins and/or other biofactors such as DNA. ${ }^{47,48}$

As a consequence of the third purpose, the scaffold should have a suitable surface chemistry enabling cell attachment, proliferation, and differentiation. Furthermore, the degradation products of the surface and bulk material should be biocompatible, causing minimal inflammatory or immune responses. ${ }^{49}$ Parallel with this field of research, the technology of threedimensional (3D) cell culture was developed. The 3D scaffolds used for cell culture also require a correct surface chemistry. A review on $3 \mathrm{D}$ cell culture matrices is available. ${ }^{50}$

Most of the implants produced starting from the most frequently applied synthetic biomaterials do not possess functional groups on the surface. Therefore, surface modification is of crucial importance in order to prepare successful tissue engineering scaffolds. In this review, we will mainly address surfaces that were developed for tissue-engineering applications.

Furthermore, it can be of great interest to spatially control the adsorption of proteins, or the adhesion of cells, onto these scaffolds. From the previous discussion, it is clear that, for example, if PEO segments with end-functionalities (which are capable of binding cells) are bound to the surface according to

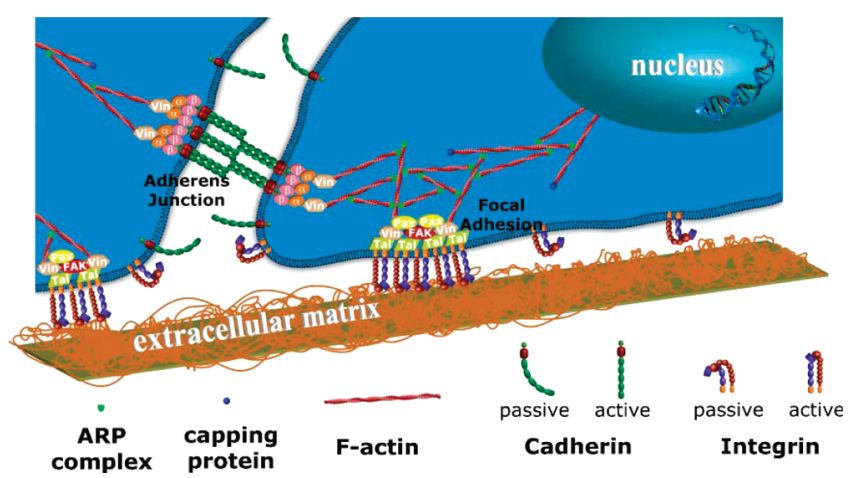

Figure 1. Adherens junction (AJ) and focal adhesion (FA) as mechanosensors. Calcium-dependent homophilic interactions between cadherins results in binding of the actin cytoskeleton via $\beta$-catenin (b), $\alpha$-catenin (a), and vinculin (Vin) complexes. Heterodimeric integrin receptors bind ECM proteins via their extracellular domains, while their cytoplasmic domains are associated with a supramolecular plaque containing talin (Tal), vinculin (Vin), paxillin (Pax), focal adhesion kinase (FAK), etc. The plaque, in turn, is connected to the termini of actin filament bundles ${ }^{59}$ (Reproduced by permission of The Royal Society of Chemistry).

a specific pattern, cells will preferably bind on these locations. Therefore, nowadays, there is a great scientific interest in patterned surfaces ${ }^{51-54}$ or surfaces with functional group or protein gradients. ${ }^{55-58}$ Currently, patterned surfaces are limited to two dimensions, thus excluding the application for 3D implants.

In the previous paragraphs, several reasons for surface modification were presented and illustrated. As we will mainly discuss surfaces constructed for tissue engineering purposes, we will first make an attempt to describe how cells interact with surfaces in vivo. There is a difference in how a cell/tissue naturally interacts with the ECM and with biomaterial implants. Both processes will be generally discussed. We would like to point out that this is a very complex phenomenon, which is not fully understood yet. ${ }^{59}$ On the basis of the most recent understanding of cell adhesion, we will try to outline what characteristics are of major importance for surfaces in tissue engineering.

1.1.3. Cell-Material Interaction. Understanding the mechanism of the cell adhesion, proliferation and differentiation is essential for the design of tissue engineering biomaterials/ surfaces. ${ }^{60}$ It is crucial to understand, and control, the switch between cell phases of growth and differentiation in order to create successful implants. $^{61}$

Generally, cells bind to the ECM through the cell membrane receptors. There are several classes of these receptors. The receptors are also called protrusions, which are micrometersized sheet-like structures composed of an actin filament mesh with, on the end, smaller hair-like protrusions, "filopodia". These filopodia consist of long, thin actin filament bundles which act as feelers that sense the environment of the cell. When the filopodia find a suitable binding site, a so-called receptor binding site, the filopodia bind to this site, and a feedback signaling pathway within the cell allows more receptors to be localized in that region of the cell. ${ }^{62}$

One class of receptors include the integrins, which bind selectively to specific binding sites such as Arg-Gly-Asp (RGD) tripeptide found in cell adhesive proteins such as vitronectin, laminin, and fibronectin (Figure 1). In addition to attachment, these connections mediate several intracellular signals. These define mobility and cellular shape, and regulate the cell cycle. $^{63,64}$ 
For cell-cell contacts, adherens junctions are involved in "coupling" adjacent cells through $\mathrm{Ca}^{2+}$-dependent homophilic linkage of transmembrane cadherin molecules. ${ }^{59}$

Considering biomaterial-cell interactions, these receptors will sense the environment of the cell, which is now a biomaterial surface. If this surface contains binding sites, similar to the natural ECM, it can be regarded as a biomimetic material. As a consequence, cells will interact with the material in a comparable way and, theoretically, will recognize the implant as if it were a part of the body. The receptor binding to the ligands, present on the biomimetic material, determines the strength of the cell attachment, the cell migration rate, and the extent of cytoskeletal organization formation. ${ }^{65}$

In order to achieve this biomimetic behavior, there are generally two possibilities. First of all immobilization (ionic, adsorptive or covalent) of complete proteins can be performed on the surface of the biomaterial. Second, it is possible to introduce the specific binding sites, such as RGD, on the biomaterial surface. These strategies provide control over ligand type and density but not over molecular-level spatial organization of ECM. ${ }^{59}$ To achieve spatial control over the presence of molecules on a surface and to control several cell processes in culture, including the attachment and spatial distribution of cells, apoptosis, and differentiation, protein patterning approaches are currently being developed. ${ }^{59}$

The availability of functional groups on the surface in order to covalently couple or include biofactors in the scaffolds should thus be considered. The presence of the functional groups directly influences the cell adhesion and differentiation. Several papers demonstrate the surface-dependent differences in integrin binding. ${ }^{64}$ It can be stated that the surface chemistry will effect the cell differentiation and attachment because of the integrin binding specificity. ${ }^{64,66}$ For example, the influence of polar functionalities seems to exhibit intermediate levels of focal adhesion components, while the hydrophobic substrates displayed the lowest levels. ${ }^{60}$ Iwasaki et al. recently designed biomembrane mimetic polymers having a phospholipid polar group and carbohydrate side chains in order to obtain synthetic materials capable of selectively recognizing proteins and cells, and preserving their functions. ${ }^{67}$ Fischer et al. reported the surface coating with associating triblock proteins by means of a hydrogel that physically adsorbs to a substrate. ${ }^{68}$ These are just a few of the many examples of recent research in this field.

In order to mimic the natural ECM, not only the surface chemistry and presence of ligands should be considered. The ECM is a fibrous environment consisting of different proteins such as collagen, fibronectin, and so forth. There is a growing interest in novel technologies such as electrospinning (ESP) that are able to mimic the structural properties of the ECM by creating micro- and nanofibers.

A new trend seems to emerge in the field of scaffold design where different scaffold fabrication technologies and different biomaterials are combined to provide cells with mechanical, phycicochemical, and biological cues at the macro-, micro-, and nanoscale. ${ }^{69-72}$

The interaction of a biomaterial surface with the surrounding tissue after implantation is a process that can be subdivided into four different stages. ${ }^{62}$ In the first stage, a water shell is formed around the material in a couple of nanoseconds. Second, a layer of plasma proteins will be adsorbed, predominantly consisting of albumin, fibrinogen, immunoglobulin type $\mathrm{G}$ ( $\operatorname{IgG})$, fibronectin, and von Willebrand factor. ${ }^{14}$ During the third stage, cells reach the surface and will interact with the implant through the protein coating. This complex process is dependent on several critical surface properties and is strongly influenced by biological molecules. This third stage occurs from as early as minutes up to days after implantation. In a final stage, the useful life of the implant, is the continuing development of the early implant stages. The duration of this stage can vary from days to several decades. Among other factors, the adsorption of proteins to biomaterials has a strong influence on the inflammatory response of the body. ${ }^{73}$

As already discussed in the previous section, it is of major importance to minimize the inflammatory response when implanting an artificial biomaterial. As an example, poly(D,Llactic acid) (PLA) is probably one of the most widely used biomaterials. This polyester has been Food and Drug Administration (FDA)-approved and demonstrates a good biocompatibility and biodegradability. Furthermore, it degrades to lactic acid, a natural compound. In some cases though, biodegradable polyesters exhibited inflammatory responses. ${ }^{74}$ Research has been performed to understand ${ }^{75,76}$ and overcome ${ }^{77}$ these problems. Surface modification of implants fabricated from PLA and other aliphatic polyesters seems to be a promising strategy that is implemented by many groups.

A review on recent studies correlating surface functionality with protein adsorption, cell behavior, and tissue responses is available elsewhere. ${ }^{14}$

1.1.4. General Surface Modification Strategies of Biomaterials. From the previous discussion it is clear that both chemical and physical properties of surfaces are determining factors for cell fate. From this insight, different strategies can be proposed to change a surface.

It is also clear that chemical and physical surface modification will have to take into account all the previously discussed factors. The final purpose of the surface modification will be a guide in order to select a promising surface modification strategy. From a chemical point of view, these different strategies for surface modification have one thing in common: the introduction of functional groups.

A first strategy to change an inert surface could be the covalent bonding of longer polymer chains to the surface. As mentioned, this is frequently applied for binding of PEO to surfaces in order to increase the surface hydrophilicity. If covalent binding should be achieved, it is, of course, first necessary to introduce functional groups to the surface.

Another possible approach in order to render a higher surface hydrophilicity and wettability consists of the introduction of chemical polar groups on surfaces. These groups can also be used to immobilize biomimetic molecules such as proteins (ionic or covalent) or peptides.

If polar groups such as carboxyl, hydroxyl, or amine groups are introduced on a surface, one could expect a higher wettability, a more polar character and thus a more hydrophilic surface. The charge of the introduced groups will also correlate with the hydrophobicity. Because of this relation, the controlled modification of polarity, hydrophobicity, and charge is a complicated process where fine-tuning of the most ideal properties for a certain application is often a very labor-intensive project.

Furthermore, it was shown that physical properties such as roughness correlate with the cell morphology, and thus its final fate. $^{69}$

In the preceding paragraphs, we outlined several applications and examples and briefly discussed the interaction between cells/ organisms and surfaces/biomaterials. We will now consider and compare several practical methods which enable researchers to (1) change the chemical composition of the surface by introduc- 
ing functional groups and (2) engineer the physical and mechanical properties.

1.2. How Are Surfaces Changed? 1.2.1. Bulk Modification. Bulk modification is a strategy whereby cell-signaling peptides are incorporated into the biomaterials, and the resulting recognition sites are not only present on the surface but also in the bulk of the materials. ${ }^{65}$ This is mostly beneficial for applications focusing on injectable biomimetic materials. The encapsulation of cells within these materials is desirable for localized delivery by injection, thus avoiding a surgical procedure. Two main groups of injectable materials include hydrogels and microspheres.

An example is the synthesis of alginate-based hydrogels covalently functionalized using RGD spaced by a four amino acids sequence, Gly-Gly-Gly-Gly (GGGG), which was reported by Marler et al. ${ }^{78}$ The fine-tuning of the viscoelastic properties of these kinds of gels is required in order to achieve a gel that is injectable and able to occupy a defined space that matches the complex shape at the site of defect. Luo et al. reported the functionalization of butanediamine-grafted PLA, using maleic anhydride. These polymers were used for subsequent immobilization of RGD. Films were prepared and evaluated in terms of cytocompatibility, showing promising results. ${ }^{79}$ Another example is the delivery of mesenchymal stem cells through injection of a peptide-based hydrogel. ${ }^{80}$ Fittkau et al. reported that the desired response of specific cell types to tissue engineering scaffolds could be optimized through a combinatory approach to the use of biomimetic peptides. ${ }^{81}$ This group studied the bulk modification of PEO with RGD, Tyr-Ile-Gly-Ser-Arg (YIGSR), and Pro-His-Ser-Arg-Asn (PHSRN). Hydrogels modified with YIGSR or PHSRN showed only limited cell adhesion. When these peptides were combined with RGD, the YIGSR peptide was found to selectively enhance the migration of human microvascular endothelial cells by $25 \%$ compared to RGD-only modified materials. This indicates that the incorporation of multiple biomimetic factors can result in a more successful scaffold. Nevertheless, fine-tuning of the incorporated concentrations and the viscoelastic properties of the delivery system remain challenges to be tackled.

The bulk incorporation of enzymatically degradable peptide sequences and/or functional groups in biomaterials offers opportunities to fine-tune the degradation rate. Mann et al. reported the development of photocross-linkable PEO hydrogels with protease sensitive peptide sequences. ${ }^{82}$

1.2.2. Surface Modification. Surface modification differs from bulk modification in this respect that an object/film is fabricated from a bulk material and subsequently only the surface is modified.

It is possible to categorize the different available surface modification strategies in several ways. For example, some processes are single-step processes; others consist of two or more subsequent steps in order to achieve the desired modification.

A surface can be changed chemically by introduction of functional groups or by covalent coupling of molecules onto the surface. Another approach is the physical adsorption of a polymer onto the surface. This is, for example, the case for dipcoating processes, ${ }^{83}$ but we will not include all of these physical surface modifications except for self-assembled monolayers (SAMs), which are also based on physical interactions.

We will first focus on different methods which are used to introduce specific functional groups on the surface. As the number of publications in this field is rather high, it is impossible to cover all the scientific work that was performed during the past few decades. The following should be seen as an introduction and a compilation of the most common strategies.

Second, the immobilization of proteins or other bioactive molecules such as growth factors will be briefly discussed.

1.2.3. Introduction of Functional Groups on Surfaces. A lot of different methods are available for the introduction of functional groups on a surface.

The most common industrial techniques for direct surface modification include flame treatment, metal deposition, irradiation techniques, and corona-discharge techniques. Flame treatment and corona-discharge can be regarded as specific kinds of plasma treatment.

The modification of a surface by grafting polymers onto the surfaces can also be achieved in a variety of manners. Graft polymerization can be achieved by an ionic mechanism, a coordination mechanism, coupling mechanism or free-radical mechanism. The free-radical mechanism can be subdivided in chemical grafting, mechano-chemical grafting and radiation induced-grafting. Radiation-induced grafting can be achieved by using different kinds of radiation. High-energy radiation such as $\gamma$-rays, X-rays and electron beams are known as ionizing radiation. Midenergy radiation, mostly UV rays, laser or plasma sources and low-energy radiation (infrared, ultrasonic, microwave (MW) and visible sources) can bring about desired changes in the polymer backbone depending upon the irradiation time and energy of radiation. ${ }^{84}$

Some more recent techniques include radical living polymerizations such as atom transfer radical polymerization $(\mathrm{ATRP})^{85-87}$ and reversible addition-fragmentation chain transfer polymerization (RAFT) ${ }^{88-90}$ from surfaces.

It is clear that not all these techniques will be of the same interest for biomaterials. In what follows, we will introduce the most commonly applied techniques for surface modification in the field of biomaterials.

It can also be understood that a lot of research in the field combined methods or used methods that are not always straightforward to categorize.

Wet-Chemical Methods for Surface Modification. A first class of methods includes the wet-chemical methods. This involves the reaction between a chemical compound in solution and a surface. Classic examples include aminolysis and alkaline or acidic hydrolysis. Treatment with hydrogen peroxide is considered a wet chemical method. The hydroperoxides, which are thus introduced on the surface, serve as initiation sites for the subsequent grafting of vinyl monomers.

In Table 1, an overview of some interesting work on hydrolysis of surfaces is presented. This is not a complete overview, but it should enable the reader to gain some insight in the evolution within the field and the possible strategies, materials, and methods that have been applied so far.

Hydroxyl and carboxyl end-groups are generated when a poly ester is hydrolyzed via autocatalytic cleavage of main-chain ester-bonds. ${ }^{91}$ Normally roughness and hydrophilicity of the surface increase. ${ }^{92}$ In some cases, both enhanced cell attachment and spreading are reported. In general, subsequent immobilization of natural proteins tends to increase cell adhesion and viability. ${ }^{93,94}$

For an overview of some interesting work on aminolysis, we refer to Table 2. As for hydrolysis, this also is a surface degradation reaction, roughness also tends to increase, and thus wettability increases. Characterization of surfaces is a rather specific field with specific complications and limitations. It is challenging to evaluate to what extend the change in wettability is due to the introduction of amine groups on the surface, and 
Table 1. Hydrolysis: An Overview of Some Interesting Papers Reporting on Surface Hydrolysis by Acid of Basic Degradation

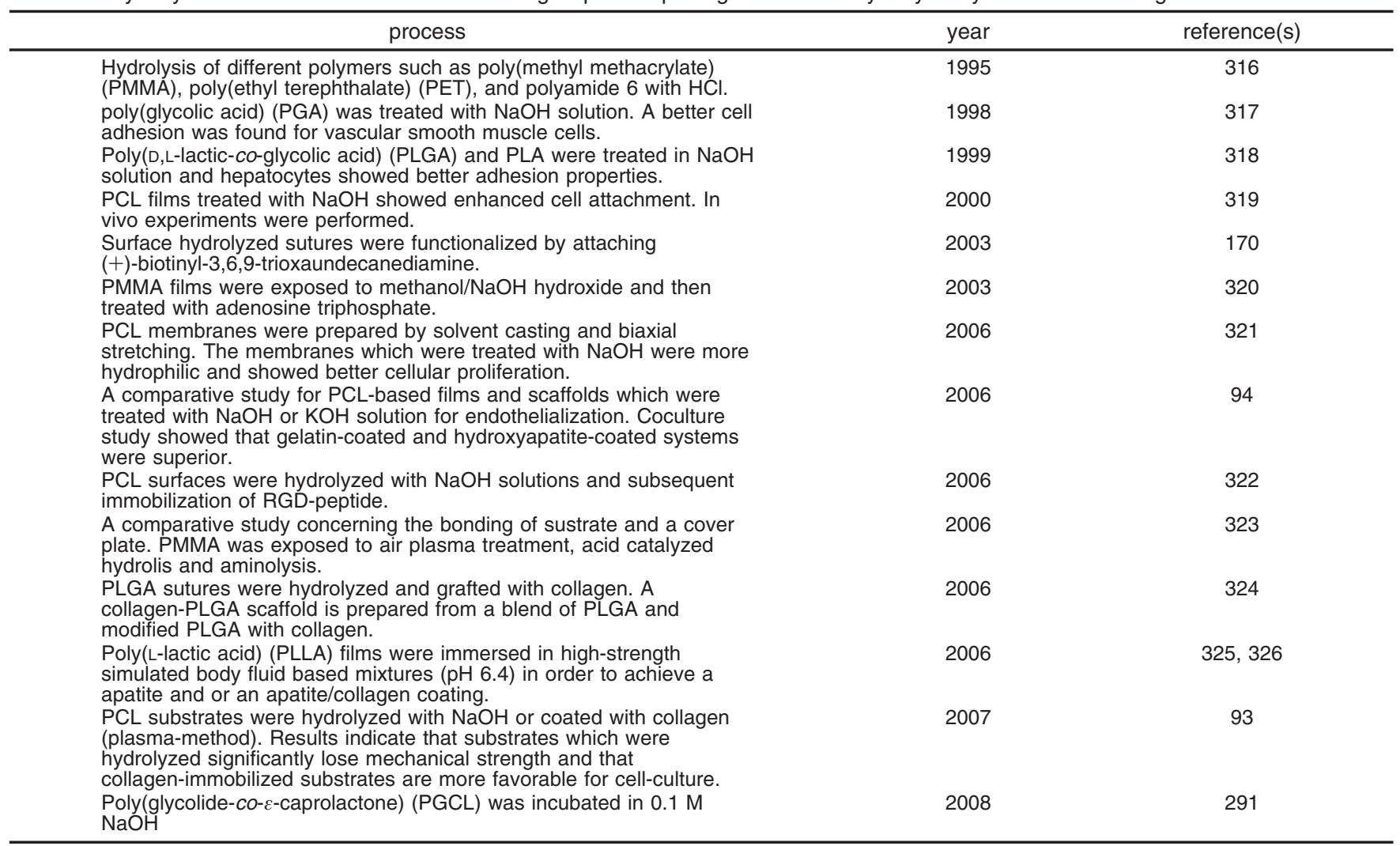

Table 2. Aminolysis: An Overview of Some Interesting Papers Reporting on Surface Aminolysis by Treatment with Different (Di)amines

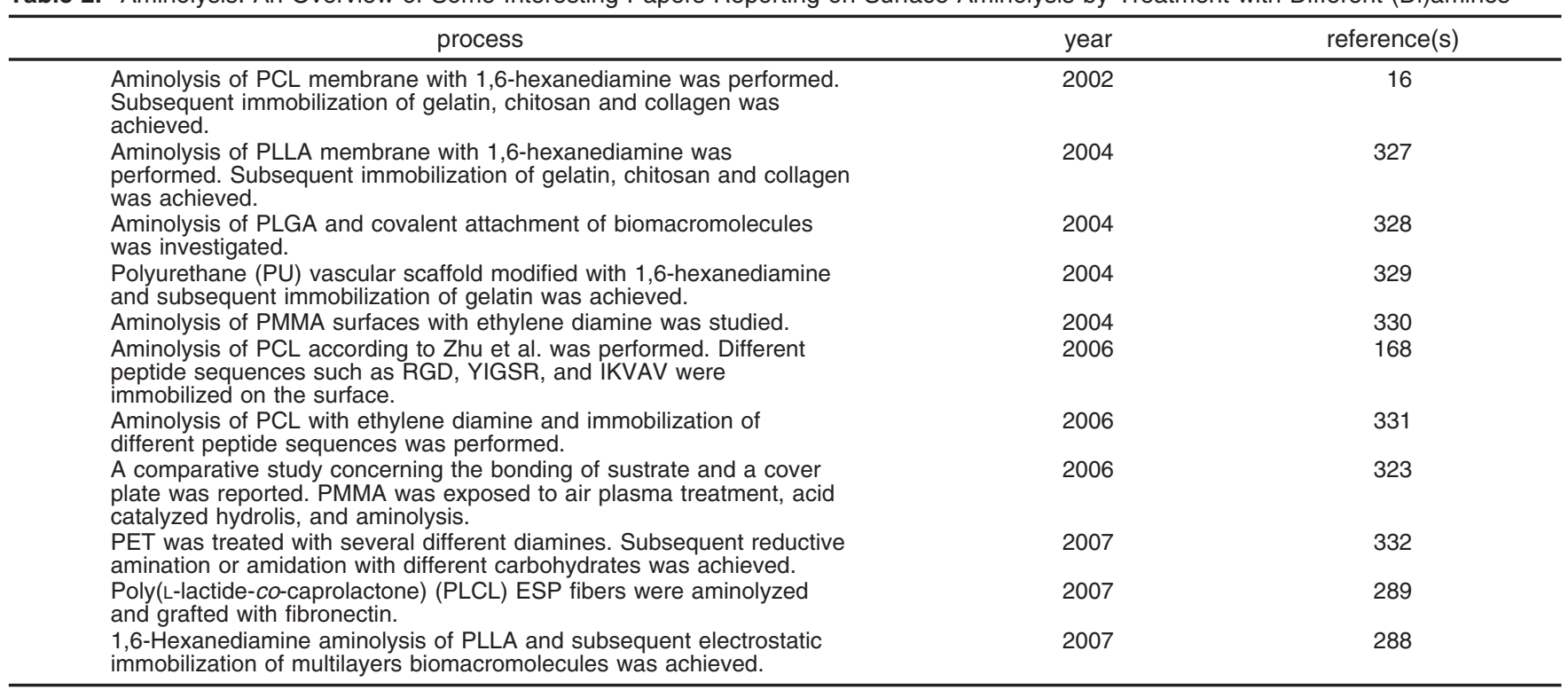

to what extend the increased wettability can be attributed to the increased roughness.

In general, these wet chemical methods are very useful, but some drawbacks should be noted. The most important disadvantage is that these reactions are nonspecific, introducing a range of functional groups. The degree of surface modification may not be repeatable comparing polymers of different molecular weight, crystallinity, or tacticity. ${ }^{95}$ Irregular surface etching has indeed been reported. ${ }^{84}$ As this surface degradation affects the outer shell of the device a loss of mechanical properties ${ }^{93}$ or faster degradation might be the case.

Surface modification of surfaces treated with hydrogen peroxide has also been reported. Hydrogen peroxide decomposes to hydroxyl radicals, which are more reactive than other oxidative chemicals by applying ultraviolet radiation. ${ }^{96}$ This technique is used to create hydroperoxide groups on polymers by immersing samples in hydrogen peroxide solution and simultaneous irradiation with UV-light. ${ }^{97}$ This is called photooxidization. In the next step, the sample is immersed in a monomer solution and exposed a second time to UV-light to initiate the graft polymerization. ${ }^{97-100}$

Another form of oxidization was reported by Goddard et al. Low-density polyethylene (LDPE) samples were treated with chromic acid to introduce carboxylic groups. ${ }^{95}$ Oxidization of surfaces can cause severe changes in chemical, physical, mechanical, and biological properties. 
Ozone Treatment. A second strategy implies oxidization of the surface of a biomaterial by exposing it to ozone. Ozone can be used as such, but it was found that a combination of ozone and UV irradiation increased the kinetics of the process significantly. This observation could be attributed to different pathways for both methods. ${ }^{101} \mathrm{UV}$-ozone treatment of different materials such as polyethylene (PE), poly(etheretherketone), poly(vinyl fluoride), and PS were studied. ${ }^{102-104}$

As for wet-chemical treatment, it can be stated that this is a nonspecific technique. Furthermore, the surface composition will depend on the cleaning procedure. In addition, reorientation at the surface seems to occur. ${ }^{104}$ Another concern is the degradation of polymers, which is known to be enhanced by ozone. ${ }^{105}$

Following on ozone-treatment, subsequent grafting of monomers on the oxidized surface is possible. 2-Hydroxyethyl methacrylate (HEMA) was grafted to ozonated polypropylene (PP) samples. ${ }^{106}$

Recently Liu et al. reported the grafting of different hydrophilic polymers such as PEO, chitosan, and poly(vinyl alcohol) (PVA) to an ultrafiltration membrane composed of polyethersulfone by an ozone/UV combination. The modified films demonstrated increased hydrophilicity, reduced protein adsorption, and increased roughness. ${ }^{107}$

UV-Treatment and Photografting. UV treatment has been extensively used for surface graft polymerization of polymers in the presence of a photoinitiator or photosensitizer. ${ }^{108,109}$ Depending on the chemical structure of the grafted polymer, different functionalities are introduced to the surface. UV can be applied while the sample is kept under vacuum conditions (VUV), or submerged in an inert gas such as argon, or covered with monomer solution. Often, the photoinitiator, mostly benzophenone (BPO), is either precoated on the substrate or present in solution. UV light excites the BPO, which can abstract hydrogen atoms from the polymer film when it relaxes, thus creating free radicals on the surface.

Some authors have reported the introduction of polymers with amine-side-chains. The photoinduced graft polymerization of acrylamide (AAm) on PP membranes for the improvement of the antifouling properties was reported. ${ }^{110}$ In a more recent study, the grafting of 2-aminoethyl methacrylate (AEMA) was described. ${ }^{111}$ The group also reported the use of air-plasma to increase the hydrophilic and antifouling character of the PP membranes. ${ }^{112}$

Wang et al. recently studied the photografting of methyl methacrylate (MMA) onto high-density polyethylene (HDPE) initiated by a proper butanone/water/ethanol mixture as a new photoinitiating system. ${ }^{113}$

In order to increase the protein resistance of polydimethylsiloxane, a phosphorylcholine group functional methacrylate monomer was graft polymerized on the surface using BPO as a photoinitiator. ${ }^{114}$ The resistance to protein adsorption could be tuned by controlling the graft density.

In literature, the complexity of the photografting process has been nicely demonstrated. This was done by systematically investigating the effects of the principal parameters determining the graft density. The complex interaction between irradiation time, molar ratio, monomer concentration, photoinitiator, UV and solvent determines the overall degree of grafting. ${ }^{115}$ No predictive model is available, so, for each combination of a surface and a monomer, an optimization is required.

One of the drawbacks of the above-mentioned systems includes the requirement of solvents. The solvent selection has a great impact on the extent of grafting. ${ }^{116}$ In order to overcome this problem Albertson et al. developed a solvent-free grafting technique that consists of the subjection of biodegradable polymers to the vapor phase of a monomer and inducing the grafting reaction by photoinitiation. ${ }^{116-121}$

More extensive reviews about UV treatment are available elsewhere. ${ }^{108,109,122}$

Self-Assembly. Self-assembly is the process whereby a disordered system of components forms and organizes a structure or pattern as a consequence of specific, local interactions among the components themselves, without external direction. In the case of surfaces, this implies that certain molecules are able to interact with a surface and form a SAM on the surface. Depending on the chemical structure of the molecules making up the SAM-layer, different functionalities can be introduced onto the surface. The best known phenomenon is the interaction between n-alkane thiols and gold. A lot of work has been done in this field. SAMs on gold have also been engineered to enable dynamic control of interfacial acticity, such as wettability and chemical reactivity of the surface. Control was achieved by light, ${ }^{123,124}$ electrochemical signals, ${ }^{125-127}$ and inducing conformational change by means of a temperature change below the lower critical solution temperature ${ }^{128}$ or a $\mathrm{pH}$ change. ${ }^{129}$

Spatially defined arrays of SAMs can be prepared by combining self-assembly with patterning methods such as microcontact printing and photolithography. ${ }^{1,126}$

SAMs are typically formed on gold and silver, which limits their applicability. To overcome this limitation block-copolymers with an amphibhilic nature are being investigated to form selfassembled layers onto polymers. These layers are formed by hydrophobic interactions. The group of Rypacek did a lot of work in the field of Langmuir-Blodgett films with amphiphilic block copolymers. ${ }^{130}$ For example, Popelka et al. created PEO-PLA block copolymers, which formed a SAM on polylactide surfaces. ${ }^{131}$ These copolymers were further functionalized with RGD to render random patterned surfaces. Murphy et al. reported a similar strategy to form degradable coatings on colloidal PS particles. ${ }^{132}$

The paradigm of using the self-assembling and selforganizational properties of various compounds such as proteins, bioceramics, and even cells can be found in various fields such as tissue-engineering ${ }^{133}$ and bioprinting. ${ }^{44,134-137}$

High-Energy Radiation. The most common radiation types, used in industry, include $\gamma$-radiation and e-beam radiation. ${ }^{138}$ Ion beams are used in order to achieve ion implantation in the outer surface layer or to deposit coatings. Many different ions have been employed for irradiating polymers such as hydrogen and helium atoms, as well as ions of gold or uranium. ${ }^{138}$ Ion implantation does not directly introduce functional groups onto the surface but the surface chemistry, and thus the surface properties, are changed.

For the treatment of polymers, it should be noted that highenergy irradiation can cause additional chemical effects. Free radicals can recombine, leading to cross-linking. Chains can be cleaved, leading to degradation of the polymer. ${ }^{116,139}$ These processes occur mostly simultaneously. Higher-energy radiation is considered not a viable route for the modification of most biodegradable polymers. ${ }^{140,141}$

During the past decades, the interaction between biomaterials and $\gamma$-radiation has gained major scientific interest. ${ }^{142}$ Highenergy photons can be used to change surfaces in different manners. These photons create radical sites on surfaces and free molecules which can lead to propagation or termination reactions such as recombination. Comparable to plasma strategies, postir- 
radiation and syn-irradiation can be distinguished for $\gamma$-ray irradiation. These strategies will be discussed later in the section on plasma.

$\gamma$-Ray irradiation can initiate the polymerization and grafting of a monomer to a surface ${ }^{143-146}$ (syn-irradiation), or it can produce peroxides and hydroperoxides on a surface that can be subsequently used as initiating sites for graft polymerization ${ }^{147}$ (postirradiation). Finally, $\gamma$-ray irradiation in water can lead to hydroxylation of the surface. ${ }^{145}$

Ion-beam based processes, such as ion implantation and ionbeam-assisted deposition (IBAD), offer a wide array of beneficial surface property modifications without adversely affecting bulk properties. ${ }^{148}$ Ion implantation is often used to improve friction, fretting resistance, and biocompatibility. IBAD is used to apply antimicrobial coatings, to apply sealant coatings to prevent water or oxygen permeation, and to create metalized traces on polymers. It was reported that the ion implantation into PE leads to a partial loss of hydrogen atoms, followed by the oxidation of the surface layer. ${ }^{149}$ This oxidized layer is harder and more wettable. This increased wettability is a primary factor for biocompatibility, cell adhesion, lubrication in waterbased environment, or grafting of biopolymers.

Farquet et al. described the influence of the viscosity of a monomer solution to the effectiveness of the postirradiation grafting reaction. It was found that the viscosity is an important parameter to control surface graft polymerization. The higher the viscosity of the initial monomer solution, the higher the geminate radical recombination, and the lower the probability to initiate a polymer chain. At longer incubation times, the viscosity near the surface increases, leading to a further decrease of accessible radical sites ( $k_{\mathrm{d}} f$ is lower at higher viscosity). Considering the propagation, the viscosity seems to be less important. For $t \approx 0$, the $k_{\mathrm{p}}$ of the heterogeneous system is similar to the one in solution, i.e., lower at higher viscosity. ${ }^{150}$ The authors demonstrated that viscosity is an essential and very easily controllable parameter in surface graft-reactions.

Plasma Treatment. As we will focus on plasma treatment in the next part, the major techniques will here be outlined very briefly.

Plasma treatment can be used to directly or indirectly introduce different functionalities on inert surfaces. Direct modification includes the reactive $\mathrm{NH}_{3}$ plasma, which is known to introduce, among others, amines, where $\mathrm{O}_{2}$ plasmas introduces a mixture of mainly $\mathrm{COOH}$ and $\mathrm{OH}$ functionalities. Argon plasmas are typically used to introduce free radicals.

Indirect modification is based on the grafting of polymers bearing the desired functionalities onto the surface. Both strategies and recent advancements in the field will be discussed extensively in the next paragraph.

The use of plasma modification techniques has some major advantages. First of all, some techniques will influence the mechanical properties of the outer layer of an implant. It is clear that wet chemical treatment of a surface will cause a partial degradation and scissions of the polymers at the surface, leading to a decrease of mechanical strength and leading to a faster degradation. A comparative study demonstrated that the structural and chemical integrity of PLGA 3D scaffolds was adversely affected by wet chemical methods. ${ }^{151}$

Another advantage is that plasma enables to uniformly change surfaces, regardless of the geometry. The technique can be used on complex objects such as 3D components for tissue engineering or artificial organs, ${ }^{152}$ nanoparticles, and films. ${ }^{153}$

Another major advantage is that the use of hazardous solvents can be avoided, as plasma is a solvent-free technique.
Alternative Strategies for the Introduction of Reactive Functional Groups. Of course many other techniques have been proposed to change a surface. We will briefly discuss some of them.

Recently, surface-initiated polymerization (SIP) has attracted a lot of attention, since it has proven to be a successful technique for grafting polymers onto solid substrates. ${ }^{154-156}$ In a typical SIP process, a surface-bound initiating site is used for graft polymerization. Many different polymerization methods have been applied for SIP. ${ }^{157}$ Within this field, the application of radical living polymerizations such as $\mathrm{RAFT}^{88,89}$ and ATRP is of great interest. ${ }^{85,86,88,158}$ Some major advantages of these techniques include the longer chain length achievable and the higher graft density which can be obtained. This is a basic condition when the aim is to create polymer brushes on a surface. Some authors state that surface-initiated ATRP is opening up a new route to "precision" surface modification. ${ }^{159}$ The interested reader can find an excellent review on this topic elsewhere. ${ }^{87,159}$ Recently, Huang et al. reported the use of ATRP to graft dimethyl-amino-ethylmethacrylate from a PP surface. ${ }^{85}$ Lee et al. grafted oligo(ethylene glycol) methyl ether methacrylate from a gold surface using of ATRP. This PEO-layer was used as a nonfouling layer. "Click-chemistry" was applied on the azide-terminus of the nanobrushes in order to introduce specific functionalities for the binding of bioactive molecules. ${ }^{86}$ This strategy enabled the introduction of specific binding ligands on an inert polymer substrate.

Another new and emerging technique is the so-called molecular layer deposition (MLD). ${ }^{160-163}$ The major advantages of the MLD methods include thickness control and conformality. As far as we know, no studies addressing biocompatibility of these surfaces have been undertaken so far.

1.2.4. Immobilisation of Proteins or Other Biomimetic Clues. From the previous discussion, it is clear that there are numerous techniques that enable the modification of a surface by introducing functional groups. This chemical modification will not only alter some physical properties such as wettability, it will also enable the subsequent chemical binding of biological compounds to the surface. From the interaction of cells with their surroundings, which was previously discussed, it is assumed that this will lead to the desired biocompatibility or biofunctionality. Moreover, if cells can be triggered to interact in a desired manner with materials, the stimulation to adhere, to proliferate, and even to differentiate might be feasible. This is, as mentioned before, of major interest in the field of tissue engineering.

The immobilization of small peptides such as RGD, ${ }^{164}$ ArgGly-Asp-Ser (RGDS), Ile-Lys-Val-Ala-Val (IKVAV), and YIGSR are considered. ${ }^{54,165-169}$ Different authors reported the immobilization of biomolecules such as biotin, heparin, and insulin. $54,170,171$

There are numerous bioconjugation techniques that are applied in the field, and intensive research is being performed. The most common technique is carbodiimide coupling of a carboxylic group with a primary amine. First, the carbodiimide reacts with the carboxylic group to form a reactive intermediate. This can be stabilized by forming the reactive ester by adding (sulfo)- $N$-hydroxysuccinimide (NHS). A large deal of research in the field of surface engineering focused on the introduction of carboxylic groups onto the surface in order to be able to use this coupling method. The reader will notice the emphasis on the postirradiation grafting of acrylic acid (AA). 


\section{Nonthermal Plasma Technologies for Surface Modification}

In the previous section, we discussed some surface modification technologies, and their possible advantages and drawbacks. Plasma-based strategies for the surface modification of biodegradable polymers, and biomaterials in general, demonstrate great potential. Therefore, the focus of this part will be on these strategies. First, we will discuss the general interaction of plasma with materials, and the different strategies for surface modification that evolve from this interaction. Second, an overview of nonthermal plasma technologies for surface modification will be given. In the last section, a more extensive overview of the research performed within this area, focusing on materials, monomers, and plasma-types, will be outlined.

2.1. Plasma Surface Interactions: General Introduction. Plasma is sometimes referred to as the fourth state of matter. The term was introduced by Langmuir in $1929 .{ }^{29}$ Plasma is a partly ionized gas and can be defined as a quasi-neutral particle system in the form of gaseous or fluid-like mixtures of free electrons, ions, and radicals, generally also containing neutral particles (atoms, molecules). Some of these particles may be in an excited state. Particles in an excited state can return to their ground state by photon emission. The latter process is at least partially responsible for the luminosity of a typical plasma. ${ }^{17,84}$ In plasma, certain electrons are free, rather then bound to molecules or atoms. This means that positive and negative charges can move somewhat independently from each other. Plasma is typically obtained when gases are excited into energetic states by radio frequency (RF), MW, or electrons from a hot filament discharge.

Plasmas are frequently subdivided into nonequilibrium (or nonthermal/low-temperature/cold) and equilibrium (or thermal/ high-temperature/hot) plasmas. Thermal equilibrium implies that the temperature of all species (electrons, ions, neutrals, and excited species) is the same. This is, for example, true for stars as well as for fusion plasmas. High temperatures are required to form these types of plasmas, typically ranging from $4000 \mathrm{~K}$ for easy-to-ionize elements such as cesium to $20000 \mathrm{~K}$ for hardto-ionize elements, such as helium. ${ }^{172,173}$ In contrast, plasmas with strong deviations from kinetic equilibrium have electron temperatures that are much higher than the temperature of the ions and neutrals and are classified as nonequilibrium plasmas. It is obvious that the high temperatures used in thermal plasmas are destructive for polymers, and most applications for biopolymer surface modification will make use of nonthermal or cold plasmas. Therefore in this paper, we will limit ourselves to this type of plasma sources.

It is clear that plasma is a very reactive environment in which several different interactions between plasma and a surface are possible. Three main categories of plasma reactions can be distinguished, according to the outcome of the interaction: plasma polymerization, plasma treatment, and plasma etching (or ablation). Plasma polymerization means that an organic monomer is converted in reactive fragments which polymerize and are deposited to the substrate. In this way, coating can be achieved. This polymerization can be initiated in the vapor phase or at the surface. The coating and the substrate will both be bombarded with ions from the plasma, and thus etching occurs. Not all gases lead to reactive intermediates which can polymerize. This is the case for different gases such as $\mathrm{He}, \mathrm{Ar}, \mathrm{O}_{2}$, and $\mathrm{N}_{2}$. In plasma-literature they can be referred to as "inert gases", having a slightly different meaning then classical inert gases. These gases will not form a polymerized coating but will create

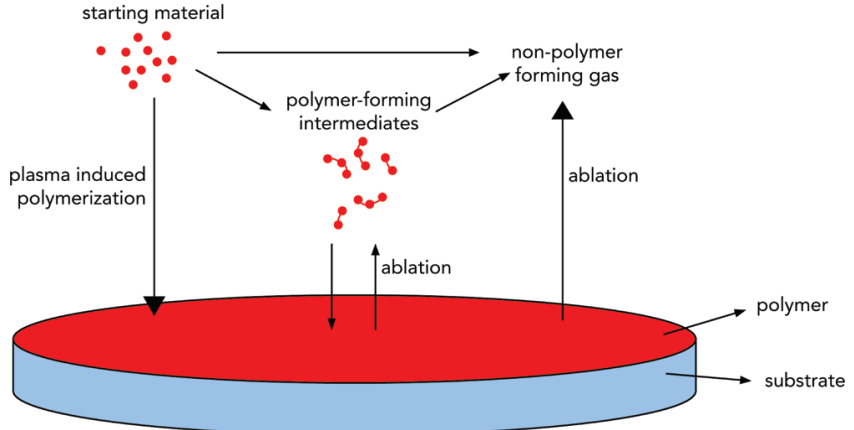

Figure 2. A schematic representation of competitive ablation polymerization.
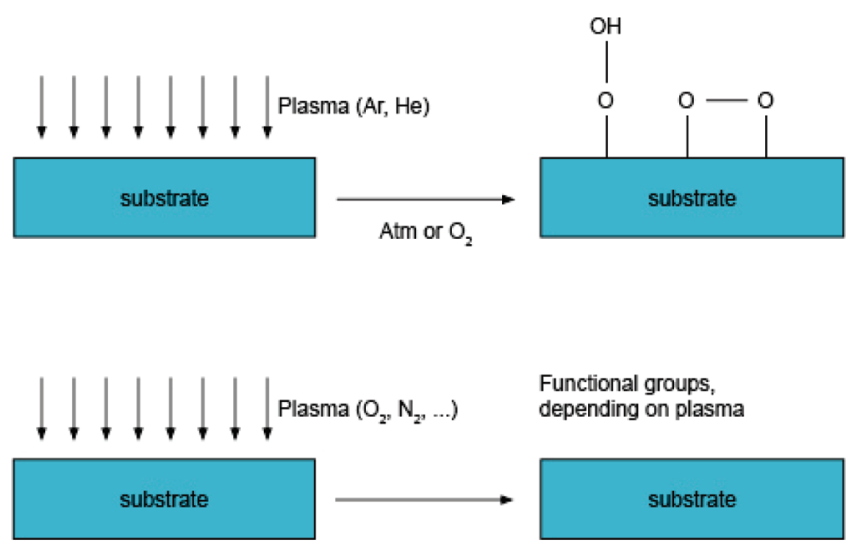

Figure 3. A schematic representation of plasma treatment with different plasma gases. Ar or He typically introduces free radicals, which can react with oxygen to form (hydro)peroxides. Other plasmas, such as oxygen and nitrogen, introduce different functional groups.

or substitute functional groups, or create radicals, on the surface. This is a typical plasma-treatment strategy.

It is clear that the process vapor, the substrates, and the process conditions will determine which process is dominant: deposition, substitution, or etching. This process was described by Yasuda in ref 174 as competitive ablation polymerization (see Figure 2).

These different interactions of plasma lead to different plasma-based surface modification strategies. We will briefly introduce them here and discuss them more extensively in the last part of this review.

Plasma Treatment. As indicated previously, plasma treatment does not apply a monomer in vapor phase but inert gases (see Figure 3). As a result, chemical functionalities are introduced onto the surfaces or free radicals are created. These radicals can be used for cross-linking or surface grafting. Typically gases such as $\mathrm{Ar}, \mathrm{He}, \mathrm{O}_{2}, \mathrm{~N}_{2}, \mathrm{NH}_{3}$, and $\mathrm{CF}_{4}$ are used. The introduced functionalities can be subsequently used to bind polymers or other molecules to the surface in order to achieve the desired surface properties. Very often, plasma treatment is used only to obtain more hydrophilic surfaces.

Plasma Postirradiation Grafting. The use of $\mathrm{He}$ and $\mathrm{Ar}$ plasma is known to introduce mainly radicals on the surface, without introducing functionalities or plasma-deposited polymers (see Figure 3). If those free radicals are subjected to the atmosphere or to $\mathrm{O}_{2}$, peroxides and hydroperoxides will be formed. Those functionalities can be used for initiation of a polymerization reaction (see Figure 4). This is a postirradiation grafting technique. Note that, in this case, the monomer is not subjected to the plasma and thus the grafted polymers will have the same composition as the polymers achieved by conventional 


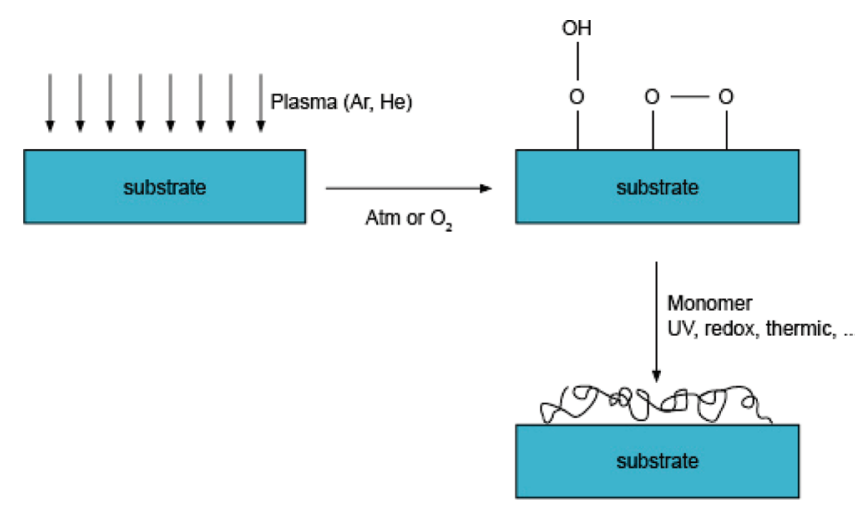

Figure 4. A schematic represetation of plasma postirradiation grafting.
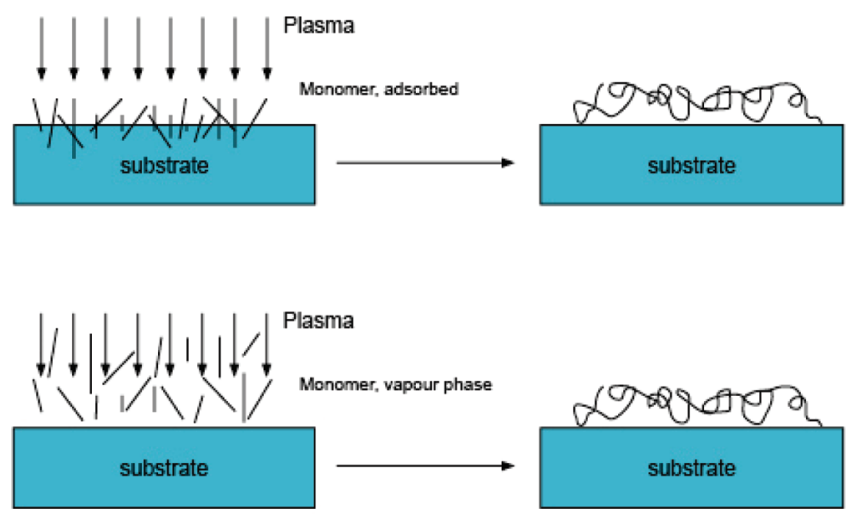

Figure 5. A schematic representation of syn-irradiation grafting and plasma polymerization.

polymerization. This type of strategy can also be referred to as a "grafting-from" approach.

In contrast to the postirradiation grafting approach, two possible strategies exist in which the monomer is subjected to plasma.

Plasma syn-Irradiation. The first strategy includes the adsorption of a monomer to the substrate, which is then subjected to plasma (see Figure 5). The plasma will create radicals in the adsorbed monomer layer and a substrate surface, which will lead to a cross-linked polymer top-layer. This is a syn-irradiation grafting method and a typical plasma-induced polymerization strategy.

Plasma Polymerization: Deposition. Another surface modification strategy is based on the plasma state polymerization. A monomer in vapor phase which is introduced in the plasma is converted in reactive fragments (see Figure 5). These can combine to polymers in the gas phase (plasma-state polymerization). The polymers formed in a plasma will not necessarily have a structure and composition that is comparable to polymers achieved by conventional polymerization techniques. It is noteworthy that plasma polymerization occurs with many monomers in the vapor phase, even if they do not contain unsaturated bonds or cyclic structures. These polymers can be deposited on the substrate, thus creating a plasma-deposited polymer coating on the surface. This is a grafting-to approach, and also a so-called syn-grafting, or simultaneous grafting.

In literature, in some cases, the term "preirradiation" refers to "postirradiation" $66,144,175,176$ and "simultaneous grafting" or "syn-irradiation" can be used to refer to direct grafting". 144

In general "grafting to" a surface refers to the binding of a polymer to a surface, while "grafting from" means that the polymer is grown starting from initiating sites on the surface.
It is suggested that the "grafting to" approach leads to lower grafting densities because of the concentration gradient built up by the already grafted chains. ${ }^{177}$ As the addition of monomer to an initiating site or a growing chain end is not strongly hindered by the already grafted chains in good solvent conditions, it is believed that this approach will lead to a higher grafting-density and a thicker grafted layer. ${ }^{159,178-180}$

2.2. Nonthermal Plasma Sources. As discussed before, for surface-modification of polymers in the biomedical field, mainly cold plasma sources are of interest. The type of plasma and the technical equipment will be of great importance. For example, some plasmas are more homogeneous then others. First, a brief overview of different nonthermal plasma sources will be given, discussing strong and weak points of each type, followed by some recent trends and technical developments in the field.

In plasma technology, nonthermal plasmas are generated by an electrical gas discharge. The application of a strong electric field to a neutral gas ensures ionization in the gas volume and the created charged particles are accelerated in the applied electrical field. Especially the electrons are affected by the field due to their light mass and gain most energy. They achieve high temperatures $\left(10^{5}-10^{6} \mathrm{~K}\right)$, while the heavy ions efficiently exchange their energy by collisions with the background gas and thus remain cold. The gas temperature is below $473 \mathrm{~K}$. On collision between energetic electrons and neutral molecules, radicals are created. These radicals play an important role in the chemical activity of the plasma. As a result of the low gas temperature, plasma surface treatment is applicable to heatsensitive materials, such as biopolymers. ${ }^{181}$

Typical for surface modification developed plasma sources is that they operate at low pressures $\left(10^{-3}-1000 \mathrm{~Pa}\right)$. At low pressure the discharge is more stable, and it is easier to control the plasma reactions. A long mean free path of the gas particles guarantees only few collisions and thus only a small reduction in the number of chemically active species.

The application field of plasma technology is growing very fast. Moreover, increasing demands from industry encourage the continuous development of more efficient and more flexible plasma techniques. Therefore, it can be noticed that in recent plasma technology research, large efforts are made to develop atmospheric pressure technology-based plasma reactors to overcome the disadvantages of low pressure. Because there is no need for vacuum devices, the investment costs are much lower, and atmospheric plasma technology can easily be scaled up to industrial dimensions and integrated in in-line processes. ${ }^{182,183}$

The difficulty of working at atmospheric pressure is that instabilities in the discharge rapidly arise, so that transition to a thermal arc discharge is likely to take place. This transition is undesirable because of the loss of homogeneity as the discharge constricts to a narrow current channel. Moreover, the high current density causes an increase in gas temperature, which dispels the nonthermal character of the discharge. Therefore, the major challenge for atmospheric pressure technology is finding a mechanism to prevent this transition. Different solutions are based on limiting the discharge maintenance time by working in a pulsed regime so that the instabilities do not have enough time to develop. ${ }^{184}$ In this way, for example, pulsed corona and MW discharges can be employed at atmospheric pressure. ${ }^{185}$ Dielectric barrier discharges (DBDs) prevent the transition to an arc discharge by autopulsation of the discharge in an alternating current (AC) arrangement with a dielectric barrier covering one or both electrodes. ${ }^{186,187}$ Another method to prevent accumulation of charges is to apply a fast gas flow 


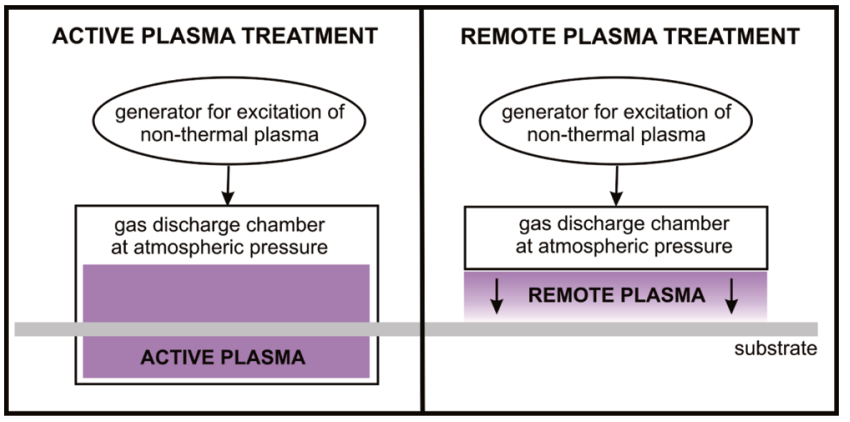

Figure 6. Active versus remote atmospheric plasma treatment.

in transverse direction so that instabilities are "blown" away, for example, in the direct current (DC) glow discharge. ${ }^{188}$

Recently, several authors reported the use of atmospheric plasma for the modification of surfaces of polymers and biomaterials. ${ }^{189-196}$ These authors reported successful surface modification by means of atmospheric plasma. These promising results demonstrate the feasibility of atmospheric plasma surface modification for biomedical applications. For example, atmospheric plasma deposition of patterned substrates demonstrated adherence of cells to plasma polymer islands, even for human U937 macrophages, which normally do not adhere on tissue culture plates. ${ }^{189}$ Another interesting application of atmospheric plasma's can be found in the field of sterilization. Park et al. reported a MW-induced argon plasma system that operates at atmospheric pressure. ${ }^{197-200}$ It was demonstrated that this sterilization method is easy to use, requires significantly less time than the other traditional methods and other established plasma sterilization methods, and it is nontoxic. ${ }^{197}$ Stoffels et al. reported the development of an atmospheric plasma-needle, which will be discussed later. ${ }^{201}$

According to the location of the treated sample with respect to the gas discharge chamber, surface treatment with atmospheric plasma technology can be divided into active and remote plasma treatment as shown in Figure 6. In the active plasma treatment, the substrate to be treated will pass between the electrodes. In this way, there is direct contact between the substrate surface and the active plasma. In remote plasma treatment, the substrate is located outside the plasma chamber, but passes in the gas stream that runs through the plasma chamber and that is loaded with radicals and other active species. The sample is treated in the afterglow of the plasma. An active plasma treatment has the advantage of a higher concentration of active species near the surface of the substrate, while for remote plasma treatment, this concentration decreases as a function of distance to the plasma chamber and depends on the lifetime of the active species. ${ }^{194}$ On the other hand, the active plasma treatment faces a risk of backside treatment and pin-holing, while the remote treatment prevents damages from the discharge as the discharge current does not flow through the sample. Moreover, remote treatment allows the possibility to treat the surface of materials of any thickness and any geometry (3D objects). These characteristics makes them attractive strategies for the modification of 3D tissue implants and biomaterials in general. ${ }^{202-205}$ The active treatment is often limited to thin substrates, as a result of the dimensions of the interelectrode space.

It was reported that the hydrophilicity effects of remote $\mathrm{Ar}$ plasma were more noticeable than those of direct Ar plasma. ${ }^{204}$ The authors further demonstrated that direct Ar plasma treatment caused more severe surface degradation then remote plasma treatment. It is concluded that remote plasma treatment can enhance radical reaction and restrain electron and ion etching

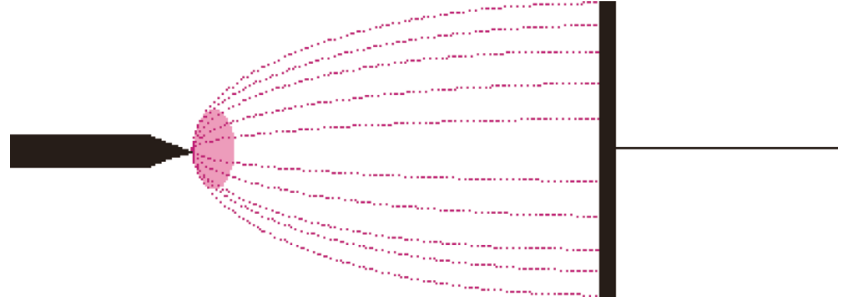

Figure 7. The point-to-plane corona discharge.
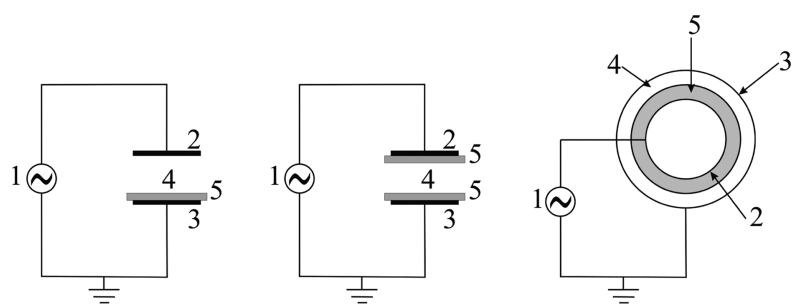

Figure 8. Typical planar and cylindrical DBD configurations: (1) AC HV source; (2) HV electrode; (3) ground electrode; (4) discharge gap; (5) dielectric barrier.

effects. $^{204}$ This property is obviously of major importance for surface modification of biodegradable biomaterials such as polyesters.

In the following paragraphs, we will briefly discuss the most significant properties of the typical nonthermal plasma sources used for surface modification. It should be noted that, for several plasma sources reported in literature, it is difficult to classify the plasma source unambiguous in one or another category because they show features of different types.

2.2.1. Corona Discharge. The corona discharge is a low current discharge caused by partial or local breakdown of a gas gap with strongly inhomogeneous electric field at atmospheric pressure. To form a nonuniform electric field distribution in the gap, the electric field near one or both electrodes must be stronger than in the rest of the discharge gap. This situation typically arises when the characteristic size of at least one of the electrodes is much smaller than the interelectrode distance, e.g., a pointed electrode and a plane (see Figure 7) or a thin wire and a cylinder. Around the sharp electrode, an inhomogeneous localized corona glowth can be observed with a small active volume. Despite this small active volume, corona discharges are often applied for treatment of polymers. ${ }^{84,206-208}$ It was suggested that corona-discharge treatment could possibly influence the biodegradability of certain biodegradable polymers. $^{209}$

2.2.2. Dielectric Barrier Discharges. A lot of different configurations can be applied in order to realize a DBD. There are three basic configurations for generating DBDs. The first type is the volume discharge arrangement, for which the most commonly applied types are shown in Figure 8. A characteristic feature of such a DBD is that at least one of the electrodes is covered by a dielectric layer. This dielectric is the essential part of the discharge. After ionization at a certain location in the discharge gap, the transported charge accumulates at the dielectric surface. This charge generates an electrical field that reduces the field in the gap and interrupts in this way the current flow after a few nanoseconds. The exact duration depends on the pressure, gas composition, and dielectric properties. By applying an AC voltage (typical frequencies: $1-100 \mathrm{kHz}$ ) with an amplitude sufficient for breakdown, a large number of microdischarges are induced, randomly distributed in time and space. The dielectric layer has two functions. It limits the amount 


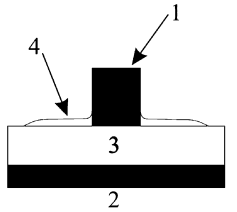

(a)

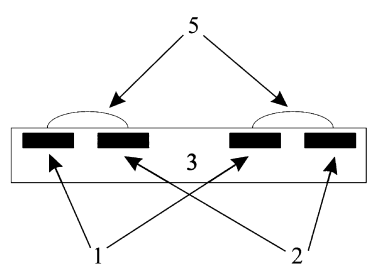

(b)
Figure 9. Surface discharge (a) and coplanar discharge (b) configurations: (1) HV electrode; (2) counter-electrode; (3) dielectric barrier; (4) surface discharge; (5) coplanar discharge.

of charge transported by a single microdischarge and distributes the microdischarges over the entire area of the electrode.

Next to this filamentary type of volume discharge, several research groups reported on diffuse discharges in DBD configurations at about atmospheric pressure and gap widths up to several centimeters. ${ }^{210-213}$ In other arrangements, one of the plane electrodes is replaced by a sharp electrode, resulting in an AC dielectric barrier corona discharge. ${ }^{214}$

The second and third arrangements for a DBD used for surface modification are the so-called surface discharge and coplanar discharge arrangement. Figure 9a shows a typical arrangement of a surface discharge: a plane dielectric with a thin or long electrode (or several in parallel) on one surface and an extended metallic cover as the counter-electrode on its reverse side. The extension of the discharge depends on the amplitude of the voltage. Figure $9 \mathrm{~b}$ shows a coplanar discharge arrangement: pairs of long parallel electrodes with opposite polarity are close to the surface embedded within a dielectric bulk. The interelectrode distance can be of the order of 100 $\mu \mathrm{m}$. In literature, there are a large number of excellent reviews on DBDs. ${ }^{186,187,215-219}$ This type of plasma was used extensively for polymer surface modification. ${ }^{189,190,220,221}$ Recently, PCL was treated with DBD plasma, and mouse osteoblasts were cultured on these surfaces. ${ }^{221}$ The cells demonstrated increased initial attachment and proliferation.

It should be noted that occasionally in literature, the term corona discharge or corona treatment has been used in connection with DBDs, although most authors prefer to use this term only for discharges between bare metal electrodes without dielectric.

2.2.3. RF Discharges. A plasma can be excited and sustained by high-frequency electromagnetic waves. When the frequency of the electromagnetic field increases, the ions and subsequently the electrons can no longer reach the electrode surface during the acceleration phase of the exciting external field. At such RFs, the interaction between the power supply and the plasma is now dominated by displacement currents rather than by real currents. $^{222}$ Therefore, these discharges can be used without electrodes in contact with the plasma. This can be a major advantage for many applications because, in this way, impurities originating from the electrodes can be avoided. In most cases the discharges are operated at low pressure, although some applications are operated outside this range and even at atmospheric pressure.

RF discharges operate in the frequency range of $1-100 \mathrm{MHz}$, most commonly at $13.56 \mathrm{MHz}$. As a consequence, the wavelength of the electromagnetic field is much larger than the chamber dimensions.

The power coupling in RF discharges can be accomplished by oscillating electric fields (capacitive coupling) or by oscillating magnetic fields (inductive coupling). Figure 10a shows the schematic setup of a capacitive coupling system in a plasma reactor for surface treatment. Inductive coupling is realized by placing the discharge in the magnetic field of an induction coil (Figure 10b).

RF discharges are used by many groups for surface modification of polymers for biomedical applications. ${ }^{151,223-229}$ Unger et al. studied the influence of the different parameters on plasma polymerized films in an in situ manner. ${ }^{229}$ The approach consisted of designing and adding a dedicated plasma preparation chamber to the main analysis chamber of different spectrometers [X-ray photoelectron spectroscopy (XPS), electron spectroscopy for chemical analysis (ESCA), near-edge X-ray absorption fine structure (NEXAFS), and time-of-flight secondary ion mass spectrometry (TOF-SIMS)]. This approach can possibly provide us with more fundamental knowledge about the basic chemical reactions which take place, and the aging process.

$M W$ Discharges. In the MW region $(0.3-10 \mathrm{GHz})$, the wavelength of the electromagnetic field becomes comparable to the dimensions of the discharge chamber resulting in other coupling mechanisms. MW sources are most available and least expensive at the frequency of $2.45 \mathrm{GHz}$, the same frequency as used in MW ovens. ${ }^{222}$

Different types of MW discharges are available, which ensures that MW plasmas can be operated over a wide range of conditions, with pressures ranging from $0.1 \mathrm{~Pa}$ up to atmospheric pressure. The majority of MW-induced plasmas (MIPs) are produced in a waveguide structure or a resonant cavity. ${ }^{230}$

The waveguide coupled reactor is one of the simplest and most used MW plasma generation configurations. The MW power is directly coupled to the plasma by inserting a dielectric (quartz) tube reactor through a rectangular waveguide, as shown in Figure 11. The plasma is initiated and maintained due to the axial high electric field at MW frequency located at the place where the waveguide surrounds the dielectric tube, which contains the working gas at low pressure.

Several groups reported the use of MW plasma reactors. ${ }^{231-236}$ A special interest in MW plasma for sterilization purposes can be noticed. ${ }^{197-200,237,238}$

In a resonant cavity reactor, the MW power is fed through a window separating the waveguide, which is normally at atmospheric pressure, from the cylindrical vacuum cavity, where the plasma is generated (Figure 12).

During the past decades, different industrial applications of electron cyclotron resonance (ECR) plasma reactors were developed using a configuration similar to that shown in Figure 13. In such a configuration, the plasma is generated from the interaction between an electric field at MW frequency and a superimposed magnetic field, in such a way that the electrons are in resonance with the MW field. ${ }^{172}$ The ECR reactor essentially consists of two parts: a resonance region and a process region where the substrates are treated. The created plasma flows along the magnetic field lines from the resonance zone into the process chamber, where the energetic ions and free radicals impinge on the substrate surface.

The ECR system has been investigated by several groups for surface modification of polymers and biomaterials. .33,239-241 $^{2}$

2.2.4. Emerging Trends in Plasma Source Technology. As already mentioned before, it is sometimes difficult to unambiguously categorize different discharges. During the past decades, inspired by the search for stable and homogeneous atmospheric pressure discharges, the majority of the described plasma sources in literature are combinations of the above-described techniques. 


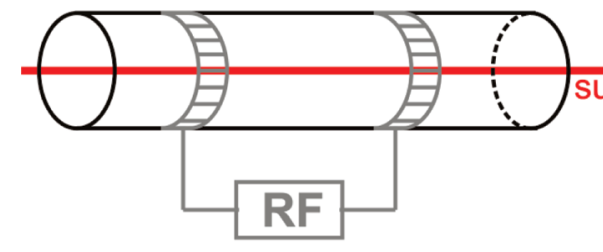

(a)

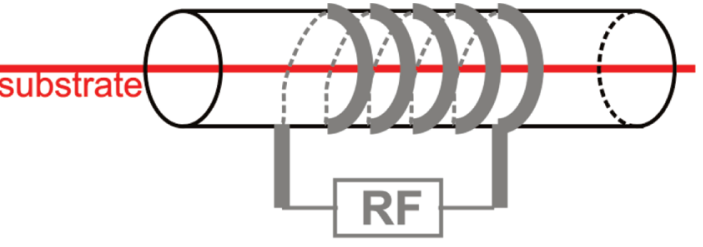

(b)

Figure 10. Capacitive coupling (a) and inductive coupling (b) of RF discharges.

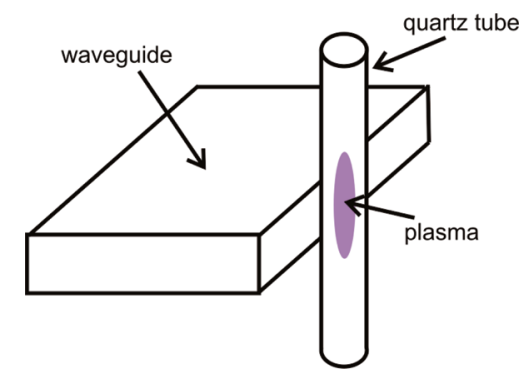

Figure 11. A typical waveguide-coupled MW plasma reactor.

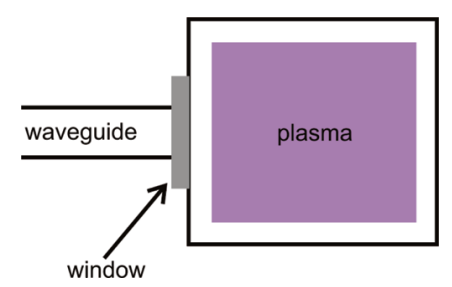

Figure 12. A typical resonant cavity MW plasma reactor.

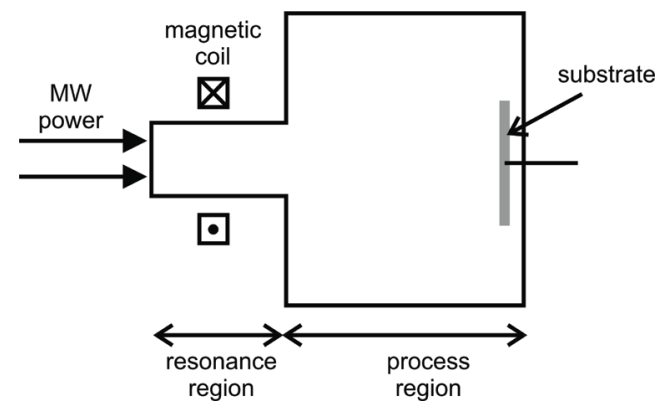

Figure 13. A typical ECR configuration for material processing.

In this last paragraph, we will describe two general concepts using such combinations that are thoroughly studied at the moment:

Microplasmas. Spatially confining atmospheric pressure, nonequilibrium plasmas to dimensions of $1 \mathrm{~mm}$ or smaller is a promising approach for the generation and maintenance of stable glow discharges at atmospheric pressure. ${ }^{242,243}$ Such discharges are called microplasmas and represent a new and emerging field of plasma technology. Microplasmas show a remarkable stability toward arcing. At this point of time, the mechanisms that are responsible for this behavior are still on the frontiers of knowledge. One mechanism is the so-called " $p d$ "-scaling. The breakdown voltage of a discharge depends on the product of pressure $p$ and electrode separation $d$ (Paschen curve). ${ }^{242}$ As a consequence, the voltage required to ignite a discharge can be kept low for essentially all gases even at atmospheric pressure if the electrode separation is below $1 \mathrm{~mm}$. Another mechanism that contributes to the observed stability of microdischarges is the high loss of charge carriers to the surrounding walls. Microplasmas are able to selectively generate chemical reactive species which could open up a wide range of applications in, e.g., surface treatment. ${ }^{244}$
Plasma Jet. As mentioned before, it is desirable for some applications to work with a remote plasma treatment and for this purpose several sources were developed. The plasmas produced are not spatially bound or confined by electrodes and are often referred to as cold plasma jets. Plasma needle, plasma plume, and plasma pencil are other designations of plasma jets. $^{245,246}$ Some authors even use the term plasma torch, but usually this name is reserved for thermal plasmas employed in industry for cutting and welding applications.

Plasma jets normally operate at atmospheric pressure and are widely tested for biomedical applications. ${ }^{245}$ Typical plasma jets are launched into the surrounding environment by devices that internally generate atmospheric pressure nonthermal plasmas. ${ }^{246}$ The jets are blown outside the source by a gas flow. In this way, the treatment occurs in the afterglow of the discharge. Plasma jets are generated in different gases and mixtures and their power sources cover a wide spectrum of frequencies from DC to MWs. ${ }^{245,246}$

As mentioned before, Stoffels et al. reported the development of a so-called plasma needle. ${ }^{201}$ This is a nondestructive atmospheric plasma source which can be easily manipulated. The miniaturization of this plasma needle gives this technique great potential in diverse application fields such as the treatment of dental cavities, ${ }^{247}$ site-specific sterilization, ${ }^{248}$ in vivo localized cell-detachment, ${ }^{249}$ and different surgeries. ${ }^{245}$ A pulsed plasma pencil, which operates at atmospheric pressure and room termperature, has been reported. ${ }^{250-253}$

These miniaturized, nonthermal, atmospheric plasma jets are considered to be very promising in the field of biomaterial surface modification. As this new technology evolves, instruments and experimental set-ups for the modification of biomaterials can be expected to appear in the near future. These plasmas can possibly be used in combination with a robotic arm in order to "draw" a predefined pattern of functional groups on a biomaterial.

2.3. Different Plasma Strategies for Surface Modification: Recent Achievements. The different interactions between a material and plasma were discussed, and the different plasma-based surface modification strategies were exemplified. An overview of different plasma-sources was given, and some emerging trends within this field were presented. Next, the practical application of these different strategies and recent results in the field of biomaterial modification will be discussed. We will focus on (1) plasma treatment, (2) postirradiation grafting, (3) syn-irradiation grafting, and (4) various plasma polymerization strategies. In each section, a table summarizing important and/or recent literature will be presented focusing on the type of plasma, monomer, and substrate applied.

2.3.1. Plasma Treatment. As discussed earlier, several gases can be used to create functional groups or free radicals on the surface of polymers. An overview of the most important research on surface modification of biodegradable polymers, using plasma treatment is presented in Table 3 . 
Table 3. Representative Overview of Plasma Treatment of Polymer Surfaces ${ }^{a}$

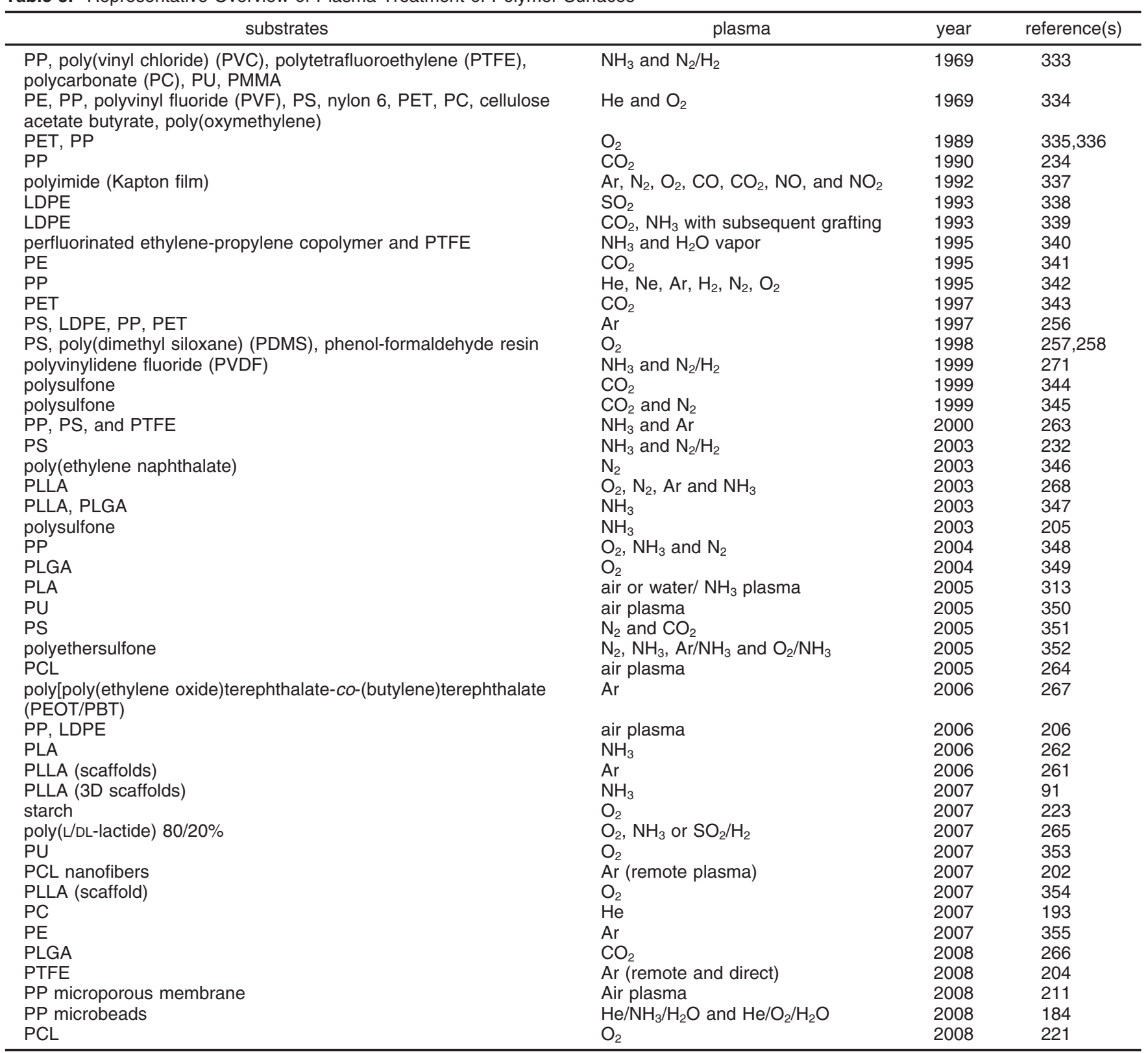

${ }^{a}$ The table presents a comprehensive overview of the substrates, the plasma type, and year of publication of the research.

First, we will discuss the changes which may be introduced and the general effects of plasma treatment on the surface of polymers. Stability and aging will be the subject of the next section, and some examples of immobilization and biocompatibility tests will be considered.

Plasma treatment of a surface has a set of different consequences. Typically, the surface wettability is increased, functional groups are introduced, roughness is increased, and chain scission and/or cross-linking can occur. Some of these phenomena are interconnected, as discussed in the previous section. The final surface properties are a complex interplay between the substrate, gases, processing parameters, cleaning procedure, storage time (aging), and conditions.

Generally, $\mathrm{O}_{2}$-plasma treatment leads to the introduction of oxygen-containing functional groups such as carboxylic acid groups, peroxide groups (due to postplasma reactions), and hydroxyl groups. Carboxylic groups may also be introduced by $\mathrm{CO}_{2}$ or CO-plasmas. $\mathrm{CO}_{2}$-plasma treatment also produces hydroxyls, ketones, aldehydes, and esters. ${ }^{254}$ Nitrogen, ammonia and $\mathrm{N}_{2} / \mathrm{H}_{2}$-plasmas introduce primary, secondary, and tertiary amines, as well as amides. Polymers that are treated with Ar or He plasma will not lead to the incorporation of new functionalities on the polymer surface, but free radicals will be created on the surface. ${ }^{255}$ These free radicals can react with oxygen from the atmosphere. ${ }^{256}$ It can thus be concluded that plasma treatment does not result in a unique functionality, which means it can not be considered to be a selective technique.

The effect of postplasma rearrangements (surface adaptation) and reactions (postplasma oxidation) should not be underestimated. Siow et al. presented a very nice overview of studies on aging effects. ${ }^{254}$ The authors conclude that surface chemistry should be characterized at the time of biological testing in order to be able to correlate chemical surface composition with biological response. ${ }^{254}$ Sharma et al. ${ }^{193}$ demonstrated that oxygen levels on the PC surface continued to increase until $72 \mathrm{~h}$ after He plasma treatment. The wettability of the PC dropped initially from $93^{\circ}$ to $30^{\circ}$, but recovered up to $67^{\circ}$ due to aging effects. Murakami et al. linked the dynamic behavior of the 
surface properties during aging to a reorientation of the introduced polar groups. ${ }^{257,258}$

A surface has the tendency to minimize the interfacial energy. This is the driving-force for surface adaptation. For example, if a $\mathrm{O}_{2}$-plasma-treated PDMS surface is aged in air, the surface returns to a low-energy-state. This phenomenon can be explained by a reorientation of the polar groups toward the interface, minimizing the interfacial free energy. ${ }^{259}$ When aging was performed in water, or in aqueous phase, the polar groups were still present on the surface, minimizing the interfacial free energy by expanding the polar groups toward the polar solvent. In this respect, the temperature is also an important factor influencing the aging of plasma-treated polymers. A rapid change of the contact angle at higher temperatures supports the idea that the changes occurring are caused by polymer chain motion, reorienting the polar groups into the bulk. ${ }^{260}$

Another effect is the postplasma oxidation. This is a reaction between remaining radicals and atmospheric oxygen.

Normally, surface wettability is increased by the introduction of the polar functional groups to the mostly inert surfaces of polymers. As this effect is correlated to surface chemistry (and thus surface energy) it is also time-dependent as exemplified before.

Plasma-treated surfaces can be used to immobilize ligands with a biological activity. RGDS was immobilized using $\mathrm{Ar}$ plasma treatment onto PLLA porous scaffolds. ${ }^{261}$ It was reported that both the attachment of osteoblastic-like cells and their proliferation were enhanced. Zhao et al. reported an improved cell-affinity of a PLA film toward fibroblasts after $\mathrm{NH}_{3}$-plasma treatment and subsequent immobilization of collagen. ${ }^{262}$ The covalently immobilized collagen films were superior for cell attachment and proliferation compared to the films with collagen adsorbed on the surface or just $\mathrm{NH}_{3}$-plasma-treated films.

Hyaluronic acid (HA) was successfully immobilized on different materials modified with $\mathrm{Ar}$ and $\mathrm{NH}_{3} .{ }^{263}$ The authors noted that steric effects were involved in the reactivity of the HA toward the surface groups. The authors suggested the application of a bifunctional oligomethylene-bridged coupling reagent.

As a critical remark, it should be taken into account that many proteins tend to physisorb to plasma surfaces or normal polymer surfaces. This process can be difficult to distinguish from covalent immobilization. ${ }^{254}$ In order to evaluate this, researchers should ensure that the targeted reactive group is present in a sufficiently high concentration, at the time of covalent immobilization. Storage-techniques should be evaluated and new storage methods should thus be developed.

Different biocompatibility studies were performed on these substrates, mostly encouraging results were reported.

Alves et al. reported $\mathrm{O}_{2}$-plasma modification of blends of cornstarch with different polymers. It is worth mentioning that plasma modification did not lead to an increased cell proliferation and adhesion for all these materials. ${ }^{223}$ Osteoblast-like cells (osteosarcoma) were used in this study.

As mentioned before ESP fibers have the potential to mimic the ECM morphology. ESP-PCL fibers were coated with gelatin, using carbodiimide coupling. ${ }^{264}$ The PCL fibers were treated with air plasma to introduce carboxylic groups, which were then covalently coupled with gelatin. It was shown that endothelial cells spread and proliferate better on the gelatingrafted material. The authors reported that endothelial cells were oriented along gelatin-grafted aligned nanofibers. The nongrafted aligned nanofibers did not demonstrate this property.
Gugala et al. reported the influence of different plasma treatments on the attachment, growth and activity of rat osteoblasts cultured on poly(L/DL-lactide). ${ }^{265}$ The treatment with ammonia plasma seemed to be the most efficacious compared to $\mathrm{O}_{2}$ or $\mathrm{SO}_{2} / \mathrm{H}_{2}$-plasmas.

The anchorage of basic fibroblast growth factor on $\mathrm{CO}_{2-}$ plasma-treated PLGA films greatly increased the adhesion and growth of mouse fibroblast cells. ${ }^{266}$

Woodfield et al. concluded that Ar plasma treatment was not a suitable surface modification technique for PEOT/PBT block copolymers. Chondrocyte adhesion improved, but the ability of these substrates to maintain the chondrocyte phenotype was reversed. $^{267}$

Wan et al. reported that the modification of PLLA substrates with $\mathrm{NH}_{3}$-plasma generates surfaces to which cells adhere. The adhered cells possessed a higher resistance to shear stress. ${ }^{268}$

It is noteworthy that, if one has a closer look at Table 3, an emerging interest in surface modification of biodegradable polymers such as PLA and PCL can be seen during the past decades. This is a general tendency in the field of implants.

Plasma treatment thus results in a variety of different functionalities ${ }^{255}$ often with a low stability. During the plasma treatment, damaging processes occur such as fragmentation by charged particle bombardment or radiation damage. ${ }^{269}$ In order to minimize or completely avoid these effects, two kinds of strategies have been applied. It was demonstrated that minimizing the applied energy and minimizing the plasma density results in less pronounced changes. A second strategy in order to prevent loss of functionalities is the separation between the introduction of functionalities on the surface and the direct plasma. This can be in space (down stream, or remote plasma) ${ }^{204}$ or in time (postirradiation grafting). In research, which compared grafting and the plasma treatment procedures, for the introduction of different functionalities, the grafting was the most selective technique, leading to more homogeneous distribution of the functionalities and better precursor retention. ${ }^{270,271} \mathrm{~A}$ better retention of the mechano-chemical properties was also demonstrated when compared to aminolysis and hydrolysis. ${ }^{93,269,271}$

2.3.2. Plasma Postirradiation Grafting. In literature, postirradiation grafting is often referred to as "plasma-induced graft (co)polymerization". Grafting strategies lead to covalent bonding of selective functionalities to the surface. An overview of the most commonly applied polymer substrates, plasmas, and monomers is given in Table 4.

In the postirradiation grafting literature, three strategies can be distinguished. ${ }^{269}$ In a first strategy, the plasma-activated substrate is brought into direct contact with the monomers in gas phase. ${ }^{236,269,271}$ In a second strategy, the substrate is immediately transferred to a monomer-solution. ${ }^{191,207}$ A third possibility includes an approach in which substrates are allowed to react with oxygen from ambient atmosphere ${ }^{93,224,272}$ or with pure oxygen $^{273}$ in order to create peroxides and hydroperoxides on the surface. These are subsequently used as initiators. Peroxides can be initiated by UV-radiation ${ }^{37,93,272}$ or thermically. ${ }^{152,191,203,224,273-280}$ Catalysts can be used, ${ }^{281}$ initiators, ${ }^{276}$ as well as inhibitors that prevent the homopolymerization of the monomer, ${ }^{203,280,282}$ which is especially of interest when AA is the monomer. The polymerization of $\mathrm{AA}$ is a fast reaction, which will be in competition with the graft-polymerization. ${ }^{283}$

Focusing on the third strategy, it is clear that the number of (hydro)peroxides generated on the surface will greatly influence the grafting-density. Each peroxide group is a potential initiatingsite. Mostly these (hydro)peroxides are determined by means of a spectroscopic reaction with 1,1-diphenyl-2-picrylhydrazyl 
Table 4. Representative Overview of Plasma Postirradiation Grafting on Polymer Surfaces ${ }^{a}$

\begin{tabular}{|c|c|c|c|}
\hline substrates & plasma/ monomer(s) & year & reference(s) \\
\hline $\mathrm{PE}$ & glow discharge/AAm & 1986 & 275 \\
\hline HDPE & AAm & 1993 & 287 \\
\hline porous $\mathrm{PE}$ & Air/AA & 1993 & 277,278 \\
\hline silicone rubber & $\mathrm{Ar} / \mathrm{HEMA}$ & 1996 & 152 \\
\hline silicone rubber & $\mathrm{Ar} / \mathrm{AA}$ & 1996 & 175,274 \\
\hline PTFE & $\mathrm{CO}_{2}$ activation/AA & 1997 & 236,356 \\
\hline PTFE & $\mathrm{H}_{2} \mathrm{O}$ vapor/AA & 1999 & 231 \\
\hline PTFE & $\mathrm{Ar}-\mathrm{O}_{2}$ mixture/AA & 1999 & 224 \\
\hline PET & $\mathrm{O}_{2} / \mathrm{AA}$ & 2000 & 171 \\
\hline PET & $\mathrm{Ar} / \mathrm{AA}$ & 2001 & 273 \\
\hline $\begin{array}{l}\text { stainless steel } \\
\text { (modified) }\end{array}$ & Ar/PEO-MA & 2001 & 22 \\
\hline HDPE & $\mathrm{Ar} / \mathrm{AA}$ & 2003 & 276 \\
\hline PU & $\mathrm{O}_{2} / \mathrm{AA}$ & 2004 & 283 \\
\hline $\mathrm{PCL}$ & Ar/AA & 2004 & 272 \\
\hline PDMS & $\begin{array}{l}\text { Ar plasma based } \\
\text { ion beam/AA }\end{array}$ & 2005 & 357 \\
\hline PP & $\mathrm{O}_{2} / \mathrm{AA}$ & 2007 & 280 \\
\hline nylon, PS & He/isopropyIAAm & 2007 & 196 \\
\hline $\mathrm{PCL}$ & Air/ AA & 2007 & 281 \\
\hline $\mathrm{PCL}$ & $\mathrm{Ar} / \mathrm{AA}$ & 2007 & 93 \\
\hline silicon wafers & $\begin{array}{l}\mathrm{H}_{2}-\mathrm{He} \text { mixture/ } \\
\text { 1-vinyl-2-pyrrolidone }\end{array}$ & 2007 & 191 \\
\hline porous PES & Air/AA & 2007 & 207 \\
\hline PVDF & $\begin{array}{l}\mathrm{Ar} / \text { maleic } \\
\text { anhydride-styrene }\end{array}$ & 2007 & 279 \\
\hline PET & $\mathrm{Ar} / \mathrm{AA}$ & 2008 & 195 \\
\hline PTFE & $\begin{array}{l}\text { Ar/AA, 4-vinylpyridine and } \\
\text { 1-vinylimidazole }\end{array}$ & 2008 & 203 \\
\hline PET & $\mathrm{O}_{2} / \mathrm{AA}$ & 2008 & 358 \\
\hline
\end{tabular}

${ }^{a}$ The table presents a comprehensive overview of the substrates, the activation/monomer(s), and year of publication of the research.

(DPPH). ${ }^{147,152,175,275,276}$ Also the use of 2,2,6,6-tetramethyl-1piperidinyloxy (TEMPO) has been reported for demonstrating the presence of free radicals on silicon surfaces. ${ }^{191}$ Another approach consists of measuring the $\mathrm{O} 1 \mathrm{~s} / \mathrm{C} 1 \mathrm{~s}$ ratio, using XPS, after a certain plasma-treatment time as a way of estimating the maximal oxygen content. ${ }^{152}$

All of these strategies have their specific restrictions. The first strategy is only applicable to monomers with a sufficiently high vapor pressure. The second strategy might be affected by some side reactions during transport of the plasma-treated polymer from the plasma reactor to the monomer solution. This is related to the short lifetime of free radicals. The third strategy involves a two-step reaction, accompanied by a loss of yield in both steps. The two-step process also introduces more parameters, affecting the overall complexity of this approach. Parameters such as temperature, UV-intensity, type of UV $\left(\lambda_{\max }\right)$, monomer concentration, solvent, cleaning procedure, and so forth can all have an influence on the grafting efficiency.

In some cases plasma technology is used to introduce functional groups which are then reacted with other molecules, ${ }^{284}$ in order to finally couple polymers to the surface. This type of "grafting" will not be considered within this section, as we would identify this as a plasma treatment process with subsequent linking-reactions.

Müller et al. compared plasma treatment, plasma polymerization, and plasma grafting for the introduction of primary amino groups on microfiltration membranes. ${ }^{271}$ It was found that the introduction of primary amine groups was maximized when the grafting method is applied. The authors explained this phenomenon as a fragmenting plasma effect. When a monomer is subjected to plasma, several side-reactions can occur. In this case, hydrogen abstraction may take place from the amino group in the plasma, which can result in a more heterogeneous formation of several types of amino compounds. In general, the major advantage of postirradiation strategy is the ability to avoid these side-reactions, and thus obtain a high specificity.
As for plasma-treated membranes, aging is equally important for postirradiation grafted substrates. ${ }^{254,285}$ Gupta et al. compared the effect of 30 days storage period on the grafting density of AA on PET films, ${ }^{282}$ demonstrating important changes in surface chemistry when stored at ambient temperature. If the surface was functionalized with collagen, the effect of aging was far less significant. It was demonstrated that the grafting degree of poly(ethylene oxide) methacrylate (PEO-MA) decreased with storage time at room temperature but remained unchanged at $-130{ }^{\circ} \mathrm{C}$. This suggests that storage at lower temperature is effective in retaining the grafting levels. ${ }^{286}$ (Please note that this work concerned a $\gamma$-irradiation process).

A very common approach for the immobilization of biomolecules is the postirradiation grafting of AA with subsequent carbodiimide mediated immobilization. ${ }^{93,272,274,277,278,281,287}$ Carbodiimide chemistry was used by Baquey et al. to couple a $\mathrm{NH}_{2}-\mathrm{PEO}-\mathrm{NH}_{2}$ spacer arm to the AA-grafted surface. ${ }^{224}$ Subsequent coupling of small peptides was also achieved by means of 1-ethyl-3-(3-dimethylaminopropyl) carbodiimide hydrochloride (EDC)-coupling. Alternative physisorption to surfaces $^{288}$ was used to immobilize biomacromolecules.

Kim et al. reported the immobilization of heparin and/or insulin on a PET surface grafted with AA in order to obtain a better blood compatibility. The coagulation tests showed that PET grafted with PEO only demonstrated a slight improvement, while the PET surfaces with PEO and immobilized heparin or insulin showed a significant improvement. These results suggest that the immobilization of the heparin helped to suppress the blood coagulation. ${ }^{171}$ It is anticipated that insulin increased the proliferation of tissue cells. This work illustrates once more the benefits that can be obtained by the immobilization of biomacromolecules.

In order to enhance cell adhesion and proliferation in tissue engineering, the immobilization of collagen on a postirradiation grafted substrate has been studied extensively. ${ }^{93,202,272-274,281}$ The coating of collagen, in general, was also studied in order to decrease foreign-body reaction ${ }^{13,278}$ and tumor formation. ${ }^{277}$ Alternatively to covalent immobilization, the dip-coating process was also reported in order to coat a surface with collagen. ${ }^{282}$ These collagen-immobilized surfaces were tested with a diversity of cells such as human umbilical vein endothelial cells (HUVECs), ${ }^{281}$ human dermal fibroblasts (HDFs), ${ }^{202,272}$ cornea epithelial cells, ${ }^{274}$ and different types of smooth muscle cells. ${ }^{93,273}$ They all demonstrated favorable response from cells. Mostly attachment was improved, spreading and proliferation were reported to be enhanced, and growth on surfaces (with a normal cell morphology) was demonstrated. ${ }^{273}$

Shin et al. reported a postirradiation technique based on $\gamma$-ray grafting of AA onto PLCL and subsequent immobilization of gelatin with EDC/NHS coupling. The gelatin-immobilized surfaces were tested with human mesenchymal stem cells. The results of different test suggested that gelatin-immobilized substrates may be a good stem cell delivery carrier. ${ }^{146}$

Not only collagen has been immobilized on postirradiation grafted surface. Sano et al. grafted AAM to HDPE films and subsequent modification led to carboxyl groups or amino groups for immobilization of protein A. The protein could be successfully bound to both functionalities. Immobilization of a small peptide [Arg-Gly-Asp-Cys (RGDC)] was also reported ${ }^{224}$ using a $\mathrm{NH}_{2}-\mathrm{PEO}-\mathrm{NH}_{2}$ spacer arm.

It is worth mentioning that a growing interest in plasmagrafting of biodegradable materials took place during the 1990s. More recently, a shift to surface modification of more advanced biodegradable polymers, such as the PLCL and other copolymers 
Table 5. Representative Overview of Plasma-Polymerized, Deposited Polymers on Surfaces ${ }^{a}$

\begin{tabular}{|c|c|c|c|}
\hline substrates & monomer & year & reference(s) \\
\hline PE and mica & AA & 1990 & 296 \\
\hline LDPE & allyl phenyl Sulphone, allyl amine, & 1993 & $338,339,359$ \\
\hline $\begin{array}{l}\text { KBr windows (IR) and silicon wafers } \\
\text { covered with gold (XPS) }\end{array}$ & $\begin{array}{l}\text { propylamine, unsaturated allylamine, propargylamine, } \\
1 \text {-propanol, allyl alcohol, and propargyl alcohol }\end{array}$ & $1995-1996$ & 360,361 \\
\hline glass slides and PVC-films & $\begin{array}{l}\text { propargyl alcohol, propargyl acid, methylbutynol, allyl alcohol, AA, } \\
\text { acrylic aldehyde, furfuryl alcohol, ethylene glycol, ethylene glycol } \\
\text { dimethylether }\end{array}$ & 1996 & 362 \\
\hline silicon, $\mathrm{KCl}$ and PET & allylalcohol & 1996 & 363 \\
\hline glass coverslip, wrapped with an aluminum foil & acrylic (propenoic) acid and propanoic acid & 1996 & 364 \\
\hline aluminum substrate & allyl amine/1,7-octadiene and AA/hexane & 1996 & 365 \\
\hline $\mathrm{KBr}$ pellets and silicon wafers & benzene, 1,2,4-trifluorobenzene, and hexafluorobenzene & 1998 & 366 \\
\hline aluminum foil & allylalcohol/1,7-octadiene & 1998 & 367 \\
\hline (oxidized) aluminum & $\mathrm{AA}$ & 1998 & 368,369 \\
\hline polyimide & 1,3-diaminopropane, ethylene diamine & 1999 & 370,371 \\
\hline 6-well tissue culture plates, aluminum foil & AA/1,7-octadiene & 1999 & $305,372,373$ \\
\hline PTFE & allylalcohol, AA, allylamine and acrylonitrile & 2001 & 297 \\
\hline stainless steel chips & isopropyl alcohol & 2002 & 295 \\
\hline Ti alloy & allylamine & 2002 & 303 \\
\hline polysulfone membranes, Al foil and glass & ethylenediamine, diaminocyclohexane & 2003 & 300 \\
\hline metal sheet, coated with epoxy resin and aluminum. & allylalcohol, allylamine, $\mathrm{AA} /$ ethylene or butadiene as initiator & 2003 & 374 \\
\hline polysulfone & $n$-butylamine, allylamine, and allyl alcohol & 2003 & 205,375 \\
\hline $\begin{array}{l}\text { uncoated silicone, silicone wafers coated with } \\
\text { Au or Al, indium tin oxide glass and glass }\end{array}$ & aniline & 2004 & 376 \\
\hline PS & isopropyl alcohol & 2004 & 304 \\
\hline Silicon & styrene & 2004 & 377 \\
\hline PLA (3D substrate) & allylamine & 2005 & 294 \\
\hline silicon & ethylene & 2005 & 378 \\
\hline silicon & allylalcohol & 2005 & 379 \\
\hline silicon & tetrafluoroethylene & 2005 & 380 \\
\hline PU & allylalcohol & 2006 & 381 \\
\hline silicon & allylamine & 2006 & 382 \\
\hline glass & styrene & 2007 & 383 \\
\hline PET & PEO & 2007 & 384 \\
\hline PLLA (3D) & AA & 2007 & 306 \\
\hline PS & $\begin{array}{l}\text { AA, HEMA, } N \text {-vinyl-2-pyrrolidinone, } N \text {-vinylform-amide, } \\
\text { allylamine, and hexylamine }\end{array}$ & 2008 & 385 \\
\hline PLGA (scaffolds) & heptylamine & 2008 & 151 \\
\hline silicone and PP & $\mathrm{NH}_{3}$ /ethylene & 2008 & 228 \\
\hline silicone & ethylene and styrene with allylamine or allylalcohol & 2008 & 386,387 \\
\hline perfluorinated poly(ethylene-co-propylene) and PET & $n$-heptylamine or allylamine & 2008 & 225,226 \\
\hline glass & $\begin{array}{l}\text { acetylene and protein [bovine serum albumin-fluorescein } \\
\text { isothiocyanate (BSA-FITC)] }\end{array}$ & 2008 & 220 \\
\hline silicon & allylamine & 2008 & 302 \\
\hline glass & hexane and allylamine & 2008 & 58 \\
\hline PE & maleic anhydride & 2008 & 301 \\
\hline
\end{tabular}

${ }^{a}$ The table presents a comprehensive overview of the substrates, the monomer(s) and year of publication of the research.

can be noted. ${ }^{146,151,289-291}$ It can be stated that, as biomaterials evolve, the substrate studied in surface modification evolves as well. It can thus be expected that the most promising biomaterials that are currently being developed will be the subject of future surface modification studies.

2.3.3. Plasma syn-Irradiation Grafting. As discussed before, it is possible to graft a polymer onto a surface by preadsorption of comounds, followed by plasma treatment.

Sasai et al. reported the grafting of vinylmethylether-maleic anhydride (VEMA) onto LDPE. ${ }^{292}$ First, the VEMA was soaked to the LDPE surface layer using a mixed solvent cyclohexanon/ $p$-xylene $(19: 1, \mathrm{v} / \mathrm{v})$. The dried substrate with the adsorbed VEMA was then subjected to Ar plasma to covalently graft the VEMA to the LDPE surface. Please note that this grafting technique was reported previously by these authors. ${ }^{293}$ The authors used it to create $\mathrm{COOH}$ functionality, which was then used to immobilize an ATRP initiator. ${ }^{292}$

Double-plasma strategies have also been applied. Ding et al. reported the immobilization of chitosan on PLLA. The substrates were first subjected to plasma and exposed to the atmosphere in order to create peroxides. In a separate step, chitosan was adsorbed to the surface. After drying, the substrate was exposed a second time to plasma. This is a typical syn-irradiation step where substrate and grafted polymer are simultaneously exposed to plasma. The substrates demonstrated a poor cell adhesion while proliferation was similar to glass substrates. ${ }^{61}$
2.3.4. Plasma Polymerization: Deposition. Plasma deposition is distinct from plasma grafting in that respect that it coats the substrate rather than covalently binding species to the modified polymer surface. ${ }^{294}$ The plasma polymerized polymers possess different chemical and physical properties compared to polymers obtained using more conventional synthesis methods.

A wide variety of substrates and monomers has been applied so far. A nonexhaustive overview of the most commonly applied substrates and monomers is given in Table 5. Depending on the chemical nature of the monomer, the coating possesses different chemical and physical properties. A hexane plasma will lead to hydrophobic surfaces, while an allylamine plasma will result in hydrophilic surfaces. Zelzer et al. studied gradient surfaces based on these plasmas. ${ }^{58}$ The gradient surfaces were prepared by means of a diffusion-controlled plasma polymerization technique. Briefly, in order to prepare gradient surfaces, a mask was clamped $0.04 \mathrm{~mm}$ above a glass coverslip with an AAm coating. The hexane plasma diffused under the mask, leading to a gradual thinner polymer coating. Cell tests showed that fibroblast cells attached preferably to the more hydrophilic side of the sample. ${ }^{58}$

A correlation between the plasma chemistry and the character of the deposited film has been reported. ${ }^{295,296}$ First of all, the monomer can react in different ways in plasma. For example, a dissociation-ionization reaction will lead to a different reactive fragment than a protonation reaction, followed by dehydroge- 
nation reaction. Different combinations of plasma conditions such as power, pressure, and duty factor will favor one of these different chemical pathways. In order to achieve homogeneous coatings with a retention of functional groups and avoid crosslinking reactions, it is suggested that low wattage, or discharge power, and low duty cycle can be advantageous. ${ }^{296-299}$

If pulsed plasma is applied, the pulsing frequency was demonstrated to influence the chemistry of the deposited film. ${ }^{300}$ The concentration of free amines was higher at lower pulse duration $(<0.5 \mathrm{~ms})$, suggesting that the microsecond range is more preferable for technological processes. This was also reported for hydroxyl-containing coatings. ${ }^{297}$

It can be assumed that for each monomer, an optimization should be performed, varying both the applied plasma conditions and gases. In addition, possible side-reactions should be taken into account. ${ }^{297}$ Little fundamental theoretical knowledge or a general predictive model is available. In general, one could state that "softer" plasma reaction conditions lead to fewer sidereactions.

Stability and aging are a major concern for plasma polymerized thin layers. In this respect, we would like to refer to Siow et al., who discussed the recent work in this area. ${ }^{254}$ An interesting study in this field was performed by Drews et al., who studied the hydrolysis and stability of thin pulsed plasma maleic anhydride coatings. It was found that shorter treatment time gave rise to thinner films, which were more stable then thicker films. ${ }^{301}$ The hydrolysis and stability of the coatings depended strongly on the plasma power. With increasing plasma power, coatings became more stable. This could be explained by a higher cross-linking at higher plasma power, thus resulting in a better stability. Furthermore, the number of available carboxylic acid groups on the surface increased with decreasing power. This is consistent with the proposed dependence of the cross-linking on the plasma power.

As there is a great interest in the surface modification of 3D implants, we would also like to refer to the work of Barry et al., who modified the surface of PLA scaffolds. They compared plasma grafting with plasma polymerization, using allylamine. ${ }^{294}$ XPS measurements of the scaffolds at set intervals demonstrated that the grafting resulted in a more homogeneous N-concentration through the scaffold while plasma polymerization led to a higher $\mathrm{N}$-concentration on the outer and inner surface compared to the grafting procedure. The authors found that deposition treated scaffolds showed higher metabolic activity then the grafted scaffolds. Moreover, cells were found in the center of the scaffolds, which was not the case for the grafted scaffolds. This type of comparative studies will definitely assist in the development of better performing tissue engineering scaffolds.

The adsorption of plasmid DNA has also been applied in a comparative study. First, allylamine was plasma polymerized, and subsequent grafting of PEO was achieved. It was demonstrated that DNA preferably binds to the allylamine plasma deposited coating, and that both hydrophobic and electrostatic interactions contribute to the binding. ${ }^{302}$ This suggests that it is possible to achieve spatially DNA adsorption patterns on patterned allylamine/PEO surfaces. It was possible to manipulate the DNA adsorption and desorption by applying an electrical bias.

Kingshott et al. studied effects of cloud-point grafting, chain length, and density of PEO layers on competitive adsorption of different ocular proteins. ${ }^{226}$ Methoxy-terminated aldehyde-PEO $\left(M_{\mathrm{r}} 5000 \mathrm{~g} / \mathrm{mol}\right)$ and dialdehyde-PEO $\left(M_{\mathrm{r}} 3400 \mathrm{~g} / \mathrm{mol}\right)$ were grafted by reductive amination onto two surfaces possessing a different amine group density, generated by RF glow discharge

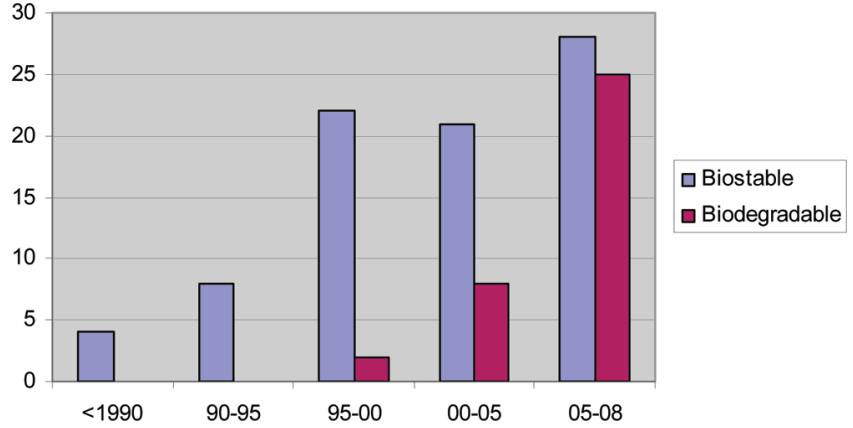

Figure 14. Comparative graph showing the number of articles, discussed in this review, that focus on biostable or biodegradable polymers.

deposition of $n$-heptylamine (low density) or allylamine (high density). The binding of PEO was optimal at cloud-point conditions. The authors demonstrated that the key-factor is optimization of PEO chain density in order to achieve minimal adsorption.

Apart from these and other adsorption studies of biomolecules, bioactive proteins were also covalently immobilized on plasma-polymerized films. ${ }^{303}$

Fibroblasts were cultured on modified samples. ${ }^{58,235,294,304}$ All authors reported positive effects such as fast adhesion and high cell activity. It was reported that fibroblasts tend to attach preferentially to the more hydrophilic regions achieved by plasma polymerization of allylamine or isopropyl alcohol. ${ }^{58,304}$

The acid plasma copolymer layers from AA/1,7-octadiene showed comparable levels of cell attachment to collagen I for keratinocytes. ${ }^{305}$

A 3D porous PLLA scaffold was treated with AA plasma. Cell adhesion and proliferation of chondrocytes was substantially improved as compared to unmodified scaffolds. ${ }^{306}$

\section{Trends, Future Prospects and Conclusions}

It is always dangerous to draw overhead conclusions from a limited amount of data and information. We would like to discuss some general trends in the field of surface engineering and plasma applications, based on the literature presented in this review.

When we consider the number of publications in surface engineering, we could state that it is a very fast developing field. When we look at the number of publications studying biodegradable polymers we see a strong increase the recent decade (Figure 14). It is safe to state that surface engineering of biodegradable polymers is of interest for many research groups and has seen a strong growth the past 10 years. This does not mean that there is a shift from biostable to biodegradable polymers. There still are a high number of publications concerning surface modification of biostable polymers. Probably, the new developing fields of tissue engineering and regenerative medicine create the need for surface modification of biodegradable polymers while, simultaneously, there is still a lot of work to be done in order to improve existing, biostable implants.

During the past decades, researchers active in the field of surface modification tried to avoid the use of hazardous organic solvents, which might impose problems toward cell viability. ${ }^{118,120,307}$ Solvent-free techniques such as plasma and organic vapor deposition techniques are the subject of intense research. This could be considered as a general trend in surface modification.

From the work presented in this review, it is clear that a better understanding of the cell-biomaterial interaction is of crucial 
importance. The knowledge of the cell-ECM interaction can provide us with important clues about which strategies should be pursued. As our fundamental understanding of these complex phenomena further develops, we will be able to achieve better control over cell-adhesion, proliferation and differentiation.

The control over conformational change and bioactivity of proteins/peptides when they are being immobilized onto a surface will be necessary in order to design successful scaffolds for tissue engineering. ${ }^{303}$

Another trend is the achievement of better control over the modified surface, both thickness and chemical composition. The development of new technologies/methods such as microplasmas, jets, and remote plasmas will certainly create new possibilities and push the limits of current surface-control. As new techniques are being developed, it will probably become possible to modify surfaces at atmospheric pressure, in an industrialized setting. Most likely controlled patterns of functionality will be robotically drawn on biomaterial surfaces in the near future.

In plasma treatment, it is our impression that less common gases and mixtures of gases are more and more the subject of current research.

Concerning postirradiation grafting, a lot of research has been performed on the immobilization of AA, probably due to the extensive use of EDC-coupling. Other potentially interesting monomers such as AAm, 4-vinylpyridine, and 1-vinylimidazole ${ }^{203,275}$ might be neglected because of this focus. New and promising copolymers have been studied recently. ${ }^{290,308-310}$ As in tissue engineering, more and more biocomposites are used, and it is not unlikely that plasma surface modification of these composite materials will open up new possibilities.

We believe that, in the future, a broader exploration and variety of plasmas, monomers, biomaterials, and composites will enable us to achieve scaffolds with desired mechnical and biodegradation properties.

This accounts for plasma polymerization as well. More complex mixtures of gases and solvents are being explored; systems and plasma polymerization conditions are being finetuned.

On the basis of current research, it seems that soft plasma conditions, such as low wattage and short pulses, might be advantageous in order to retain functionality, especially in techniques where the monomer is also subjected to the plasma.

A better knowledge of aging effects, and thus the actual composition of the surface on the time of immobilization, is desirable. ${ }^{254}$ Better storage techniques are needed. The effect of the used storage method on the surface composition/ confirmation should be discussed more often.

Recent areas such as ATRP and RAFT grafting from a surface could possibly lead to more homogeneous layers, and better defined graft polymers with a smaller polydispersity. ${ }^{87}$ The effects on cell-viability of some of the reagents might be of concern. In this respect, the MLD technique could be very interesting. In the near future this emerging technique will probably be used for biomedical applications.

Mostly, surface modification is studied on two-dimensional (2D) substrates. The field will coevolve with the fields which use surface modification, and thus it can be expected that the study of 3D porous scaffolds will become more important, ${ }^{94,169,261,288,294,306,311-313}$ especially scaffolds created by rapid prototyping or other recent techniques such as ESP. ${ }^{37,202,264,289,314}$ Some studies demonstrated the applicability of plasma techniques for surface modification of the interior of porous scaffolds. ${ }^{261,294,306,311,312}$ It is our believe that a com- bination of the patient specific, highly porous, $100 \%$ interconnected scaffolds, which can be prepared by rapid prototyping with state-of-the-art plasma surface modification technology and new techniques such as cell-sheet engineering, can greatly improve the success of modern tissue engineering scaffolds. ${ }^{315}$

Acknowledgment. We thank the Ghent University for financial support.

\section{References and Notes}

(1) Castner, D. G.; Ratner, B. D. Biomedical surface science: Foundations to frontiers. Surf. Sci. 2002, 500 (1-3), 28-60.

(2) Chilkoti, A.; Hubbell, J. A. Biointerface science. MRS Bulletin 2005, 30 (3), 175-176.

(3) Nath, N.; Hyun, J.; Ma, H.; Chilkoti, A. Surface engineering strategies for control of protein and cell interactions. Surf. Sci. 2004, 570 (12), 98-110.

(4) Peppas, N. A.; Langer, R. New challenges in biomaterials. Science 1994, 263 (5154), 1715-1720.

(5) Langer, R.; Tirrell, D. A. Designing materials for biology and medicine. Nature 2004, 428 (6982), 487-492.

(6) Williams, D. F.; Cunningham, J. Materials in Clinical Dentistry; Oxford University Press: Oxford/New York, 1979; Vol. vi, p 376.

(7) Anderson, D. G.; Burdick, J. A.; Langer, R. Materials science - Smart biomaterials. Science 2004, 305 (5692), 1923-1924.

(8) Ratner, B. D. Biomaterials Science: An Introduction to Materials in Medicine, 2nd ed.; Elsevier Academic Press: San Diego/London, 2004.

(9) Ramakrishna, S.; Mayer, J.; Wintermantel, E.; Leong, K. W. Biomedical applications of polymer-composite materials: A review. Compos. Sci. Technol. 2001, 61 (9), 1189-1224.

(10) Leong, K. F.; Cheah, C. M.; Chua, C. K. Solid freeform fabrication of three-dimensional scaffolds for engineering replacement tissues and organs. Biomaterials 2003, 24 (13), 2363-2378.

(11) Chen, V. J.; Ma, P. X. Nano-fibrous poly(L-lactic acid) scaffolds with interconnected spherical macropores. Biomaterials 2004, 25 (11), 2065-2073.

(12) Khalil, S.; Nam, J.; Sun, W. Multi-nozzle deposition for construction of 3D biopolymer tissue scaffolds. Rapid Prototyping J. 2005, 11 (1), 9-17.

(13) van Wachem, P. B.; Hendricks, M.; Blaauw, E. H.; Dijk, F.; Verhoeven, M. L. P. M.; Cahalan, P. T.; van Luyn, M. J. A. (Electron) microscopic observations on tissue integration of collagen-immobilized polyurethane. Biomaterials 2002, 23 (6), 1401-1409.

(14) Thevenot, P.; Hu, W. J.; Tang, L. P. Surface chemistry influences implant biocompatibility. Current Topics in Medicinal Chemistry 2008, 8 (4), 270-280.

(15) Wang, Z. G.; Wan, L. S.; Xu, Z. K. Surface engineerings of polyacrylonitrile-based asymmetric membranes towards biomedical applications: An overview. J. Membr. Sci. 2007, 304 (1-2), 8-23.

(16) Zhu, Y. B.; Gao, C. Y.; Liu, X. Y.; Shen, J. C. Surface modification of polycaprolactone membrane via aminolysis and biomacromolecule immobilization for promoting cytocompatibility of human endothelial cells. Biomacromolecules 2002, 3 (6), 1312-1319.

(17) Chu, P. K.; Chen, J. Y.; Wang, L. P.; Huang, N. Plasma-surface modification of biomaterials. Materials Science \& Engineering R-Reports 2002, 36 (5-6), 143-206.

(18) Andrade, J. D.; Hlady, V. Protein adsorption and materials biocompatibility - A tutorial review and suggested hypotheses. Adv. Polym. Sci. 1986, 79, 1-63.

(19) Kondo, A.; Fukuda, H. Effects of adsorption conditions on kinetics of protein adsorption and conformational changes at ultrafine silica particles. J. Colloid Interface Sci. 1998, 198 (1), 34-41.

(20) Jung, S. Y.; Lim, S. M.; Albertorio, F.; Kim, G.; Gurau, M. C.; Yang, R. D.; Holden, M. A.; Cremer, P. S. The Vroman effect: A molecular level description of fibrinogen displacement. J. Am. Chem. Soc. 2003, 125 (42), 12782-12786.

(21) Park, A.; Wu, B.; Griffith, L. G. Integration of surface modification and $3 \mathrm{D}$ fabrication techniques to prepare patterned poly(L-lactide) substrates allowing regionally selective cell adhesion. J. Biomater. Sci., Polym. Ed. 1998, 9 (2), 89-110.

(22) Zhang, F.; Kang, E. T.; Neoh, K. G.; Wang, P.; Tan, K. L. Surface modification of stainless steel by grafting of poly(ethylene glycol) for reduction in protein adsorption. Biomaterials 2001, 22 (12), 15411548.

(23) Sheu, M. S.; Hoffman, A. S.; Feijen, J. A glow-discharge treatment to immobilize poly(ethylene oxide) poly(propylene oxide) surfactants 
for wettable and nonfouling biomaterials. J. Adhes. Sci. Technol. 1992, 6 (9), 995-1009.

(24) Sheu, M. S.; Hoffman, A. S.; Ratner, B. D.; Feijen, J.; Harris, J. M. Immobilization of polyethylene oxide surfactants for non-fouling biomaterial surfaces using an argon glow-discharge treatment. $J$. Adhes. Sci. Technol. 1993, 7 (10), 1065-1076.

(25) McGuigan, A. P.; Sefton, M. V. The influence of biomaterials on endothelial cell thrombogenicity. Biomaterials 2007, 28 (16), 2547 2571.

(26) Goodman, S. L.; Tweden, K. S.; Albrecht, R. M. Platelet interaction with pyrolytic carbon heart-valve leaflets. J. Biomed. Mater. Res. 1996, 32 (2), 249-258.

(27) Mustard, J. F.; Packham, M. A. Role of blood and platelets in atherosclerosis and complications of atherosclerosis. Thromb. Diath. Haemorrh. 1975, 33 (3), 444-456.

(28) Favia, P.; d'Agostino, R. Plasma treatments and plasma deposition of polymers for biomedical applications. Surf. Coat. Technol. 1998, $98(1-3), 1102-1106$.

(29) Gombotz, W. R.; Hoffman, A. S. Gas-discharge techniques for biomaterial modification. CRC Crit. Rev. Biocompat. 1987, 4 (1), $1-42$.

(30) Kohler, A. S.; Parks, P. J.; Mooradian, D. L.; Rao, G. H. R.; Furcht, L. T. Platelet adhesion to novel phospholipid materials: Modified phosphatidylcholine covalently immobilized to silica, polypropylene, and PTFE materials. J. Biomed. Mater. Res. 1996, 32 (2), 237-242.

(31) Iwasaki, Y.; Ijuin, M.; Mikami, A.; Nakabayashi, N.; Ishihara, K. Behavior of blood cells in contact with water-soluble phospholipid polymer. J. Biomed. Mater. Res. 1999, 46 (3), 360-367.

(32) Iwasaki, Y.; Mikami, A.; Kurita, K.; Yui, N.; Ishihara, K.; Nakabayashi, N. Reduction of surface-induced platelet activation on phospholipid polymer. J. Biomed. Mater. Res. 1997, 36 (4), 508-515.

(33) Yang, J.; Yamato, M.; Shimizu, T.; Sekine, H.; Ohashi, K.; Kanzaki, M.; Ohki, T.; Nishida, K.; Okano, T. Reconstruction of functional tissues with cell sheet engineering. Biomaterials 2007, 28 (34), 50335043.

(34) Yamato, M.; Akiyama, Y.; Kobayashi, J.; Yang, J.; Kikuchi, A.; Okano, T. Temperature-responsive cell culture surfaces for regenerative medicine with cell sheet engineering. Prog. Polym. Sci. 2007, 32 (8-9), 1123-1133.

(35) Yang, J.; Yamato, M.; Nishida, K.; Hayashida, Y.; Shimizu, T.; Kikuchi, A.; Tano, Y.; Okano, T. Corneal epithelial stem cell delivery using cell sheet engineering: Not lost in transplantation. J. Drug Targeting 2006, 14 (7), 471-482.

(36) Chen, K. S.; Ku, Y. A.; Lin, H. R.; Yan, T. R.; Sheu, D. C.; Chen, T. M. Surface grafting polymerization of $N$-vinyl-2-pyrrolidone onto a poly(ethylene terephthalate) nonwoven by plasma pretreatment and its antibacterial activities. J. Appl. Polym. Sci. 2006, 100 (1), 803 809.

(37) Yao, C.; Li, X. S.; Neoh, K. G.; Shi, Z. L.; Kang, E. T. Surface modification and antibacterial activity of electrospun polyurethane fibrous membranes with quaternary ammonium moieties. J. Membr. Sci. 2008, 320 (1-2), 259-267.

(38) Zhang, W.; Ji, J. H.; Zhang, Y. H.; Yan, Q.; Kurmaev, E. Z.; Moewes, A.; Zhao, J.; Chu, P. K. Effects of NH3, O-2, and N-2 co-implantation on $\mathrm{Cu}$ out-diffusion and antimicrobial properties of copper plasmaimplanted polyethylene. Appl. Surf. Sci. 2007, 253 (22), 8981-8985.

(39) Chu, P. K. Enhancement of surface properties of biomaterials using plasma-based technologies. Surface \& Coatings Technology 2007, 201 (19-20), 8076-8082

(40) Ho, J. P. Y.; Wu, S. L.; Poon, R. W. Y.; Chung, C. Y.; Tjong, S. C.; Chu, P. K.; Yeung, K. W. K.; Lu, W. W.; Cheung, K. M. C.; Luk, K. D. K. Oxygen plasma treatment to restrain nickel out-diffusion from porous nickel titanium orthopedic materials. Surf. Coat. Technol. 2007, 201 (9-11), 4893-4896.

(41) Singh, R.; Dahotre, N. B. Corrosion degradation and prevention by surface modification of biometallic materials. J. Mater. Sci.: Mater. Med. 2007, 18 (5), 725-751.

(42) Langer, R.; Vacanti, J. P. Tissue engineering. Science 1993, 260 (5110), 920-926.

(43) Griffith, L. G.; Naughton, G. Tissue engineering - Current challenges and expanding opportunities. Science 2002, 295 (5557), 1009.

(44) Mironov, V.; Prestwich, G.; Forgacs, G. Bioprinting living structures. J. Mater. Chem. 2007, 17 (20), 2054-2060.

(45) Bonassar, L. J.; Vacanti, C. A. Tissue engineering: The first decade and beyond. J. Cell. Biochem. 1998, 297+.

(46) Putnam, A. J.; Mooney, D. J. Tissue engineering using synthetic extracellular matrices. Nat. Med. 1996, 2 (7), 824-826.
(47) Hollister, S. J.; Maddox, R. D.; Taboas, J. M. Optimal design and fabrication of scaffolds to mimic tissue properties and satisfy biological constraints. Biomaterials 2002, 23 (20), 4095-4103.

(48) Yeong, W. Y.; Chua, C. K.; Leong, K. F.; Chandrasekaran, M. Rapid prototyping in tissue engineering: Challenges and potential. Trends Biotechnol. 2004, 22 (12), 643-652.

(49) Peter, S. J.; Miller, M. J.; Yasko, A. W.; Yaszemski, M. J.; Mikos, A. G. Polymer concepts in tissue engineering. J. Biomed. Mater. Res. 1998, 43 (4), 422-427.

(50) Lee, J.; Cuddihy, M. J.; Kotov, N. A. Three-dimensional cell culture matrices: State of the art. Tissue Eng., Part B: Rev. 2008, 14 (1), 61-86.

(51) Irvine, D. J.; Doh, J.; Huang, B. Patterned surfaces as tools to study ligand recognition and synapse formation by $\mathrm{T}$ cells. Curr. Opin. Immunol. 2007, 19 (4), 463-469.

(52) Nie, Z. H.; Kumacheva, E. Patterning surfaces with functional polymers. Nat. Mater. 2008, 7 (4), 277-290.

(53) Sardella, E.; Favia, P.; Gristina, R.; Nardulli, M.; d'Agostino, R. Plasma-aided micro- and nanopatterning processes for biomedical applications. Plasma Processes Polym. 2006, 3 (6-7), 456-469.

(54) Hatakeyama, H.; Kikuchi, A.; Yamato, M.; Okano, T. Patterned biofunctional designs of thermoresponsive surfaces for spatiotemporally controlled cell adhesion, growth, and thermally induced detachment. Biomaterials 2007, 28 (25), 3632-3643.

(55) Li, B.; Ma, Y. X.; Wang, S.; Moran, P. M. A technique for preparing protein gradients on polymeric surfaces: Effects on PC12 pheochromocytoma cells. Biomaterials 2005, 26 (13), 1487-1495.

(56) Kim, M. S.; Khang, G.; Lee, H. B. Gradient polymer surfaces for biomedical applications. Prog. Polym. Sci. 2008, 33 (1), 138-164.

(57) Ruardy, T. G.; Schakenraad, J. M.; vanderMei, H. C.; Busscher, H. J. Preparation and characterization of chemical gradient surfaces and their application for the study of cellular interaction phenomena. Surf. Sci. Rep. 1997, 29 (1), 3-30.

(58) Zelzer, M.; Majani, R.; Bradley, J. W.; Rose, F. R. A. J.; Davies, M. C.; Alexander, M. R. Investigation of cell-surface interactions using chemical gradients formed from plasma polymers. Biomaterials 2008, 29 (2), 172-184.

(59) Girard, P. P.; Cavalcanti-Adam, E. A.; Kemkemer, R.; Spatz, J. P. Cellular chemomechanics at interfaces: Sensing, integration and response. Soft Matter 2007, 3 (3), 307-326.

(60) Keselowsky, B. G.; Collard, D. M.; Garcia, A. J. Surface chemistry modulates focal adhesion composition and signaling through changes in integrin binding. Biomaterials 2004, 25 (28), 5947-5954.

(61) Ding, Z.; Chen, J. N.; Gao, S. Y.; Chang, J. B.; Zhang, J. F.; Kang, E. T. Immobilization of chitosan onto poly-L-lactic acid film surface by plasma graft polymerization to control the morphology of fibroblast and liver cells. Biomaterials 2004, 25 (6), 1059-1067.

(62) Roach, P.; Eglin, D.; Rohde, K.; Perry, C. C. Modern biomaterials: a review-bulk properties and implications of surface modifications. J. Mater. Sci.: Mater. Med. 2007, 18 (7), 1263-1277.

(63) Lutolf, M. P.; Hubbell, J. A. Synthetic biomaterials as instructive extracellular microenvironments for morphogenesis in tissue engineering. Nat. Biotechnol. 2005, 23 (1), 47-55.

(64) Keselowsky, B. G.; Collard, D. M.; Garcia, A. J. Integrin binding specificity regulates biomaterial surface chemistry effects on cell differentiation. Proc. Natl. Acad. Sci. U.S.A. 2005, 102 (17), 59535957.

(65) Shin, H.; Jo, S.; Mikos, A. G. Biomimetic materials for tissue engineering. Biomaterials 2003, 24 (24), 4353-4364.

(66) Li, B.; Ma, Y. X.; Wang, S.; Moran, P. M. Influence of carboxyl group density on neuron cell attachment and differentiation behavior: Gradient-guided neurite outgrowth. Biomaterials 2005, 26 (24), 49564963.

(67) Iwasaki, Y.; Takami, U.; Shinohara, Y.; Kurita, K.; Akiyoshi, K. Selective biorecognition and preservation of cell function on carbohydrate-immobilized phosphorylcholine polymers. Biomacromolecules 2007, 8 (9), 2788-2794.

(68) Fischer, S. E.; Liu, X. Y.; Mao, H. Q.; Harden, J. L. Controlling cell adhesion to surfaces via associating bioactive triblock proteins. Biomaterials 2007, 28 (22), 3325-3337.

(69) Moroni, L.; De Wijn, J. R.; Van Blitterswijk, C. A. Integrating novel technologies to fabricate smart scaffolds. J. Biomater. Sci., Polym. Ed. 2008, 19 (5), 543-572.

(70) Moroni, L.; Licht, R.; de Boer, J.; de Wijn, J. R.; van Blitterswijk, C. A. Fiber diameter and texture of electrospun PEOT/PBT scaffolds influence human mesenchymal stem cell proliferation and morphology, and the release of incorporated compounds. Biomaterials 2006, 27 (28), 4911-4922. 
(71) Lim, J. Y.; Donahue, H. J. Cell sensing and response to micro- and nanostructured surfaces produced by chemical and topographic Patterning. Tissue Eng. 2007, 13 (8), 1879-1891.

(72) Moon, M. W.; Lee, S. H.; Sun, J. Y.; Oh, K. H.; Vaziri, A.; Hutchinson, J. W. Controlled formation of nanoscale wrinkling patterns on polymers using focused ion beam. Scr. Mater. 2007, 57 (8), 747-750.

(73) Anderson, J. M.; Rodriguez, A.; Chang, D. T. Foreign body reaction to biomaterials. Semin. Immunol. 2008, 20 (2), 86-100.

(74) Athanasiou, K. A.; Niederauer, G. G.; Agrawal, C. M. Sterilization, toxicity, biocompatibility and clinical applications of polylactic acid polyglycolic acid copolymers. Biomaterials 1996, 17 (2), 93-102.

(75) Vert, M.; Li, S. M.; Spenlehauer, G.; Guerin, P. Bioresorbability and biocompatibility of aliphatic polyesters. J. Mater. Sci.: Mater. Med. 1992, 3 (6), 432-446.

(76) Vert, M.; Li, S. M.; Garreau, H. Attempts to map the structure and degradation characteristics of aliphatic polyesters derived from lactic and glycolic acids. J. Biomater. Sci., Polym. Ed. 1994, 6 (7), 639649.

(77) Iwasaki, Y.; Sawada, S.; Ishihara, K.; Khang, G.; Lee, H. B. Reduction of surface-induced inflammatory reaction on PLGA/MPC polymer blend. Biomaterials 2002, 23 (18), 3897-3903.

(78) Marler, J. J.; Guha, A.; Rowley, J.; Koka, R.; Mooney, D.; Upton, J.; Vacanti, J. P. Soft-tissue augmentation with injectable alginate and syngeneic fibroblasts. Plast. Reconstr. Surg. 2000, 105 (6), 20492058.

(79) Luo, Y. F.; Wang, Y. L.; Niu, X. F.; Fu, C. H.; Wang, S. J. Synthesis, characterization and biodegradation of butanediamine-grafted poly(DLlactic acid). Eur. Polym. J. 2007, 43 (9), 3856-3864.

(80) Haines-Butterick, L. A.; Rajagopal, K.; Lamm, M.; Pochan, D. J.; Schnieder, J. P. Controlling hydrogelation kinetics via peptide design for three-dimensional encapsulation and injectable delivery of cells. Biopolymers 2007, 88 (4), 518-518.

(81) Fittkau, M. H.; Zilla, P.; Bezuidenhout, D.; Lutolf, M.; Human, P.; Hubbell, J. A.; Davies, N. The selective modulation of endothelial cell mobility on RGD peptide containing surfaces by YIGSR peptides. Biomaterials 2005, 26 (2), 167-174.

(82) Mann, B. K.; Gobin, A. S.; Tsai, A. T.; Schmedlen, R. H.; West, J. L. Smooth muscle cell growth in photopolymerized hydrogels with cell adhesive and proteolytically degradable domains: synthetic ECM analogs for tissue engineering. Biomaterials 2001, 22 (22), 3045 3051 .

(83) Watanabe, J.; Nederberg, F.; Atthoff, B.; Bowden, T.; Hilborn, J.; Ishihara, K. Cytocompatible biointerface on poly(lactic acid) by enrichment with phosphorylcholine groups for cell engineering. Mater. Sci. Eng. C: Biomimetic Supramol. Syst. 2007, 27 (2), 227231.

(84) Desai, S. M.; Singh, R. P. Surface modification of polyethylene. LongTerm Prop. Polyolefins 2004, 169, 231-293.

(85) Huang, J. Y.; Murata, H.; Koepsel, R. R.; Russell, A. J.; Matyjaszewski, K. Antibacterial polypropylene via surface-initiated atom transfer radical polymerization. Biomacromolecules 2007, 8 (5), 1396-1399.

(86) Lee, B. S.; Lee, J. K.; Kim, W. J.; Jung, Y. H.; Sim, S. J.; Lee, J.; Choi, I. S. Surface-initiated, atom transfer radical polymerization of oligo(ethylene glycol) methyl ether methacrylate and subsequent click chemistry for bioconjugation. Biomacromolecules 2007, 8 (2), 744 749 .

(87) Edmondson, S.; Osborne, V. L.; Huck, W. T. S. Polymer brushes via surface-initiated polymerizations. Chem Soc Rev 2004, 33 (1), 14-22.

(88) Ranjan, R.; Brittain, W. J. Tandem RAFT polymerization and click chemistry: An efficient approach to surface modification. Macromol. Rapid Commun. 2007, 28 (21), 2084-2089.

(89) Li, D. L.; Luo, Y. W.; Zhang, B. Z.; Li, B. G.; Zhu, S. P. RAFT grafting polymerization of MMA/St from surface of silicon wafer. Acta Polym. Sin. 2007, (8), 699-704.

(90) Iwasaki, Y.; Takamiya, M.; Iwata, R.; Yusa, S.; Akiyoshi, K. Surface modification with well-defined biocompatible triblock copolymers Improvement of biointerfacial phenomena on a poly(dimethylsiloxane) surface. Colloids Surf., B: Biointerfaces 2007, 57 (2), 226-236.

(91) Jiao, Y. P.; Cui, F. Z. Surface modification of polyester biomaterials for tissue engineering. Biomed. Mater. 2007, 2 (4), R24-R37.

(92) Cao, Y.; Liu, W.; Zhou, G.; Cui, L. Tissue engineering and tissue repair in immunocompetent animals: Tissue construction and repair. Handchirurgie Mikrochirurgie Plastische Chirurgie 2007, 39 (3), $156-160$.
(93) Chong, M. S. K.; Lee, C. N.; Teoh, S. H. Characterization of smooth muscle cells on poly( $\varepsilon$-caprolactone) films. Mater. Sci. Eng. C: Biomimetic Supramol. Syst. 2007, 27 (2), 309-312.

(94) Choong, C. S. N.; Hutmacher, D. W.; Triffitt, J. T. Co-culture of bone marrow fibroblasts and endothelial cells on modified polycaprolactone substrates for enhanced potentials in bone tissue engineering. Tissue Eng. 2006, 12 (9), 2521-2531.

(95) Goddard, J. M.; Hotchkiss, J. H. Polymer surface modification for the attachment of bioactive compounds. Prog. Polym. Sci. 2007, 32 (7), 698-725.

(96) Perincek, S. D.; Duran, K.; Korlu, A. E.; Bahtiyari, M. I. Ultraviolet technology. Tekstil Konfeksiyon 2007, 17 (4), 219-223.

(97) Guan, J. J.; Gao, C. Y.; Feng, L. X.; Shen, J. C. Surface modification of polyurethane for promotion of cell adhesion and growth 1: Surface photo-grafting with $\mathrm{N}, \mathrm{N}$-dimethylaminoethyl methacrylate and cytocompatibility of the modified surface. J. Mater. Sci.: Mater. Med. 2001, 12 (5), 447-452.

(98) Zhu, Y. B.; Gao, C. Y.; Guan, J. J.; Shen, J. C. Promoting the cytocompatibility of polyurethane scaffolds via surface photo-grafting polymerization of acrylamide. J. Mater. Sci.: Mater. Med. 2004, 15 (3), 283-289.

(99) Guan, J. J.; Gao, G. Y.; Feng, L. X.; Sheng, J. C. Surface photografting of polyurethane with 2-hydroxyethyl acrylate for promotion of human endothelial cell adhesion and growth. J. Biomater. Sci., Polym. Ed. 2000, 11 (5), 523-536.

(100) Zhu, Y. B.; Gao, C. Y.; Shen, J. C. Surface modification of polycaprolactone with poly(methacrylic acid) and gelatin covalent immobilization for promoting its cytocompatibility. Biomaterials 2002, 23 (24), 4889-4895.

(101) Walzak, M. J.; Flynn, S.; Foerch, R.; Hill, J. M.; Karbashewski, E.; Lin, A.; Strobel, M. UV and ozone treatment of polypropylene and poly(ethylene-terephthalate). J. Adhes. Sci. Technol. 1995, 9 (9), 1229-1248.

(102) Mathieson, I.; Bradley, R. H. Improved adhesion to polymers by UV/ ozone surface oxidation. Int. J. Adhes. Adhes. 1996, 16 (1), 29-31.

(103) Mathieson, I.; Bradley, R. H. Effects of ultra-violet ozone oxidation on the surface-chemistry of polymer-films. Adv. Eng. Mater. 1995, 99-1, 185-191.

(104) Davidson, M. R.; Mitchell, S. A.; Bradley, R. H. Surface studies of low molecular weight photolysis products from UV-ozone oxidised polystyrene. Surf. Sci. 2005, 581 (2-3), 169-177.

(105) Singh, B.; Sharma, N. Mechanistic implications of plastic degradation. Polym. Degrad. Stab. 2008, 93 (3), 561-584.

(106) Gatenholm, P.; Ashida, T.; Hoffman, A. S. Hybrid biomaterials prepared by ozone-induced polymerization 0.1 . Ozonation of microporous polypropylene. J. Polym. Sci., Part A: Polym. Chem. 1997, 35 (8), 1461-1467.

(107) Liu, S. X.; Kim, J. T.; Kim, S. Effect of polymer surface modification on polymer-protein interaction via hydrophilic polymer grafting. $J$. Food Sci. 2008, 73 (3), E143-E150.

(108) Kato, K.; Uchida, E.; Kang, E. T.; Uyama, Y.; Ikada, Y. Polymer surface with graft chains. Prog. Polym. Sci. 2003, 28 (2), 209-259.

(109) Deng, J.; Wang, L.; Liu, L.; Yang, W. Developments and new applications of UV-induced surface graft polymerizations. Prog. Polym. Sci. 2009, 34 (2), 156-193.

(110) Yu, H. Y.; He, J. M.; Liu, L. Q.; He, X. C.; Gu, J. S.; Wei, X. W. Photoinduced graft polymerization to improve antifouling characteristics of an SMBR. J. Membr. Sci. 2007, 302 (1-2), 235-242.

(111) Yu, H. Y.; Xu, Z. K.; Lei, H.; Hu, M. X.; Yang, Q. Photoinduced graft polymerization of acrylamide on polypropylene microporous membranes for the improvement of antifouling characteristics in a submerged membrane-bioreactor. Sep. Purif. Technol. 2007, 53 (1), 119-125.

(112) Yu, H. Y.; Liu, L. Q.; Tang, Z. Q.; Yan, M. G.; Gu, J. S.; Wei, $\mathrm{X}$. W. Surface modification of polypropylene microporous membrane to improve its antifouling characteristics in an SMBR: Air plasma treatment. J. Membr. Sci. 2008, 311 (1-2), 216-224.

(113) Wang, H. L.; Brown, H. R.; Li, Z. R. Aliphatic ketones/water/alcohol as a new photoinitiating system for the photografting of methacrylic acid onto high-density polyethylene. Polymer 2007, 48 (4), 939948.

(114) Goda, T.; Matsuno, R.; Konno, T.; Takai, M.; Ishihara, K. Photografting of 2-methacryloyloxyethyl phosphorylcholine from polydimethylsiloxane: Tunable protein repellency and lubrication property. Colloids Surf., B: Biointerfaces 2008, 63 (1), 64-72.

(115) Xing, C. M.; Deng, J. P.; Yang, W. T. Surface photografting polymerization of binary monomers maleic anhydride and n-butyl vinyl ether on polypropylene film I. Effects of principal factors. Polym. J. 2002, 34 (11), 801-808. 
(116) Edlund, U.; Kallrot, M.; Albertsson, A. C. Single-step covalent functionalization of polylactide surfaces. J. Am. Chem. Soc. 2005, 127 (24), 8865-8871.

(117) Kallrot, M.; Edlund, U.; Albertsson, A. C. Surface functionalization of degradable polymers by covalent grafting. Biomaterials 2006, 27 (9), 1788-1796.

(118) Kallrot, M.; Edlund, U.; Albertsson, A. C. Covalent grafting of poly(Llactide) to tune the in vitro degradation rate. Biomacromolecules $\mathbf{2 0 0 7}$, 8 (8), 2492-2496.

(119) Wirsen, A.; Sun, H.; Albertsson, A. C. Solvent free vapour phase photografting of acrylamide onto poly(methyl methacrylate). Polymer 2005, 46 (13), 4554-4561.

(120) Wirsen, A.; Sun, H.; Albertsson, A. C. Solvent-free vapor-phase photografting of acrylamide onto poly(ethylene terephthalate). Biomacromolecules 2005, 6 (5), 2697-2702.

(121) Wirsen, A.; Sun, H.; Emilsson, L.; Albertsson, A. C. Solvent free vapor phase photografting of maleic anhydride onto poly(ethylene terephthalate) and surface coupling of fluorinated probes, PEG, and an RGD-peptide. Biomacromolecules 2005, 6 (4), 2281-2289.

(122) Uyama, Y.; Kato, K.; Ikada, Y. Surface modification of polymers by grafting. Grafting/Charact. Tech./Kinet. Model. 1998, 137, 139

(123) Ichimura, K.; Oh, S. K.; Nakagawa, M. Light-driven motion of liquids on a photoresponsive surface. Science 2000, 288 (5471), 1624-1626.

(124) Nakagawa, M.; Ichimura, K. Photocontrollability of liquid crystal alignment by a self-assembled monolayer formed from azobenzenecontaining tetracation through coulombic interactions. Mol. Cryst. Liq. Cryst. 2000, 345, 599-604.

(125) Yousaf, M. N.; Houseman, B. T.; Mrksich, M. Turning on cell migration with electroactive substrates. Angew Chem Int Edit 2001, 40 (6), 1093+.

(126) Westcott, N. P.; Yousaf, M. N. Synergistic microfluidic and electrochemical strategy to activate and pattern surfaces selectively with ligands and cells. Langmuir 2008, 24 (6), 2261-2265.

(127) Yeo, W. S.; Mrksich, M. Electroactive self-assembled monolayers that permit orthogonal control over the adhesion of cells to patterned substrates. Langmuir 2006, 22 (25), 10816-10820.

(128) Nath, N.; Chilkoti, A. Creating "smart" surfaces using stimuli responsive polymers. Adv. Mater. 2002, 14 (17), 1243+.

(129) Zhang, Q. L.; Xia, F.; Sun, T. L.; Song, W. L.; Zhao, T. Y.; Liu, M. C.; Jiang, L. Wettability switching between high hydrophilicity at low $\mathrm{pH}$ and high hydrophobicity at high $\mathrm{pH}$ on surface based on pH-responsive polymer. Chem. Commun. 2008, (10), 1199-1201.

(130) Kubies, D.; Machova, L.; Brynda, E.; Lukas, J.; Rypacek, F Functionalized surfaces of polylactide modified by LangmuirBlodgett films of amphiphilic block copolymers. J. Mater. Sci.: Mater. Med. 2003, 14 (2), 143-149.

(131) Popelka, S.; Machova, L.; Rypacek, F. Adsorption of poly(ethylene oxide)-block-polylactide copolymers on polylactide as studied by ATR-FTIR spectroscopy. J. Colloid Interface Sci. 2007, 308 (2), 291299.

(132) Murphy, K. A.; Eisenhauer, J. M.; Savin, D. A. Synthesis, selfassembly and adsorption of PEO-PLA block copolymers onto colloidal polystyrene. J. Polym. Sci., Part B: Polym. Phys. 2008, 46 (3), 244-252.

(133) Kikuchi, M.; Ikoma, T.; Itoh, S.; Matsumoto, H. N.; Koyama, Y.; Takakuda, K.; Shinomiya, K.; Tanaka, J. Biomimetic synthesis of bone-like nanocomposites using the self-organization mechanism of hydroxyapatite and collagen. Compos. Sci. Technol. 2004, 64 (6), 819-825.

(134) Jakab, K.; Neagu, A.; Mironov, V.; Markwald, R. R.; Forgacs, G. Engineering biological structures of prescribed shape using selfassembling multicellular systems. Proc. Natl. Acad. Sci. U.S.A. 2004 101 (9), 2864-2869.

(135) Mironov, V. Beyond cloning: Toward human printing. Futurist 2003, 37 (3), 34-37.

(136) Mironov, V.; Boland, T.; Trusk, T.; Forgacs, G.; Markwald, R. R. Organ printing: computer-aided jet-based 3D tissue engineering. Trends Biotechnol. 2003, 21 (4), 157-161.

(137) Mironov, V.; Reis, N.; Derby, B. Bioprinting: A beginning. Tissue Eng. 2006, 12 (4), 631-634.

(138) Clough, R. L. High-energy radiation and polymers: A review of commercial processes and emerging applications. Nucl. Instrum. Methods Phys. Res., Sect. B: Beam Interact. Mater. Atoms 2001, 185 , 8-33.

(139) Sodergard, A. Perspectives on modification of aliphatic polyesters by radiation processing. J. Bioact. Compat. Polym. 2004, 19 (6), 511 525 .
(140) Gupta, M. C.; Deshmukh, V. G. Radiation effects on poly(lactic acid). Polymer 1983, 24 (7), 827-830.

(141) Loo, S. C. J.; Ooi, C. P.; Boey, Y. C. F. Radiation effects on poly(lactide-co-glycolide) (PLGA) and poly(L-lactide) (PLLA). Polym. Degrad. Stab. 2004, 83 (2), 259-265.

(142) Amato, I.; Ciapettia, G.; Pagani, S.; Marletta, G.; Satriano, C.; Baldini, N.; Granchi, D. Expression of cell adhesion receptors in human osteoblasts cultured on biofunctionalized poly-( $\varepsilon$-caprolactone) surfaces. Biomaterials 2007, 28 (25), 3668-3678.

(143) Yang, Y.; Porte, M. C.; Marmey, P.; El Haj, A. J.; Amedee, J.; Baquey, C. Covalent bonding of collagen on poly(L-lactic acid) by gamma irradiation. Nucl. Instrum. Methods Phys. Res., Sect. B: Beam Interact. Mater. Atoms 2003, 207 (2), 165-174.

(144) Cho, E. H.; Lee, S. G.; Kim, J. K. Surface modification of UHMWPE with gamma-ray radiation for improving interfacial bonding strength with bone cement (II). Curr. Appl. Phys. 2005, 5 (5), 475-479.

(145) Shojaei, A.; Fathi, R.; Sheikh, N. Adhesion modification of polyethylenes for metallization using radiation-induced grafting of vinyl monomers. Surf. Coat. Technol. 2007, 201 (16-17), 7519-7529.

(146) Shin, Y. M.; Kim, K. S.; Lim, Y. M.; Nho, Y. C.; Shin, H. Modulation of spreading, proliferation, and differentiation of human mesenchymal stem cells on gelatin-immobilized poly(L-lactide- $c o$ - $\varepsilon$-caprolactone) substrates. Biomacromolecules 2008, 9 (7), 1772-1781.

(147) Shim, J. K.; Na, H. S.; Lee, Y. M.; Huh, H.; Nho, Y. C. Surface modification of polypropylene membranes by gamma-ray induced graft copolymerization and their solute permeation characteristics. J. Membr. Sci. 2001, 190 (2), 215-226.

(148) Sioshansi, P.; Tobin, E. J. Surface treatment of biomaterials by ion beam processes. Surf. Coat. Technol. 1996, 83 (1-3), 175-182.

(149) Jagielski, J.; Turos, A.; Biefinski, D.; Abdul-Kader, A. M.; Platkowska, A. Ion-beam modified polymers for biomedical applications. Nucl. Instrum. Methods Phys. Res., Sect. B: Beam Interact. Mater. Atoms 2007, 261 (1-2), 690-693.

(150) Farquet, P.; Kunze, A.; Padeste, C.; Solak, H. H.; Guersel, S. A.; Scherer, G. G.; Wokaun, A. Influence of the solvent viscosity on surface graft-polymerization reactions. Polymer 2007, 48 (17), 49364942.

(151) Djordjevic, I.; Britcher, L. G.; Kumar, S. Morphological and surface compositional changes in poly(lactide-co-glycolide) tissue engineering scaffolds upon radio frequency glow discharge plasma treatment. Appl. Surf. Sci. 2008, 254 (7), 1929-1935.

(152) Lee, S. D.; Hsiue, G. H.; Kao, C. Y.; Chang, P. C. T. Artificial cornea: Surface modification of silicone rubber membrane by graft polymerization of pHEMA via glow discharge. Biomaterials 1996, 17 (6), 587-595.

(153) Ryu, G. H.; Yang, W. S.; Roh, H. W.; Lee, I. S.; Kim, J. K.; Lee, G. H.; Lee, D. H.; Park, B. J.; Lee, M. S.; Park, J. C. Plasma surface modification of poly(D,L-lactic-co-glycolic acid)(65/35) film for tissue engineering. Surf. Coat. Technol. 2005, 193 (1-3), 60-64.

(154) Bantz, M. R.; Brantley, E. L.; Weinstein, R. D.; Moriarty, J.; Jennings, G. K. Effect of fractional fluorination on the properties of ATRP surface-initiated poly(hydroxyethyl methacrylate) films. J. Phys. Chem. B 2004, 108 (28), 9787-9794.

(155) Brantley, E. L.; Holmes, T. C.; Jennings, G. K. Modification of ATRP surface-initiated poly(hydroxyethyl methacrylate) films with hydrocarbon side chains. J. Phys. Chem. B 2004, 108 (41), 16077-16084.

(156) Brantley, E. L.; Jennings, G. K. Fluorinated polymer films from acylation of ATRP surface-initiated poly(hydroxyethyl methacrylate). Macromolecules 2004, 37 (4), 1476-1483.

(157) Chi, Y. S.; Lee, J. K.; Lee, K. B.; Kim, D. J.; Choi, I. S. Biosurface organic chemistry: Interfacial chemical reactions for applications to nanobiotechnology and biomedical sciences. Bull. Korean Chem. Soc. 2005, 26 (3), 361-370.

(158) Zhu, L.-P.; Dong, H.-B.; Wei, X.-Z.; Yi, Z.; Zhu, B.-K.; Xu, Y.-Y. Tethering hydrophilic polymer brushes onto PPESK membranes via surface-initiated atom transfer radical polymerization. J. Membr. Sci. 2008, 320 (1-2), 407-415.

(159) Tsujii, Y.; Ohno, K.; Yamamoto, S.; Goto, A.; Fukuda, T. Structure and properties of high-density polymer brushes prepared by surfaceinitiated living radical polymerization. In Surface-Initiated Polymerization I; Jordan, R., Advincula, R., Buchmeiser, M. R., Dyer, D. J., Eds.; Springer Verlag: New York, 2006; Vol. 197, pp 1-45.

(160) Adarnczyk, N. M.; Dameron, A. A.; George, S. M. Molecular layer deposition of poly(p-phenylene terephthalamide) films using terephthaloyl chloride and p-phenylenediamine. Langmuir 2008, 24 (5), 2081-2089.

(161) Dameron, A. A.; Davidson, S. D.; Burton, B. B.; Carcia, P. F.; McLean, R. S.; George, S. M. Gas diffusion barriers on polymers 
using multilayers fabricated by $\mathrm{Al}_{2} \mathrm{O}_{3}$ and rapid $\mathrm{SiO}_{2}$ atomic layer deposition. J. Phys. Chem. C 2008, 112 (12), 4573-4580.

(162) Dameron, A. A.; Seghete, D.; Burton, B. B.; Davidson, S. D.; Cavanagh, A. S.; Bertrand, J. A.; George, S. A. Molecular layer deposition of alucone polymer films using trimethylaluminum and ethylene glycol. Chem. Mater. 2008, 20 (10), 3315-3326.

(163) Du, Y.; George, S. M. Molecular layer deposition of nylon 66 films examined using in situ FTIR spectroscopy. J. Phys. Chem. C 2007, 111 (24), 8509-8517.

(164) Tugulu, S.; Silacci, P.; Stergiopulos, N.; Klok, H. A. RGD Functionalized polymer brushes as substrates for the integrin specific adhesion of human umbilical vein endothelial cells. Biomaterials 2007, 28 (16), 2536-2546.

(165) Reyes, C. D.; Petrie, T. A.; Burns, K. L.; Schwartz, Z.; Garcia, A. J. Biomolecular surface coating to enhance orthopaedic tissue healing and integration. Biomaterials 2007, 28 (21), 3228-3235.

(166) Goddard, J. M.; Hotchkiss, J. H. Tailored functionalization of lowdensity polyethylene surfaces. J. Appl. Polym. Sci. 2008, 108 (5), 2940-2949.

(167) Jozwiak, A. B.; Kielty, C. M.; Black, R. A. Surface functionalization of polyurethane for the immobilization of bioactive moieties on tissue scaffolds. J. Mater. Chem. 2008, 18 (19), 2240-2248.

(168) Santiago, L. Y.; Nowak, R. W.; Rubin, J. P.; Marra, K. G. Peptidesurface modification of poly(caprolactone) with laminin-derived sequences for adipose-derived stem cell applications. Biomaterials 2006, 27 (15), 2962-2969.

(169) Yoon, J. J.; Song, S. H.; Lee, D. S.; Park, T. G. Immobilization of cell adhesive RGD peptide onto the surface of highly porous biodegradable polymer scaffolds fabricated by a gas foaming/salt leaching method. Biomaterials 2004, 25 (25), 5613-5620.

(170) Lee, K. B.; Yoon, K. R.; Woo, S. I.; Choi, I. S. Surface modification of poly(glycolic acid) (PGA) for biomedical applications. J. Pharm. Sci. 2003, 92 (5), 933-937.

(171) Kim, Y. J.; Kang, I. K.; Huh, M. W.; Yoon, S. C. Surface characterization and in vitro blood compatibility of poly(ethylene terephthalate) immobilized with insulin and/or heparin using plasma glow discharge. Biomaterials 2000, 21 (2), 121-130.

(172) Bogaerts, A.; Neyts, E.; Gijbels, R.; van der Mullen, J. Gas discharge plasmas and their applications. Spectrochim. Acta, Part B: At. Spectrosc. 2002, 57 (4), 609-658.

(173) Lieberman, M. A.; Lichtenberg, A. J. Principles of Plasma Discharges and Materials Processing, 2nd ed.; Wiley-Interscience: Hoboken, NJ, 2005; p 757.

(174) Vossen, J. L.; Kern, W. Thin Film Processes; Academic Press: New York, 1978; Vol. xi, p 564

(175) Lee, S. D.; Hsiue, G. H.; Kao, C. Y. Preparation and characterization of a homobifunctional silicone rubber membrane grafted with acrylic acid via plasma-induced graft copolymerization. J. Polym. Sci., Part A: Polym. Chem. 1996, 34 (1), 141-148.

(176) Wang, Y. M.; Pan, Y.; Wang, Y. L.; Wu, G. P.; Wang, Y. J.; Nikitin, L. N.; Lu, X. B. Bulk graft modification of polyolefin membrane by combining pre-irradiation-induced graft and supercritical $\mathrm{CO}_{2}$ swelling polymerization. J. Supercrit. Fluids 2008, 44 (1), 62-70.

(177) Mansky, P.; Liu, Y.; Huang, E.; Russell, T. P.; Hawker, C. J. Controlling polymer-surface interactions with random copolymer brushes. Science 1997, 275 (5305), 1458-1460.

(178) Tsubokawa, N.; Maruyama, K.; Sone, Y.; Shimomura, M. Graftpolymerization of acrylamide from ultrafine silica particles by use of a redox system consisting of ceric ion and reducing groups on the surface. Polym. J. 1989, 21 (6), 475-481.

(179) Prucker, O.; Ruhe, J. Mechanism of radical chain polymerizations initiated by azo compounds covalently bound to the surface of spherical particles. Macromolecules 1998, 31 (3), 602-613.

(180) Prucker, O.; Ruhe, J. Synthesis of poly(styrene) monolayers attached to high surface area silica gels through self-assembled monolayers of azo initiators. Macromolecules 1998, 31 (3), 592-601.

(181) Stoffels, E.; Kieft, I. E.; Sladek, R. E. J. Superficial treatment of mammalian cells using plasma needle. J. Phys. D: Appl. Phys. 2003 36 (23), 2908-2913.

(182) Araya, M.; Yuji, T.; Watanabe, T.; Kashihara, J.; Sumida, Y. Application to cleaning of waste plastic surfaces using atmospheric non-thermal plasma jets. Thin Solid Films 2007, 515 (9), 4301-4307.

(183) Wolf, R. A. Unique atmospheric plasma surface pretreatment approach for improving adhesion. J. Vinyl Addit. Technol. 2007, 13 (2), 87-90

(184) Bhoj, A. N.; Kushner, M. J. Repetitively pulsed atmospheric pressure discharge treatment of rough polymer surfaces: II. Treatment of micro-beads in $\mathrm{He} / \mathrm{NH}_{3} / \mathrm{H}_{2} \mathrm{O}$ and $\mathrm{He} / \mathrm{O}_{2} / \mathrm{H}_{2} \mathrm{O}$ mixtures. Plasma Sources Sci. Technol. 2008, 17 (3),
(185) Fridman, A.; Chirokov, A.; Gutsol, A. Non-thermal atmospheric pressure discharges. J. Phys. D: Appl. Phys. 2005, 38 (2), R1-R24.

(186) Kogelschatz, U.; Eliasson, B.; Egli, W. Dielectric-barrier discharges. Principle and applications. J. Phys. IV 1997, 7 (C4), 47-66.

(187) Kogelschatz, U. Dielectric-barrier discharges: Their history, discharge physics, and industrial applications. Plasma Chem. Plasma Process. 2003, 23 (1), 1-46.

(188) Akishev, Y.; Goossens, O.; Callebaut, T.; Leys, C.; Napartovich, A.; Trushkin, N. The influence of electrode geometry and gas flow on corona-to-glow and glow-to-spark threshold currents in air. J. Phys. D: Appl. Phys. 2001, 34 (18), 2875-2882.

(189) Girard-Lauriault, P. L.; Mwale, F.; Iordanova, M.; Demers, C.; Desjardins, P.; Wertheimer, M. R. Atmospheric pressure deposition of micropatterned nitrogen-rich plasma-polymer films for tissue engineering. Plasma Processes Polym. 2005, 2 (3), 263-270.

(190) Heyse, P.; Dams, R.; Paulussen, S.; Houthofd, K.; Janssen, K.; Jacobs, P. A.; Sels, B. F. Dielectric barrier discharge at atmospheric pressure as a tool to deposit versatile organic coatings at moderate power input. Plasma Processes Polym. 2007, 4 (2), 145-157.

(191) Lewis, G. T.; Nowling, G. R.; Hicks, R. F.; Cohen, Y. Inorganic surface nanostructuring by atmospheric pressure plasma-induced graft polymerization. Langmuir 2007, 23 (21), 10756-10764.

(192) Okubo, M.; Tahara, M.; Saeki, N.; Yamamoto, T. Surface modification of fluorocarbon polymer films for improved adhesion using atmospheric-pressure nonthermal plasma graft-polymerization. Thin Solid Films 2008, 516 (19), 6592-6597.

(193) Sharma, R.; Holcomb, E.; Trigwell, S.; Mazumder, M. Stability of atmospheric-pressure plasma induced changes on polycarbonate surfaces. J. Electrost. 2007, 65 (4), 269-273.

(194) Temmerman, E.; Akishev, Y.; Trushkin, N.; Leys, C.; Verschuren, J. Surface modification with a remote atmospheric pressure plasma: dc glow discharge and surface streamer regime. J. Phys. D: Appl. Phys. 2005, 38 (4), 505-509.

(195) Wang, J. K.; Liu, X. Y.; Choi, H. S. Graft copolymerization kinetics of acrylic acid onto the poly(ethylene terephthalate) surface by atmospheric pressure plasma inducement. J. Polym. Sci. Part B: Polym. Phys. 2008, 46 (15), 1594-1601.

(196) Wang, X. L.; McCord, M. G. Grafting of poly( $N$-isopropylacrylamide) onto nylon and polystyrene surfaces by atmospheric plasma treatment followed with free radical graft copolymerization. J. Appl. Polym. Sci. 2007, 104 (6), 3614-3621.

(197) Park, B. J.; Lee, D. H.; Park, J. C.; Lee, I. S.; Lee, K. Y.; Hyun, S. O.; Chun, M. S.; Chung, K. H. Sterilization using a microwaveinduced argon plasma system at atmospheric pressure. Phys. Plasmas 2003, 10 (11), 4539-4544.

(198) Park, B. J.; Takatori, K.; Lee, M. H.; Han, D. W.; Woo, Y. I.; Son, H. J.; Kim, J. K.; Chung, K. H.; Hyun, S. O.; Park, J. C. Escherichia coli sterilization and lipopolysaccharide inactivation using microwaveinduced argon plasma at atmospheric pressure. Surf. Coat. Technol. 2007, 201 (9-11), 5738-5741.

(199) Park, B. J.; Takatori, K.; Sugita-Konishi, Y.; Kim, I. H.; Lee, M. H.; Han, D. W.; Chung, K. H.; Hyun, S. O.; Park, J. C. Degradation of mycotoxins using microwave-induced argon plasma at atmospheric pressure. Surf. Coat. Technol. 2007, 201 (9-11), 5733-5737.

(200) Park, J. C.; Park, B. J.; Han, D. W.; Lee, D. H.; Lee, I. S.; Hyun, S. O.; Chun, M. S.; Chung, K. H.; Aihara, M.; Takatori, K. Fungal sterilization using microwave-induced argon plasma at atmospheric pressure. J. Microbiol. Biotechnol. 2004, 14 (1), 188-192.

(201) Stoffels, E.; Flikweert, A. J.; Stoffels, W. W.; Kroesen, G. M. W. Plasma needle: A non-destructive atmospheric plasma source for fine surface treatment of (bio)materials. Plasma Sources Sci. Technol. 2002, 11 (4), 383-388.

(202) Duan, Y.; Wang, Z.; Yan, W.; Wang, S.; Zhang, S.; Jia, J. Preparation of collagen-coated electrospun nanofibers by remote plasma treatment and their biological properties. J. Biomater. Sci., Polym. Ed. 2007, 18 (9), 1153-1164.

(203) Turmanova, S.; Minchev, M.; Vassilev, K.; Danev, G. Surface grafting polymerization of vinyl monomers on poly(tetrafluoroethylene) films by plasma treatment. J. Polym. Res. 2008, 15 (4), 309318.

(204) Chen, W.; Jie-Rong, C.; Ru, L. Studies on surface modification of poly(tetrafluoroethylene) film by remote and direct Ar plasma. Appl. Surf. Sci. 2008, 254 (9), 2882-2888.

(205) Gancarz, I.; Bryjak, J.; Pozniak, G.; Tylus, W. Plasma modified polymers as a support for enzyme immobilization - II. Amines plasma. Eur. Polym. J. 2003, 39 (11), 2217-2224.

(206) Novak, I.; Pollak, V.; Chodak, I. Study of surface properties of polyolefins modified by corona discharge plasma. Plasma Processes Polym. 2006, 3 (4-5), 355-364. 
(207) Zhu, L. P.; Zhu, B. K.; Xu, L.; Feng, Y. X.; Liu, F.; Xu, Y. Y. Coronainduced graft polymerization for surface modification of porous polyethersulfone membranes. Appl. Surf. Sci. 2007, 253 (14), 6052 6059.

(208) Walsh, D.; Furuzono, T.; Tanaka, J. Preparation of porous composite implant materials by in situ polymerization of porous apatite containing $\varepsilon$-caprolactone or methyl methacrylate. Biomaterials 2001, 22 (11), 1205-1212.

(209) Osawa, S.; Yokoyama, T.; Hanada, M.; Ogawa, T. Control of degradation rate of biodegradable polymers by corona discharge treatment. Kobunshi Ronbunshu 2001, 58 (11), 581-587.

(210) Massines, F.; Gouda, G. A comparison of polypropylene-surface treatment by filamentary, homogeneous and glow discharges in helium at atmospheric pressure. J. Phy. D: Appl. Phys. 1998, 31 (24), 3411-3420.

(211) Okazaki, S.; Kogoma, M.; Uehara, M.; Kimura, Y. Appearance of stable glow-discharge in air, argon, oxygen and nitrogen at atmosphericpressure using a 50-Hz source. J. Phys. D: Appl. Phys. 1993, 26 (5), 889-892.

(212) Roth, J. R.; Rahel, J.; Dai, X.; Sherman, D. M. The physics and phenomenology of one atmosphere uniform glow discharge plasma (OAUGDP (TM)) reactors for surface treatment applications. J. Phys. D: Appl. Phys. 2005, 38 (4), 555-567.

(213) Roth, J. R.; Sherman, D. M.; Ben Gadri, R.; Karakaya, F.; Chen, Z. Y.; Montie, T. C.; Kelly-Wintenberg, K.; Tsai, P. P. Y. A remote exposure reactor (RER) for plasma processing and sterilization by plasma active species at one atmosphere. IEEE Trans. Plasma Sci. 2000, 28 (1), 56-63.

(214) Akishev, Y. S.; Grushin, M. E.; Monich, A. E.; Napartovich, A. P.; Trushkin, N. I. One-atmosphere argon dielectric-barrier corona discharge as an effective source of cold plasma for the treatment of polymer films and fabrics. High Energy Chem. 2003, 37 (5), 286290.

(215) Wagner, H. E.; Brandenburg, R.; Kozlov, K. V.; Sonnenfeld, A.; Michel, P.; Behnke, J. F. The barrier discharge: Basic properties and applications to surface treatment. Vacuum 2003, 71 (3), 417-436.

(216) Kogelschatz, U. Filamentary, patterned, and diffuse barrier discharges IEEE Trans. Plasma Sci. 2002, 30 (4), 1400-1408.

(217) Pietsch, G. J. Peculiarities of dielectric barrier discharges. Contrib. Plasma Phys. 2001, 41 (6), 620-628.

(218) Xu, X. J. Dielectric barrier discharge - properties and applications Thin Solid Films 2001, 390 (1-2), 237-242.

(219) Gibalov, V. I.; Pietsch, G. J. The development of dielectric barrier discharges in gas gaps and on surfaces. J. Phys. D: Appl. Phys. 2000, 33 (20), 2618-2636.

(220) Heyse, P.; Roeffaers, M. B. J.; Paulussen, S.; Hofkens, J.; Jacobs, P. A.; Sels, B. F. Protein immobilization using atmospheric-pressure dielectric-barrier discharges: A route to a straightforward manufacture of bioactive films. Plasma Processes Polym. 2008, 5 (2), 186-191.

(221) Yildirim, E. D.; Ayan, H.; Vasilets, V. N.; Fridman, A.; Guceri, S.; Sun, W. Effect of dielectric barrier discharge plasma on the attachment and proliferation of osteoblasts cultured over poly $(\varepsilon-$ caprolactone) scaffolds. Plasma Processes Polym. 2008, 5 (1), 58 66.

(222) Roth, J. R. Industrial Plasma Engineering; Institute of Physics: Bristol, 1995

(223) Alves, C. M.; Yang, Y.; Carnes, D. L.; Ong, J. L.; Sylvia, V. L.; Dean, D. D.; Agrawal, C. M.; Reis, R. L. Modulating bone cells response onto starch-based biomaterials by surface plasma treatment and protein adsorption. Biomaterials 2007, 28 (2), 307-315.

(224) Baquey, C.; Palumbo, F.; Porte-Durrieu, M. C.; Legeay, G.; Tressaud, A.; d'Agostino, R. Plasma treatment of expanded PTFE offers a way to a biofunctionalization of its surface. Nucl. Instrum. Methods Phys. Res., Sect. B: Beam Interact. Mater. Atoms 1999, 151 (1-4), 255262.

(225) Kingshott, P.; McArthur, S.; Thissen, H.; Castner, D. G.; Griesser, H. J. Ultrasensitive probing of the protein resistance of PEG surfaces by secondary ion mass spectrometry. Biomaterials 2002, 23 (24), 4775-4785.

(226) Kingshott, P.; Thissen, H.; Griesser, H. J. Effects of cloud-point grafting, chain length, and density of PEG layers on competitive adsorption of ocular proteins. Biomaterials 2002, 23 (9), 2043-2056.

(227) Meyer-Plath, A. A.; Schroder, K.; Finke, B.; Ohl, A. Current trends in biomaterial surface functionalization - Nitrogen-containing plasma assisted processes with enhanced selectivity. Vacuum 2003, 71 (3), 391-406.

(228) Truica-Marasescu, F.; Wertheimer, M. R. Nitrogen-rich plasmapolymer films for biomedical applications. Plasma Processes Polym. 2008, 5 (1), 44-57.
(229) Unger, W. E. S.; Swaraj, S.; Oran, U.; Lippitz, A. Radio frequency (r.f.) plasma-deposited polymer films: influence of external plasma parameters as viewed by comprehensive in-situ surface chemical analysis by XAS, XPS, and ToF-SIMS. Surf. Interface Anal. 2006, 38 (4), 522-525.

(230) Eliasson, B.; Kogelschatz, U. Nonequilibrium volume plasma chemical-processing. IEEE Trans. Plasma Sci. 1991, 19 (6), 1063-1077.

(231) Konig, U.; Nitschke, M.; Menning, A.; Sperling, C.; Simon, F.; Arnhold, C.; Werner, C.; Jacobasch, H. J. Plasma modification of polytetrafluoroethylene for immobilization of the fibrinolytic protein urokinase. Surf. Coat. Techno. 1999, 119, 1011-1015.

(232) Meyer-Plath, A. A.; Finke, B.; Schroder, K.; Ohl, A. Pulsed and CW microwave plasma excitation for surface functionalization in nitrogencontaining gases. Surf. Coat. Technol. 2003, 174, 877-881.

(233) Peng, J.; Jian, X. G.; Li, Q.; Deng, X. L.; Gu, B. Study of modification of poly(phthalazinone ether sulfone ketone) film treated by carbon dioxide microwave plasma. Acta Polym. Sin. 2000, (3), 354-357.

(234) Poncinepaillard, F.; Chevet, B.; Brosse, J. C. Functionalization of polypropylene by a microwave $(433 \mathrm{MHz})$ cold-plasma of carbondioxide - Surface modification or surface degradation. Eur. Polym. J. 1990, 26 (3), 333-339.

(235) Ren, T. B.; Weigel, T.; Groth, T.; Lendlein, A. Microwave plasma surface modification of silicone elastomer with allylamine for improvement of biocompatibility. J. Biomed. Mater. Res., Part A 2008, 86 (1), 209-219.

(236) Vasilets, V. N.; Hermel, G.; Konig, U.; Werner, C.; Muller, M.; Simon, F.; Grundke, K.; Ikada, Y.; Jacobasch, H. J. Microwave $\mathrm{CO}_{2}$ plasma-initiated vapour phase graft polymerization of acrylic acid onto polytetrafluoroethylene for immobilization of human thrombomodulin. Biomaterials 1997, 18 (17), 1139-1145.

(237) Brandenburg, R.; Krohmann, U.; Stieber, M.; Weltmann, K. D.; Woedtke, T. V.; Ehlbeck, J.; Antimicrobial treatment of heat sensitive products by atmospheric pressure plasma sources. In Plasma Assisted Decontamination of Biological and Chemical Agents; Güçeri, S., Fridman, A., Eds.; Springer: New York, 2008; pp 51-63.

(238) Lee, K. Y.; Park, B. J.; Lee, D. H.; Lee, I. S.; Hyun, S. O.; Chung, K. H.; Park, J. C. Sterilization of Escherichia coli and MRSA using microwave-induced argon plasma at atmospheric pressure. Surf. Coat. Technol. 2005, 193 (1-3), 35-38.

(239) Behnisch, J.; Mehdorn, F.; Hollander, A.; Zimmermann, H. Mechanistic approach to the plasma polymerization of acrylic acid by a pulsed MW(ECR) plasma. Surf. Coat. Technol. 1998, 98 (1-3), 875878.

(240) Guan, W. S.; Wen, Y. J.; Ying, Y. X.; Qian, S. J. Study of graft copolymerization modification of Teflon surface with ECR plasma. In ICPP 96 Contributed Papers - Proceedings of the 1996 International Congress on Plasma Physics; Sugai, H., Hayashi, T., Eds.; Japan Society Plasma Science and Nuclear Fusion Research: Nagoya, Japan, 1997, Vols. 1/2, 1810-1813.

(241) Guruvenket, S.; Komath, M.; Vijayalakshmi, S. P.; Raichur, A. M.; Rao, G. M. Wettability enhancement of polystyrene with electron cyclotron resonance plasma with argon. J. Appl. Polym. Sci. 2003, 90 (6), 1618-1623.

(242) Foest, R.; Schmidt, M.; Becker, K. Microplasmas, an emerging field of low-temperature plasma science and technology. Int. J. Mass Spectrom. 2006, 248 (3), 87-102.

(243) Becker, K. H.; Schoenbach, K. H.; Eden, J. G. Microplasmas and applications. J. Phys. D: Appl. Phys. 2006, 39 (3), R55-R70.

(244) Kogelschatz, U. Applications of microplasmas and microreactor technology. Contrib. Plasma Phys. 2007, 47 (1-2), 80-88.

(245) Stoffels, E. "Tissue processing" with atmospheric plasmas. Contrib. Plasma Phys. 2007, 47 (1-2), 40-48.

(246) Laroussi, M.; Akan, T. Arc-free atmospheric pressure cold plasma jets: A review. Plasma Processes Polym. 2007, 4 (9), 777-788.

(247) Sladek, R. E. J.; Stoffels, E.; Walraven, R.; Tielbeek, P. J. A.; Koolhoven, R. A. Plasma treatment of dental cavities: A feasibility study. IEEE Trans. Plasma Sci. 2004, 32 (4), 1540-1543.

(248) Goree, J.; Liu, B.; Drake, D.; Stoffels, E. Killing of S-mutans bacteria using a plasma needle at atmospheric pressure. IEEE Trans. Plasma Sci. 2006, 34 (4), 1317-1324.

(249) Stoffels, E.; Kieft, I. E.; Sladek, R. E. J.; van den Bedem, L. J. M.; van der Laan, E. P.; Steinbuch, M. Plasma needle for in vivo medical treatment: Recent developments and perspectives. Plasma Sources Sci. Technol. 2006, 15 (4), S169-S180.

(250) Laroussi, M.; Hynes, W.; Akan, T.; Lu, X. P.; Tendero, C. The plasma pencil: A source of hypersonic cold plasma bullets for biomedical applications. IEEE Trans. Plasma Sci. 2008, 36 (4), 1298-1299. 
(251) Laroussi, M.; Lu, X. Room-temperature atmospheric pressure plasma plume for biomedical applications. Appl. Phys. Lett. 2005, 87 (11), 113902-1-113902-3.

(252) Laroussi, M.; Tendero, C.; Lu, X.; Alla, S.; Hynes, W. L. Inactivation of bacteria by the plasma pencil. Plasma Processes Polym. 2006, 3 $(6-7), 470-473$

(253) Lu, X.; Laroussi, M. Dynamics of an atmospheric pressure plasma plume generated by submicrosecond voltage pulses. J. Appl. Phys. 2006, 100 (6), . -

(254) Siow, K. S.; Britcher, L.; Kumar, S.; Griesser, H. J. Plasma methods for the generation of chemically reactive surfaces for biomolecule immobilization and cell colonization - A review. Plasma Processes Polym. 2006, 3 (6-7), 392-418.

(255) Grace, J. M.; Gerenser, L. J. Plasma treatment of polymers. J. Dispersion Sci. Technol. 2003, 24 (3-4), 305-341.

(256) France, R. M.; Short, R. D. Plasma treatment of polymers - Effects of energy transfer from an argon plasma on the surface chemistry of poly(styrene), low density poly(ethylene), poly(propylene) and poly(ethylene terephthalate). J. Chem. Soc., Faraday Trans. 1997 93 (17), 3173-3178.

(257) Murakami, T.; Kuroda, S.; Osawa, Z. Dynamics of polymeric solid surfaces treated with oxygen plasma: Effect of aging media after plasma treatment. J. Colloid Interface Sci. 1998, 202 (1), 37-44.

(258) Murakami, T.; Kuroda, S.; Osawa, Z. Dynamics of polymeric solid surfaces treated by oxygen plasma: Plasma-induced increases in surface molecular mobility of polystyrene. J. Colloid Interface Sci. 1998, 200 (1), 192-194.

(259) Morra, M.; Occhiello, E.; Marola, R.; Garbassi, F.; Humphrey, P.; Johnson, D. On the aging of oxygen plasma-treated polydimethylsiloxane surfaces. J. Colloid Interface Sci. 1990, 137 (1), 11-24.

(260) Chan, C. M.; Ko, T. M.; Hiraoka, H. Polymer surface modification by plasmas and photons. Surf. Sci. Rep. 1996, 24 (1-2), 3-54.

(261) Ho, M. H.; Hou, L. T.; Tu, C. Y.; Hsieh, H. J.; Lai, J. Y.; Chen, W. J.; Wang, D. M. Promotion of cell affinity of porous PLLA scaffolds by immobilization of RGD peptides via plasma treatment. Macromol. Biosci. 2006, 6 (1), 90-98.

(262) Zhao, J. H.; Wang, J.; Tu, M.; Luo, B. H.; Zhou, C. R. Improving the cell affinity of a poly(D,L-lactide) film modified by grafting collagen via a plasma technique. Biomed. Mater. 2006, 1 (4), 247252.

(263) Mason, M.; Vercruysse, K. P.; Kirker, K. R.; Frisch, R.; Marecak, D. M.; Prestwich, C. D.; Pitt, W. G. Attachment of hyaluronic acid to polypropylene, polystyrene, and polytetrafluoroethylene. Biomaterials 2000, 21 (1), 31-36.

(264) Ma, Z. W.; He, W.; Yong, T.; Ramakrishna, S. Grafting of gelatin on electrospun poly(caprolactone) nanofibers to improve endothelial cell spreading and proliferation and to control cell orientation. Tissue Eng. 2005, 11 (7-8), 1149-1158.

(265) Gugala, Z.; Gogolewski, S. Attachment, growth, and activity of rat osteoblasts on polylactide membranes treated with various low temperature radio frequency plasmas. J. Biomed. Mater. Res., Part A 2006, 76 (2), 288-299.

(266) Shen, H.; Hu, X. X.; Bei, J. Z.; Wang, S. G. The immobilization of basic fibroblast growth factor on plasma-treated poly(lactide- $\mathrm{CO}$ glycolide). Biomaterials 2008, 29 (15), 2388-2399.

(267) Woodfield, T. B. F.; Miot, S.; Martin, I.; van Blitterswijk, C. A. Riesle, J. The regulation of expanded human nasal chondrocyte redifferentiation capacity by substrate composition and gas plasma surface modification. Biomaterials 2006, 27 (7), 1043-1053.

(268) Wan, Y. Q.; Yang, J.; Yang, J. L.; Bei, J. Z.; Wang, S. G. Cell adhesion on gaseous plasma modified poly-(L-lactide) surface under shear stress field. Biomaterials 2003, 24 (21), 3757-3764.

(269) Oehr, C.; Muller, M.; Elkin, B.; Hegemann, D.; Vohrer, U. Plasma grafting - A method to obtain monofunctional surfaces. Surf. Coat. Technol. 1999, 119, 25-35.

(270) Yang, H. S.; Park, K.; Ahn, K. D.; Kim, B. S.; Han, D. K. Optimal hydrophilization and chondrocyte adhesion of PLLA films and scaffolds by plasma treatment and acrylic acid grafting. Polymer (Korea) 2006, 30 (2), 168-174.

(271) Muller, M.; Oehr, C. Plasma aminofunctionalisation of PVDF microfiltration membranes: Comparison of the in plasma modifications with a grafting method using ESCA and an amino-selective fluorescent probe. Surf. Coat. Technol. 1999, 119, 802-807.

(272) Cheng, Z. Y.; Teoh, S. H. Surface modification of ultra thin poly $(\varepsilon-$ caprolactone) films using acrylic acid and collagen. Biomaterials 2004, 25 (11), 1991-2001.

(273) Gupta, B.; Hilborn, J. G.; Bisson, I.; Frey, P. Plasma-induced craft polymerization of acrylic acid onto poly(ethylene terephthalate) films. J. Appl. Polym. Sci. 2001, 81 (12), 2993-3001.
(274) Lee, S. D.; Hsiue, G. H.; Chang, P. C. T.; Kao, C. Y. Plasma-induced grafted polymerization of acrylic acid and subsequent grafting of collagen onto polymer film as biomaterials. Biomaterials 1996, 17 (16), 1599-1608.

(275) Suzuki, M.; Kishida, A.; Iwata, H.; Ikada, Y. Graft-copolymerization of acrylamide onto a polyethylene surface pretreated with a glowdischarge. Macromolecules 1986, 19 (7), 1804-1808.

(276) Huang, C. Y.; Lu, W. L.; Feng, Y. C. Effect of plasma treatment on the AAc grafting percentage of high-density polyethylene. Surf. Coat. Technol. 2003, 167 (1), 1-10.

(277) Kinoshita, Y.; Kuzuhara, T.; Kirigakubo, M.; Kobayashi, M.; Shimura, K.; Ikada, Y. Reduction in Tumor-Formation on Porous Polyethylene by Collagen Immobilization. Biomaterials 1993, 14 (7), 546-550.

(278) Kinoshita, Y.; Kuzuhara, T.; Kirigakubo, M.; Kobayashi, M.; Shimura, K.; Ikada, Y. Soft-tissue reaction to collagen-immobilized porous polyethylene - Subcutaneous implantation in rats for $20 \mathrm{wk}$. Biomaterials 1993, 14 (3), 209-215.

(279) Muir, B. W.; Barden, M. C.; Collett, S. P.; Gorse, A. D.; Monteiro, R.; Yang, L. Q.; McDougall, N. A.; Gould, S.; Maeji, N. J. Highthroughput optimization of surfaces for antibody immobilization using metal complexes. Anal. Biochem. 2007, 363 (1), 97-107.

(280) Gupta, B.; Saxena, S.; Ray, A. Plasma induced graft polymerization of acrylic acid onto polypropylene monofilament. J. Appl. Polym. Sci. 2008, 107 (1), 324-330.

(281) Foo, H. L.; Taniguchi, A.; Yu, H.; Okano, T.; Teoh, S. H. Catalytic surface modification of roll-milled poly( $\varepsilon$-caprolactone) biaxially stretched to ultra-thin dimension. Mater. Sci. Eng. C: Biomimetic Supramol. Syst. 2007, 27 (2), 299-303.

(282) Gupta, B.; Hilborn, J.; Plummer, C.; Bisson, I.; Frey, P. Thermal crosslinking of collagen immobilized on poly(acrylic acid) grafted poly(ethylene terephthalate) films. J. Appl. Polym. Sci. 2002, 85 (9), 1874-1880.

(283) Choi, H. S.; Kim, Y. S.; Zhang, Y.; Tang, S.; Myung, S. W.; Shin, B. C. Plasma-induced graft co-polymerization of acrylic acid onto the polyurethane surface. Surf. Coat. Technol. 2004, 182 (1), 55-64.

(284) Milani, R.; Gleria, M.; Sassi, A.; De Jaeger, R.; Mazzah, A.; Jama, C.; Gengembre, L. Surface modification of plasma-treated polyamide-6 with fluorinated alcohols and azobenzene compounds using chlorinated phosphazenes as coupling agents. Mol. Cryst. Liq. Cryst. 2008, 483, 62-70.

(285) Kausch, H. H.; Anjum, N. Radiation Effects on Polymers for Biological Use; Springer: Berlin/London, 2003; Vol. viii, p 173

(286) Kwon, O. H.; Nho, Y. C.; Park, K. D.; Kim, Y. H. Graft copolymerization of polyethylene glycol methacrylate onto polyethylene film and its blood compatibility. J. Appl. Polym. Sci. 1999, 71 (4), 631-641.

(287) Sano, S.; Kato, K.; Ikada, Y. Introduction of functional-groups onto the surface of polyethylene for protein immobilization. Biomaterials 1993, 14 (11), 817-822.

(288) Gong, Y. H.; Zhu, Y. B.; Liu, Y. X.; Ma, Z. W.; Gao, C. Y.; Shen, J. C. Layer-by-layer assembly of chondroitin sulfate and collagen on aminolyzed poly(L-lactic acid) porous scaffolds to enhance their chondrogenesis. Acta Biomater. 2007, 3 (5), 677-685.

(289) Zhu, Y. B.; Leong, M. F.; Ong, W. F.; Chan-Park, M. B.; Chian, K. S. Esophageal epithelium regeneration on fibronectin grafted poly(L-lactide-co-caprolactone) (PLLC) nanofiber scaffold. Biomaterials 2007, 28 (5), 861-868.

(290) Zhu, Y. B.; Chian, K. S.; Chan-Park, M. B.; Mhaisalkar, P. S.; Ratner, B. D. Protein bonding on biodegradable poly(L-lactide-co-caprolactone) membrane for esophageal tissue engineering. Biomaterials 2006, 27 (1), 68-78.

(291) Pamula, E.; Dryzek, E. Structural changes in surface-modified polymers for medical applications. Acta Phys. Pol., A 2008, 113 (5), 1485-1493.

(292) Sasai, Y.; Oikawa, M.; Kondo, S. I.; Kuzuya, M. Surface engineering of polymer sheet by plasma techniques and atom transfer radical polymerization for covalent immobilization of biomolecules. $J$. Photopolym. Sci. Technol. 2007, 20 (2), 197-200.

(293) Kuzuya, M.; Sawa, T.; Mouri, M.; Kondo, S. I.; Takai, O. Plasma technique for the fabrication of a durable functional surface on organic polymers. Surf. Coat. Technol. 2003, 169, 587-591.

(294) Barry, J. J. A.; Silva, M. M; C, G.; Shakesheff, K. M.; Howdle, S. M.; Alexander, M. R. Using plasma deposits to promote cell population of the porous interior of three-dimensional poly(D,L-lactic acid) tissueengineering scaffolds. Adv. Funct. Mater. 2005, 15 (7), L1134-1140.

(295) Guerin, D. C.; Hinshelwood, D. D.; Monolache, S.; Denes, F. S.; Shamamian, V. A. Plasma polymerization of thin films: Correlations 
between plasma chemistry and thin film character. Langmuir $\mathbf{2 0 0 2 ,}$ 18 (10), 4118-4123.

(296) Cho, D. L.; Claesson, P. M.; Golander, C. G.; Johansson, K. Structure and surface-properties of plasma polymerized acrylic-acid layers. J. Appl. Polym. Sci. 1990, 41 (7-8), 1373-1390.

(297) Kuhn, G.; Retzko, I.; Lippitz, A.; Unger, W.; Friedrich, J. Homofunctionalized polymer surfaces formed by selective plasma processes. Surf. Coat. Technol. 2001, 142, 494-500.

(298) Chua, C. K.; Leong, K. F.; Cheah, C. M.; Chua, S. W. Development of a tissue engineering scaffold structure library for rapid prototyping. Part 2: Parametric library and assembly program. Int. J. Adv. Manuf. Technol. 2003, 21 (4), 302-312.

(299) Chu, L. Q.; Zou, X. N.; Knoll, W.; Forch, R. . Thermosensitive surfaces fabricated by plasma polymerization of $N, N$-diethylacrylamide. Surf. Coat. Technol. 2008, 202 (10), 2047-2051.

(300) Choukourov, A.; Biederman, H.; Slavinska, D.; Trchova, M.; Hollander, A. The influence of pulse parameters on film composition during pulsed plasma polymerization of diaminocyclohexane. Surf. Coat. Technol. 2003, 174, 863-866.

(301) Drews, J.; Launay, H.; Hansen, C. M.; West, K.; Hvilsted, S.; Kingshott, P.; Almdal, K. Hydrolysis and stability of thin pulsed plasma polymerised maleic anhydride coatings. Appl. Surf. Sci. 2008, 254 (15), 4720-4725.

(302) Hook, A. L.; Thissen, H.; Quinton, J.; Voelcker, N. H. Comparison of the binding mode of plasmid DNA to allylamine plasma polymer and poly(ethylene glycol) surfaces. Surf. Sci. 2008, 602 (10), 18831891.

(303) Puleo, D. A.; Kissling, R. A.; Sheu, M. S. A technique to immobilize bioactive proteins, including bone morphogenetic protein-4 (BMP4), on titanium alloy. Biomaterials 2002, 23 (9), 2079-2087.

(304) Mitchell, S. A.; Davidson, M. R.; Emmison, N.; Bradley, R. H. Isopropyl alcohol plasma modification of polystyrene surfaces to influence cell attachment behaviour. Surf. Sci. 2004, 561 (1), 110 120 .

(305) Haddow, D. B.; France, R. M.; Short, R. D.; MacNeil, S.; Dawson, R. A.; Leggett, G. J.; Cooper, E. Comparison of proliferation and growth of human keratinocytes on plasma copolymers of acrylic acid/ 1,7-octadiene and self-assembled monolayers. J. Biomed. Mater. Res. 1999, 47 (3), 379-387.

(306) Ju, Y. M.; Park, K.; Son, J. S.; Kim, J. J.; Rhie, J. W.; Han, D. K. Beneficial effect of hydrophilized porous polymer scaffolds in tissueengineered cartilage formation. J. Biomed. Mater. Res., Part B: Appl. Biomater. 2008, $85 B$ (1), 252-260.

(307) Truica-Marasescu, F.; Wertheimer, M. R. Vacuum-ultraviolet photopolymerisation of amine-rich thin films. Macromol. Chem. Phys. 2008, 209 (10), 1043-1049.

(308) Fabre, T.; Schappacher, M.; Bareille, R.; Dupuy, B.; Soum, A.; Bertrand-Barat, J.; Baquey, C. Study of a (trimethylenecarbonate$c o$ - $\varepsilon$-caprolactone) polymer - Part 2: In vitro cytocompatibility analysis and in vivo ED1 cell response of a new nerve guide. Biomaterials 2001, 22 (22), 2951-2958.

(309) Shum, A. W. T.; Li, J. S.; Mak, A. F. T. Fabrication and structural characterization of porous biodegradable poly(DL-lactic-co-glycolic acid) scaffolds with controlled range of pore sizes. Polym. Degrad. Stab. 2005, 87 (3), 487-493.

(310) Vaquette, C.; Frochot, C.; Rahouadj, R.; Muller, S.; Wang, X. Mechanical and biological characterization of a porous poly-L-lactic acid-co- $\varepsilon$-caprolactone scaffold for tissue engineering. Soft Mater. 2008, 6 (1), 25-33.

(311) Liu, X. H.; Won, Y. J.; Ma, P. X. Surface modification of interconnected porous scaffolds. J. Biomed. Mater. Res., Part A 2005, $74 A$ (1), 84-91.

(312) Ma, Z. W.; Gao, C. Y.; Gong, Y. H.; Shen, J. C. Cartilage tissue engineering PLLA scaffold with surface immobilized collagen and basic fibroblast growth factor. Biomaterials 2005, 26 (11), 12531259.

(313) Safinia, L.; Datan, N.; Hohse, M.; Mantalaris, A.; Bismarck, A. Towards a methodology for the effective surface modification of porous polymer scaffolds. Biomaterials 2005, 26 (36), 7537-7547.

(314) Chen, F.; Lee, C. N.; Teoh, S. H. Nanofibrous modification on ultrathin poly( $\varepsilon$-caprolactone) membrane via electrospinning. Mater. Sci. Eng. C: Biomimetic Supramol. Syst. 2007, 27 (2), 325-332.

(315) Desmet, T.; Schacht, E.; Dubruel, P. Rapid prototyping as an elegant production tool for polymeric tissue engineering scaffolds: A review. In Tissue Engineering: Roles, Materials and Applications; Barnes, S. J.; Harris, L. P. , Eds.; Nova Science Publishers, Inc.: Hauppauge, NY, 2008; pp 141-189.

(316) Tanahashi, M.; Yao, T.; Kokubo, T.; Minoda, M.; Miyamoto, T.; Nakamura, T.; Yamamuro, T. Apatite coated on organic polymers by biomimetic process - Improvement in its adhesion to substrate by $\mathrm{NaOH}$ treatment. J. Appl. Biomater. 1994, 5 (4), 339-347.

(317) Gao, J. M.; Niklason, L.; Langer, R. Surface hydrolysis of poly(glycolic acid) meshes increases the seeding density of vascular smooth muscle cells. J. Biomed. Mater. Res. 1998, 42 (3), 417-424.

(318) Nam, Y. S.; Yoon, J. J.; Lee, J. G.; Park, T. G. Adhesion behaviours of hepatocytes cultured onto biodegradable polymer surface modified by alkali hydrolysis process. J. Biomater. Sci., Polym. Ed. 1999, 10 (11), 1145-1158.

(319) Schantz, J. T.; Hutmacher, D. W.; Ng, K. W.; Khor, H. L.; Lim, T. C.; Teoh, S. H. Evaluation of a tissue-engineered membrane-cell construct for guided bone regeneration. Int. J. Oral Maxillofacial Implants 2002, 17 (2), 161-174.

(320) Varma, H. K.; Sreenivasan, K.; Yokogawa, Y.; Hosumi, A. In vitro calcium phosphate growth over surface modified PMMA film. Biomaterials 2003, 24 (2), 297-303.

(321) Ang, L. P. K.; Cheng, Z. Y.; Beuerman, R. W.; Teoh, S. H.; Zhu, X.; Tan, D. T. H. The development of a serum-free derived bioengineered conjunctival epithelial equivalent using an ultrathin poly( $\varepsilon$-caprolactone) membrane substrate. Invest. Ophthalmol. Visual Sci. 2006, 47 (1), 105-112.

(322) Sun, H.; Onneby, S. Facile polyester surface functionalization via hydrolysis and cell-recognizing peptide attachment. Polym. Int. 2006, 55 (11), 1336-1340.

(323) Brown, L.; Koerner, T.; Horton, J. H.; Oleschuk, R. D. Fabrication and characterization of poly(methylmethacrylate) microfluidic devices bonded using surface modifications and solvents. Lab Chip 2006, 6 (1), 66-73.

(324) Wen, F.; Chang, S.; Toh, Y. C.; Teoh, S. H.; Yu, H. Development of poly(lactic-co-glycolic acid)-collagen scaffolds for tissue engineering. Mater. Sci. Eng. C: Biomimetic Supramol. Systems 2007, 27 (2), 285-292.

(325) Chen, Y.; Mak, A. F. T.; Wang, M.; Li, J. S.; Wong, M. S. In vitro behavior of osteoblast-like cells on PLLA films with a biomimetic apatite or apatite/collagen composite coating. J. Mater. Sci.: Mater. Med. 2008, 19 (6), 2261-2268.

(326) Chen, Y.; Mak, A. F. T.; Wang, M.; Li, J. S.; Wong, M. S. PLLA scaffolds with biomimetic apatite coating and biomimetic apatite/ collagen composite coating to enhance osteoblast-like cells attachment and activity. Surf. Coat. Technol. 2006, 201 (3-4), 575-580.

(327) Zhu, H. G.; Ji, J.; Shen, J. C. Construction of multilayer coating onto poly-(DL-lactide) to promote cytocompatibility. Biomaterials 2004, 25 (1), 109-117.

(328) Croll, T. I.; O’Connor, A. J.; Stevens, G. W.; Cooper-White, J. J. Controllable surface modification of poly(lactic-co-glycolic acid) (PLGA) by hydrolysis or aminolysis I: Physical, chemical, and theoretical aspects. Biomacromolecules 2004, 5 (2), 463-473.

(329) Zhu, Y. B.; Gao, C. Y.; He, T.; Shen, J. C. Endothelium regeneration on luminal surface of polyurethane vascular scaffold modified with diamine and covalently grafted with gelatin. Biomaterials 2004, 25 (3), 423-430.

(330) Fixe, F.; Dufva, M.; Telleman, P.; Christensen, C. B. V. Functionalization of poly(methyl methacrylate) (PMMA) as a substrate for DNA microarrays. Nucleic Acids Res. 2004, 32 (1), e9-1-e9-8.

(331) Gabriel, M.; Amerongen, G. P. V.; Van Hinsbergh, V. W. M.; Amerongen, A. V. V.; Zentner, A. Direct grafting of RGD-motifcontaining peptide on the surface of polycaprolactone films. J. Biomater. Sci., Polym. Ed. 2006, 17 (5), 567-577.

(332) Bech, L.; Meylheuc, T.; Lepoittevin, B.; Roger, P. Chemical surface modification of poly(ethylene terephthalate) fibers by aminolysis and grafting of carbohydrates. J. Polym. Sci., Part A: Polym. Chem. 2007, 45 (11), 2172-2183.

(333) Hollahan, J. R.; Stafford, B. B.; Falb, R. D.; Payne, S. T. Attachment of amino groups to polymer surfaces by radiofrequency plasmas. J. Appl. Polym. Sci. 1969, 13 (4), 807.

(334) Hall, J. R.; Westerda, Ca; Devine, A. T.; Bodnar, M. J. Activated gas plasma surface treatment of polymers for adhesive bonding. J. Appl. Polym. Sci. 1969, 13 (10), 2085.

(335) Morra, M.; Occhiello, E.; Garbassi, F. Contact-angle hysteresis on oxygen plasma treated polypropylene surfaces. J. Colloid Interface Sci. 1989, 132 (2), 504-508.

(336) Morra, M.; Occhiello, E.; Garbassi, F. Contact-angle hysteresis in oxygen plasma treated poly(tetrafluoroethylene). Langmuir 1989, 5 (3), 872-876.

(337) Inagaki, N.; Tasaka, S.; Hibi, K. Surface modification of Kapton film by plasma treatments. J. Polym. Sci., Part A: Polym. Chem. 1992, 30 (7), 1425-1431. 
(338) Ko, T. M.; Lin, J. C.; Cooper, S. L. Surface characterization and platelet-adhesion studies of plasma-sulfonated polyethylene. Biomaterials 1993, 14 (9), 657-664.

(339) Ko, T. M.; Lin, J. C.; Cooper, S. L. Surface characterization and platelet-adhesion studies of plasma-carboxylated polyethylene. $J$. Colloid Interface Sci. 1993, 156 (1), 207-217.

(340) Chatelier, R. C.; Xie, X. M.; Gengenbach, T. R.; Griesser, H. J. Effects of plasma modification conditions on surface restructuring. Langmuir 1995, 11 (7), 2585-2591.

(341) Terlingen, J. G. A.; Gerritsen, H. F. C.; Hoffman, A. S.; Feijen, J. Introduction of functional-groups on polyethylene surfaces by a carbon-dioxide plasma treatment. J. Appl. Polym. Sci. 1995, 57 (8), 969-982.

(342) Coen, M. C.; Groening, P.; Dietler, G.; Schlapbach, L. Creation of a conductive surface-layer on polypropylene samples by low-pressure plasma treatments. J. Appl. Phys. 1995, 77 (11), 5695-5701.

(343) Cueff, R.; Baud, G.; Benmalek, M.; Besse, J. P.; Butruille, J. R.; Jacquet, M. X-ray photoelectron spectroscopy studies of plasmamodified PET surface and alumina/PET interface. Appl. Surf. Sci. 1997, 115 (3), 292-298.

(344) Gancarz, I.; Pozniak, G.; Bryjak, M. Modification of polysulfone membranes 1. $\mathrm{CO}_{2}$ plasma treatment. Eur. Polym. J. 1999, 35 (8), $1419-1428$

(345) Bryjak, M.; Gancarz, I.; Pozniak, G. Surface evaluation of plasmamodified polysulfone (UDEL P-1700) films. Langmuir 1999, 15 (19), 6400-6404

(346) Grace, J. M.; Zhuang, H. K.; Gerenser, L. J.; Freeman, D. R. Timeresolved investigation of the surface chemical modification of poly(ethylene naphthalate) by nitrogen plasma treatment. J. Vac. Sci. Technol. A 2003, 21 (1), 37-46.

(347) Yang, J.; Wan, Y. Q.; Yang, J. L.; Bei, J. Z.; Wang, S. G. Plasmatreated, collagen-anchored polylactone: Its cell affinity evaluation under shear or shear-free conditions. J. Biomed. Mater. Res., Part A 2003, 67 (4), 1139-1147.

(348) Bullett, N. A.; Bullett, D. P.; Truica-Marasescu, F. E.; Lerouge, S.; Mwale, F.; Wertheimer, M. R. Polymer surface micropatterning by plasma and VUV-photochemical modification for controlled cell culture. Appl. Surf. Sci. 2004, 235 (4), 395-405.

(349) Wang, Y. Q.; Qu, X.; Lu, J.; Zhu, C. F.; Wan, L. J.; Yang, J. L.; Bei, J. Z.; Wang, S. G. Characterization of surface property of poly(lactide-co-glycolide) after oxygen plasma treatment. Biomaterials 2004, 25 (19), 4777-4783.

(350) Williams, R. L.; Krishna, Y.; Dixon, S.; Haridas, A.; Grierson, I. Sheridan, C. Polyurethanes as potential substrates for sub-retinal retinal pigment epithelial cell transplantation. J. Mater. Sci.: Mater. Med. 2005, 16 (12), 1087-1092.

(351) Wang, M. J.; Chang, Y. I.; Poncin-Epaillard, F. Acid and basic functionalities of nitrogen and carbon dioxide plasma-treated polystyrene. Surf. Interface Anal. 2005, 37 (3), 348-355.

(352) Kull, K. R.; Steen, M. L.; Fisher, E. R. Surface modification with nitrogen-containing plasmas to produce hydrophilic, low-fouling membranes. J. Membr. Sci. 2005, 246 (2), 203-215.

(353) Li, Y. H.; Huang, Y. D. The study of collagen immobilization on polyurethane by oxygen plasma treatment to enhance cell adhesion and growth. Surf. Coa. Technol. 2007, 201 (9-11), 5124-5127.

(354) Hanson, A. D.; Wall, M. E.; Pourdeyhimi, B.; Loboa, E. G. Effects of oxygen plasma treatment on adipose-derived human mesenchymal stem cell adherence to poly(L-lactic acid) scaffolds. J. Biomater. Sci., Polym. Ed. 2007, 18 (11), 1387-1400.

(355) Svorcik, V.; Kotal, V.; Siegel, J.; Sajdl, P.; Mackova, A.; Hnatowicz, V. Ablation and water etching of poly(ethylene) modified by argon plasma. Polym. Degrad. Stab. 2007, 92 (9), 1645-1649.

(356) Sperling, C.; Konig, U.; Hermel, G.; Werner, C.; Muller, M.; Simon, F.; Grundke, K.; Jacobasch, H. J.; Vasilets, V. N.; Ikada, Y. Immobilization of human thrombomodulin onto PTFE. J. Mater. Sci.: Mater. Med. 1997, 8 (12), 789-791.

(357) Vladkova, T. G.; Keranov, I. L.; Dineff, P. D.; Youroukov, S. Y.; Avramova, I. A.; Krasteva, N.; Altankov, G. P. Plasma based $\mathrm{Ar}^{+}$ beam assisted poly(dimethylsiloxane) surface modification. Nucl. Instrum. Methods Phys. Res., Sect. B: Beam Interact. Mater. Atoms 2005, 236, 552-562.

(358) Ren, J. R.; Wang, J.; Sun, H.; Huang, N. Surface modification of polyethylene terephthalate with albumin and gelatin for improvement of anticoagulation and endothelialization. Appl. Surf. Sci. 2008, 255 (2), 263-266.

(359) Ko, T. M.; Cooper, S. L. Surface-properties and platelet-adhesion characteristics of acrylic-acid and allylamine plasma-treated polyethylene. J. Appl. Polym. Sci. 1993, 47 (9), 1601-1619.
(360) Fally, F.; Doneux, C.; Riga, J.; Verbist, J. J. Quantification of the functional-groups present at the surface of plasma polymers deposited from propylamine, allylamine, and propargylamine. J. Appl. Polym. Sci. 1995, 56 (5), 597-614.

(361) Fally, F.; Virlet, I.; Riga, J.; Verbist, J. J. Detailed multitechnique spectroscopic surface and bulk characterization of plasma polymers deposited from 1-propanol, allyl alcohol, and propargyl alcohol. J. Appl. Polym. Sci. 1996, 59 (10), 1569-1584.

(362) Yoshimura, K.; Hozumi, K.; Tatsuta, T.; Sawai, M.; Tsuji, O. Preparation of hydrophilic plasma-polymers derived from oxygencontaining organic monomers. J. Appl. Polym. Sci. 1996, 59 (6), 1033-1042.

(363) Rinsch, C. L.; Chen, X. L.; Panchalingam, V.; Eberhart, R. C.; Wang, J. H.; Timmons, R. B. Pulsed radio frequency plasma polymerization of allyl alcohol: Controlled deposition of surface hydroxyl groups. Langmuir 1996, 12 (12), 2995-3002.

(364) OToole, L.; Beck, A. J.; Short, R. D. Characterization of plasma polymers of acrylic acid and propanoic acid. Macromolecules 1996, 29 (15), 5172-5177.

(365) Beck, A. J.; Jones, F. R.; Short, R. D. Plasma copolymerization as a route to the fabrication of new surfaces with controlled amounts of specific chemical functionality. Polymer 1996, 37 (24), 55375539.

(366) Mackie, N. M.; Castner, D. G.; Fisher, E. R. Characterization of pulsed-plasma-polymerized aromatic films. Langmuir 1998, 14 (5), 1227-1235.

(367) France, R. M.; Short, R. D.; Duval, E.; Jones, F. R.; Dawson, R. A.; MacNeil, S. Plasma copolymerization of allyl alcohol 1,7-octadiene: Surface characterization and attachment of human keratinocytes. Chem. Mater. 1998, 10 (4), 1176-1183.

(368) Alexander, M. R.; Duc, T. M. The chemistry of deposits formed from acrylic acid plasmas. J. Mater. Chem. 1998, 8 (4), 937-943.

(369) Alexander, M. R.; Payan, S.; Duc, T. M. Interfacial interactions of plasma-polymerized acrylic acid and an oxidized aluminium surface investigated using XPS, FTIR and poly(acrylic acid) as a model compound. Surf. Interface Anal. 1998, 26 (13), 961-973.

(370) Gengenbach, T. R.; Griesser, H. J. Aging of 1,3-diaminopropane plasma-deposited polymer films: Mechanisms and reaction pathways. J. Polym. Sci., Part A: Polym. Chem. 1999, 37 (13), 2191-2206.

(371) Gengenbach, T. R.; Chatelier, R. C.; Griesser, H. J. Correlation of the nitrogen $1 \mathrm{~s}$ and oxygen 1s XPS binding energies with compositional changes during oxidation of ethylene diamine plasma polymers. Surf. Interface Anal. 1996, 24 (9), 611-619.

(372) Daw, R.; Candan, S.; Beck, A. J.; Devlin, A. J.; Brook, I. M.; MacNeil, S.; Dawson, R. A.; Short, R. D. Plasma copolymer surfaces of acrylic acid 1,7 octadiene: Surface characterisation and the attachment of ROS 17/2.8 osteoblast-like cells. Biomaterials 1998, 19 (19), 1717-1725.

(373) Whittle, J. D.; Short, R. D.; Douglas, C. W. I.; Davies, J. Differences in the aging of allyl alcohol, acrylic acid, allylamine, and octa-1,7diene plasma polymers as studied by X-ray photoelectron spectroscopy. Chem. Mater. 2000, 12 (9), 2664-2671.

(374) Friedrich, J.; Mix, R.; Kuhn, G.; Retzko, I.; Schonhals, A.; Unger, W. Plasma-based introduction of monosort functional groups of different type and density onto polymer surfaces. Part 2: Pulsed plasma polymerization. Compos. Interfaces 2003, 10 (2-3), 173223.

(375) Gancarz, I.; Bryjak, J.; Bryjak, M.; Pozniak, G.; Tylus, W. Plasma modified polymers as a support for enzyme immobilization 1. Allyl alcohol plasma. Eur. Polym. J. 2003, 39 (8), 1615-1622.

(376) Tamirisa, P. A.; Liddell, K. C.; Pedrow, P. D.; Osman, M. A. Pulsedplasma-polymerized aniline thin films. J. Appl. Polym. Sci. 2004, 93 (3), 1317-1325.

(377) Swaraj, S.; Oran, U.; Lippitz, A.; Schulze, R. D.; Friedrich, J. F.; Unger, W. E. S. Surface analysis of plasma-deposited polymer films, 2 - Analysis of post-plasma air reacted plasma polymerized styrene by X-ray photoelectron spectroscopy and X-ray absorption spectroscopy. Plasma Processes Polym. 2004, 1 (2), 134-140.

(378) Swaraj, S.; Oran, U.; Lippitz, A.; Schulze, R. D.; Friedrich, J. F.; Unger, W. E. S. Surface analysis of plasma-deposited polymer films, 4(a) - In situ characterization of plasma-deposited ethylene films by XPS and NEXAFS. Plasma Processes Polym. 2005, 2 (4), 310-318.

(379) Swaraj, S.; Oran, U.; Lippitz, A.; Friedrich, J. F.; Unger, W. E. S. Surface analysis of plasma-deposited polymer films, 6 - Analysis of plasma deposited allyl alcohol films before and after aging in air. Plasma Processes Polym. 2005, 2 (7), 572-580. 
(380) Milella, A.; Palumbo, F.; Favia, P.; Cicala, G.; d'Agostino, R. Deposition mechanism of nanostructured thin films from tetrafluoroethylene glow discharges. Pure Appl. Chem. 2005, 77 (2), 399 414.

(381) Watkins, L.; Bismarck, A.; Lee, A. F.; Wilson, D.; Wilson, K. An XPS study of pulsed plasma polymerised allyl alcohol film growth on polyurethane. Appl. Surf. Sci. 2006, 252 (23), 8203-8211.

(382) Oran, U.; Swaraj, S.; Lippitz, A.; Unger, W. E. S. Surface analysis of plasma deposited polymer films, 7 - "In situ" characterization of plasma deposited allylamine films by ToF-SSIMS, XPS and NEXAFS spectroscopy. Plasma Processes Polym. 2006, 3 (3), 288-298.

(383) Luo, H. L.; Sheng, J.; Wan, Y. Z. Plasma polymerization of styrene with carbon dioxide under glow discharge conditions. Appl. Surf. Sci. 2007, 253 (12), 5203-5207.

(384) Kumar, D. S.; Fujioka, M.; Asano, K.; Shoji, A.; Jayakrishnan, A.; Yoshida, Y. Surface modification of poly(ethylene terephthalate) by plasma polymerization of poly(ethylene glycol). Jo. Mater. Sci.: Mater. Med. 2007, 18 (9), 1831-1835.

(385) Malkov, G. S.; Martin, I. T.; Schwisow, W. B.; Chandler, J. P.; Wickes, B. T.; Gamble, L. J.; Castner, D. G.; Fisher, E. R. Pulsedplasma-induced micropatterning with alternating hydrophilic and hydrophobic surface chemistries. Plasma Processes Polym. 2008, 5 (2), 129-145.

(386) Swaraj, S.; Oran, U.; Lippitz, A.; Unger, W. E. S. Surface chemical analysis of plasma-deposited copolymer films prepared from feed gas mixtures of ethylene or styrene with allylamine. Plasma Processes Polym. 2008, 5 (1), 92-104.

(387) Swaraj, S.; Oran, U.; Friedrich, J. F.; Lippitz, A.; Unger, W. E. S. Surface chemical analysis of plasma-deposited copolymer films prepared from feed gas mixtures of ethylene or styrene with allyl alcohol. Plasma Processes Polym. 2007, 4 (4), 376-389.

BM900186S 